\title{
IDENTIFYING THE EFFECTS OF SIMULTANEOUS MONETARY POLICY
} SHOCKS

\author{
A Dissertation \\ submitted to the Faculty of the \\ Graduate School of Arts and Sciences \\ of Georgetown University \\ in partial fulfillment of the requirements for the \\ degree of \\ Doctor of Philosophy \\ in Economics
}

By

Mauricio Villamizar Villegas, M.A.

Washington, DC

April 11, 2014 
Copyright (C) 2014 by Mauricio Villamizar Villegas

All Rights Reserved 


\title{
IDENTIFYING THE EFFECTS OF SIMULTANEOUS MONETARY POLICY SHOCKS
}

\author{
Mauricio Villamizar Villegas, M.A. \\ Dissertation Advisor: Guido Kuersteiner Ph.D.
}

\begin{abstract}
The first chapter shows that during 1999-2012, the Central Bank of Colombia conducted frequent purchases of foreign currency but only occasional and moderate sales. Concurrently, the central bank adjusted its intervention interest rate to meet inflationary targets. However, the use of two simultaneous policy instruments does not necessarily equip monetary authorities with better tools to achieve their targets. On the contrary, their effects can potentially offset each other. Using proprietary data I study the effects of simultaneous policies by first deriving new measures of monetary shocks and then determining their impact on economic activity. The main findings indicate that (i) while interest rate interventions have a significant impact on real and nominal variables, foreign exchange interventions tend to have limited effects; and (ii) empirical anomalies, such as the price puzzle, are eliminated when properly accounting for the systematic responses of policy.

The second chapter uses the exchange rate expectations survey of the Central Bank of Colombia in order to test for the rational expectations hypothesis, the presence of a time-varying risk premium and the accuracy of agents' forecasts. Results indicate that (i) the forward discount rate was generally different from future exchange rate changes due to the rejection of the unbiasedness condition and to a time-varying risk premium, and (ii) while short term forecasts outperform a random walk, long term forecasts fail to do any better. In this sense, traders and analysts could do better
\end{abstract}


by following simple autoregressive models rather than by following the strategy that they pursue today.

Chapter three compares the effects of various foreign exchange intervention mechanisms, using an event study approach. Following the methodology presented in Frankel (1994) and Fatum and Hutchison (2003), we define four criteria to evaluate a successful intervention: 1) Direction, 2) Reversal, 3) Smoothing, and 4) Matching. Our main finding indicates that rule-based volatility options were successful according to all criteria. However, counterfactual exercises cast some doubts on these results when considering three out of the four criteria.

INDEX WORDS: Central bank intervention, Simultaneous policy objectives, Monetary shocks, Foreign exchange rate, Price puzzle, Exchange rate expectations, Risk premium, Market efficiency, Rational expectations 


\section{DedicAtion}

This thesis research is dedicated to my father, Rodrigo Villamizar. 


\section{ACKNOWLEDGMENTS}

I would not have been able to write this dissertation without the help of Miriam Villegas, Monica Villamizar, Mariana Villamizar and Alejandra Penuela. I am very grateful to Guido Kuersteiner for all his guidance and support. I especially thank Behzad Diba and Matthew Canzoneri for all their input. I also appreciate the valu-

able comments of Mark Huggett, Roger Lagunoff, Neil Ericsson, Irineu de Carvalho, Henry Maingi, Juan J. Echavarria and Luis Fernando Melo. Finally, I acknowledge Claire Brunel, Maisie Harris, Bledi Celiku and seminar participants at Georgetown University, the Central Bank of Colombia, and AEA meetings. All errors are my own.

Many thanks, Mauricio Villamizar Villegas 


\section{TABLE of CONTENTS}

\section{CHAPTER}

1 Fear of Floating under Inflation Targeting . . . . . . . . . . 1

1.1 Introduction . . . . . . . . . . . . . . . . . . 1

1.2 Statistical Regression-Based Setting . . . . . . . . . . . . . 3

1.3 Data and Context . . . . . . . . . . . . 7

1.4 Methodology . . . . . . . . . . . . . 13

1.5 Estimation and Results ................ . . . . . 21

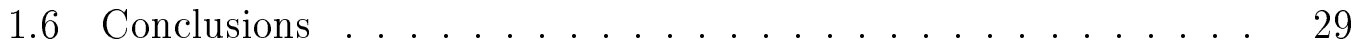

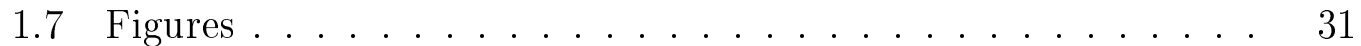

1.8 Tables ............................... 42

2 Great Expectations? Evidence from Colombia's Exchange Rate Survey 50

2.1 Introduction . . . . . . . . . . . . . 50

2.2 Forecasts, Forwards and the Risk Premium . . . . . . . . . 52

2.3 Stabilizing - Destabilizing Expectations . . . . . . . . . . 62

2.4 Heterogeneous Predictions . . . . . . . . . . . 68

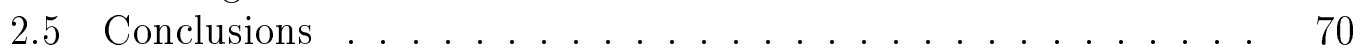

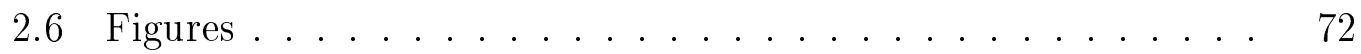

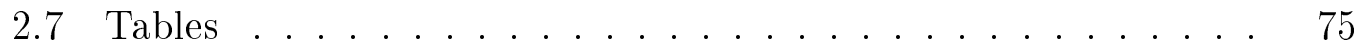

3 The Impact of Foreign Exchange Intervention in Colombia: An Event Study Approach . . . . . . . . . . . . . . . 81

3.1 Introduction . . . . . . . . . . . . . 81

3.2 Foreign Exchange Interventions . . . . . . . . . . . . 82

3.3 Methodology: An Event Study Approach . . . . . . . . . . . 85

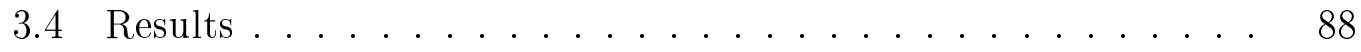

3.5 Conclusions . . . . . . . . . . . . . . . 92

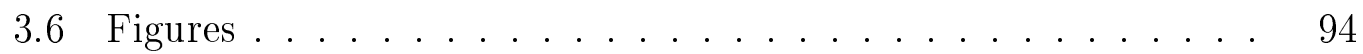

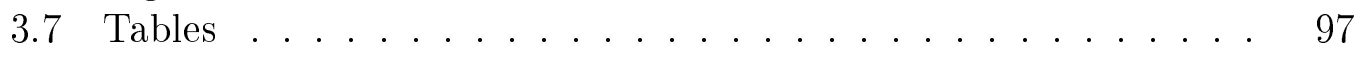

APPENDIX

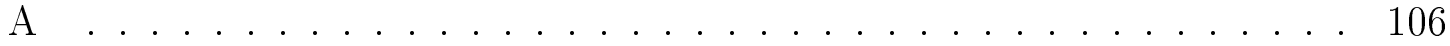

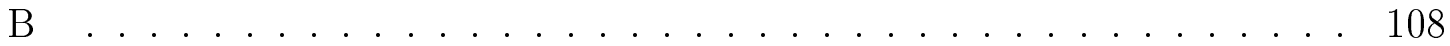

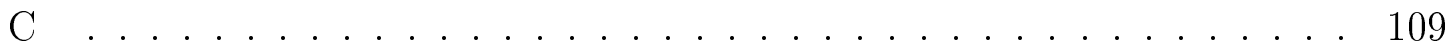

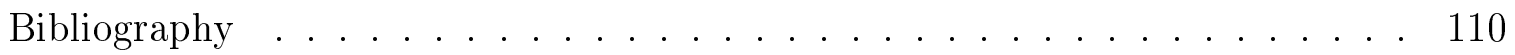




\section{LIST OF FIGURES}

1.1 Exchange Rate Equilibrium Forecast . . . . . . . . . . . . . . 31

1.2 Inflation Forecast minus Yearly Target . . . . . . . . . . . 31

1.3 Forecasted GDP Gap . . . . . . . . . . . . . . . . 32

1.4 Net Position of CBoC . . . . . . . . . . . . . . . . . . . 32

1.5 Inflation, Expected Inflation, and Inflation Target: 1999-2012 . . . . . 33

1.6 Different Mechanisms of Foreign Exchange Intervention: 1999-2012 . . 33

1.7 Interest Rate Intervention and Inter-Bank Rate of Central Bank: 1999-

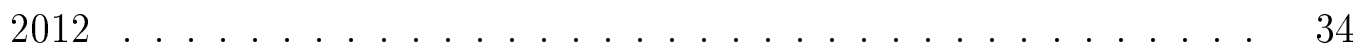

1.8 Observed Policy Instruments vs New Measures of Policy Shocks: 1999-

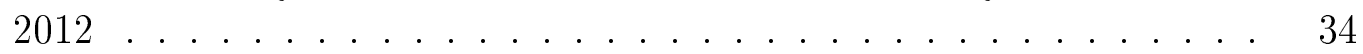

1.9 Implied IRFs of Inflation . . . . . . . . . . . . . . . . . . . . . . . . . . . 35

1.10 Implied IRFs of Industrial Production . . . . . . . . . . . . . . . 36

1.11 Implied IRFs of Aggregate Demand . . . . . . . . . . . . . . . . . 37

1.12 Implied IRFs of Exchange Rate Changes . . . . . . . . . . . . . . 38

1.13 Implied IRFs of Exchange Rate Volatility . . . . . . . . . . . . . . . . . 39

1.14 Implied IRFs of 1-year Treasury Bond's Yield . . . . . . . . . . . . 40

1.15 Counterfactual Outcomes . . . . . . . . . . . . . . . . 41

2.1 Twist in Exchange Rate Expectations . . . . . . . . . . . . . 72

2.2 Forecast Errors . . . . . . . . . . . . . . . . . . 72

$2.3 \%$ of Institutions with Correct Exchange Rate Change Direction . . . 73

$2.4 \%$ of Institutions with Expectations falling within \pm 50 Pesos . . . . 73

2.5 Forward vs. Expected Exchange Rates . . . . . . . . . . . . . . 74

2.6 Dispersion (Standard Deviation of Forecasts) . . . . . . . . . . . . . 74

3.1 Different Mechanisms of Foreign Exchange Intervention: 1999-2012 . . 94

3.2 Robustness Exercise (Direction Criterion) . . . . . . . . . . 95

3.3 Robustness Exercise (Reversal Criterion) . . . . . . . . . . . . . 95

3.4 Robustness Exercise (Smoothing Criterion) . . . . . . . . . . . 96

3.5 Robustness Exercise (Matching Criterion) . . . . . . . . . 96 


\section{LIST OF TABLES}

1.1 Foreign Exchange Interventions 1999-2012 (Billion USD purchases) • 42

1.2 Elliott-Rothenberg-Stock Test for Unit Root . . . . . . . . . . . . 43

1.3 Different Specifications for $X_{t} \ldots \ldots \ldots \ldots$. . . . . . 44

1.4 Covariances of Bivariate Process . . . . . . . . . . . . . . . 45

1.5 Tobit Estimation for Foreign Exchange Interventions . . . . . . . . . 46

1.6 OLS Estimation for Interest Rate Interventions . . . . . . . . . . 47

1.7 Policy Shocks' Orthogonality Condition . . . . . . . . . . . . . 48

1.8 Effects of Observed Policy Instruments and Policy Shocks . . . . . . . 49

2.1 Individual components of equation 2.3. (1-Month horizon) . . . . . 75

2.2 Individual components of equation 2.3. (1-Year horizon) . . . . . . 76

2.3 Risk Premium . . . . . . . . . . . . . . 76

2.4 Unbiasedness Condition . . . . . . . . . . . . . . 77

2.5 Unbiasedness Condition II . . . . . . . . . . . . . . . . 78

2.6 Orthogonality Condition . . . . . . . . . . . . . 78

2.7 Stabilizing / Destabilizing Expectations . . . . . . . . . . . 79

2.8 Out-of-Sample Forecasts: Competing Models vs. a Random Walk . . . . . 80

2.9 Accuracy of 1-month and 1-year forecasts . . . . . . . . . 80

3.1 Definition of Criteria for Successful Interventions (Purchases of USD) 97

3.2 Definition of Criteria for Successful Interventions (Sales of USD) . . . 97

3.3 Event Study Estimation for Direction Criterion . . . . . . . . . . . 98

3.4 Event Study Estimation for Reversal Criterion . . . . . . . . . . . . . . . 99

3.5 Event Study Estimation for Smoothing Criterion . . . . . . . . . . 100

3.6 Event Study Estimation for Matching Criterion . . . . . . . . . . . 101

3.7 Event Study Estimation for the case of Brazil (Counterfactual Exercise). Discretionary Interventions through the Spot Market . . . . . . 102

3.8 Event Study Estimation for the case of Brazil (Counterfactual Exercise). Discretionary Interventions through FX Options . . . . . . . . . 103

3.9 Event Study Estimation for the case of Brazil (Counterfactual Exercise). Rule-Based Interventions through FX Options . . . . . . . . . . 104

3.10 Difference-in-Difference Estimation . . . . . . . . . . . . . 104

3.11 Second Counterfactual Exercise . . . . . . . . . . . 105

B.1 Fragments of Reports Presented to Congress . . . . . . . . . . . . . 108

C.1 Autocorrelations and Cross-Correlogram . . . . . . . . . . . 109 


\title{
Chapter 1
}

FEAR OF FLOATING UNDER INFLATiON TARGETing

\begin{abstract}
"But it remains a fact that compared to conventional policy, the effects of unconventional monetary policy are very limited and uncertain" -Olivier Blanchard ${ }^{1}$
\end{abstract}

\subsection{INTRODUCTION}

Ever since the demise of the Bretton Woods system, several emerging economies that claimed to have a floating exchange rate under an inflation targeting regime have, in fact, tried to limit currency appreciation. Colombia is no exception. During 1999-2012, the Central Bank of Colombia (CBoC henceforth) conducted frequent and large-scale purchases of foreign currency but only occasional and moderate sales, revealing a bias towards trying to depreciate domestic currency. During this time, the $\mathrm{CBoC}$ also adjusted its intervention interest rate in order to meet inflationary targets and stimulate economic growth. However, the use of two simultaneous policy instruments - foreign exchange and interest rate interventions - does not necessarily equip monetary authorities with better tools to achieve their targets. On the contrary, the two effects can potentially offset each other. Given the monetary policy trilemma for open economies, combining both instruments raises the question of whether central

\footnotetext{
${ }^{1}$ IMF blog "Monetary Policy Will Never Be the Same" published on November 19, 2013
} 
banks sometimes overreach and underdeliver by having overambitious targets when the effects of policy are limited.

The main objective of this paper is to study how simultaneous central bank policies affect the economy. I extend the framework presented in Romer and Romer (2004) to allow for a multivariate policy model in which monetary instruments are governed by dependent decision processes. In the empirical application, I employ proprietary data from the $\mathrm{CBoC}$ (at a daily frequency) that includes the timing and amount of direct monetary interventions, as well as the internal forecasts that the board of directors considered when setting its policy decisions. These detailed data allow me to match the actions of the $\mathrm{CBoC}$ with stated targets and observable covariates.

Consequently, I model the undertakings of monetary authorities using a parametric approach in order to extract the unexpected component of policy (i.e. policy surprises). Similar to Angrist and Kuersteiner (2004, 2011), my identifying assumption presumes that conditional on internal forecasts and real-time financial data, policy variations can be used to identify causal effects. This assumption, sometimes referred to as selection-on-observables (covariates to be held fixed are assumed to be known and observed), provides a strong foundation for causal inference.

To date, there is a general lack of consensus within the literature on the effects of monetary policy, especially in emerging markets. To my knowledge, only a handful of studies exist that directly address the issue of having multiple policy instruments, few of which estimate their dependence, and none of which center on the Colombian economy. ${ }^{2}$ Most studies therefore fail to capture the full interaction of policy decisions and the monetary channels through which they operate. A better understanding of

\footnotetext{
${ }^{2}$ See Ostry et al. (2012), or IMF reports No. 12/16, 12/106 for evidence found in Turkey and Switzerland
} 
these mechanisms will help design more effective policy regimes and enhance our analysis of causal effects in a dynamic setting.

My investigation confirms some of the previous findings from the literature, but also uncovers new results. In contrast with a number of earlier studies such as Sims (1992), Zha (1997) and Christiano et al. (1999), I find that empirical anomalies, such as the price puzzle, are eliminated when properly accounting for the systematic responses of policy. An advantage of my estimation strategy is that it does not require the inclusion of commodity prices to resolve these anomalies as is the case for Kim and Roubini (2000), Kim (2003), and Sims and Zha (2006). On the other hand, similar to Fischer (2001a, 2001b), I find that while interest rate interventions (IRI henceforth) have a significant impact on real and nominal variables, foreign exchange interventions (FXI henceforth) tend to have more limited effects. This finding suggests that monetary authorities should conduct most of their policy through the intervention interest rate. It also supports the idea that allowing for free capital flows while having autonomous monetary policy and a managed exchange rate is, in fact, an "impossible trinity".

This paper is organized as follows: Section 2 presents the statistical regressionbased setting. Section 3 describes the data, provides a brief overview of the Colombian context and presents the two policy instruments (FXI and $I R I)$ undertaken by the CBoC. It also describes the key variables that systematically affected policy decisions. Sections 4 and 5 present the methodology and results. Finally, section 6 concludes.

\subsection{Statistical Regression-Based Setting}

Ideally, policy effects could be identified by conducting a randomized macroeconomic experiment. In this hypothetical scenario, the average causal effect of policy would 
be obtained by computing the difference between the average outcome variable after intervention episodes and after episodes of no intervention. In practice however, policy decisions do not behave this way and it is infeasible to conduct experiments at the level of national economies. The problem is that, since policy decisions are rarely isolated from economic developments, the timing and magnitude of interventions are likely to respond endogenously to factors correlated with monetary targets. It is therefore essential to extract the random component of policy from anything that may systematically react to informative variables. This component, which acts as a substitute for policy experiments, forms the basis for the statistical identification of causal effects.

Following Angrist and Kuersteiner (2004, 2011), the economy can be described by a stochastic process $\xi_{t}=\left(Y_{t}, X_{t}, D_{t}\right)$ where $Y_{t}$ is a vector of outcome variables, $D_{t}$ comprises policy instruments $\left(F X I_{t}\right.$ and $I R I_{t}$ for the Colombian case) and $X_{t}$ are all other variables needed to characterize the policy function. ${ }^{3}$ Histories of policy, outcomes and exogenous variables are explicitly characterized by:

$$
\left[\begin{array}{c}
\bar{D}_{t} \\
\bar{X}_{t} \\
\bar{Y}_{t}
\end{array}\right]=\left[\begin{array}{cccc}
D_{t} & D_{t-1} & \cdots & D_{t-k} \\
X_{t} & X_{t-1} & \cdots & X_{t-k} \\
Y_{t} & Y_{t-1} & \cdots & Y_{t-k}
\end{array}\right]
$$

The "sufficient" statistic that policymakers use to determine policy at time " $t$ " is described by $z_{t}=\Phi_{t}\left(\bar{Y}_{t}, \bar{X}_{t}, \bar{D}_{t-1}\right)$, for a given mapping $\Phi_{t}$, and decisions about policy are governed by a deterministic component of observed random variables $D_{i}\left(z_{t}, t\right)$, and by an unobserved idiosyncratic shock $\epsilon_{i t}$. Note that $z_{t}$ may contain the realization of policy instruments up to period " $t-1$ ".

The policy setting equation, in a linear model, is therefore:

\footnotetext{
${ }^{3}$ Outcome variables are admissible in $X_{t}$ as long as they have at least a 1-period lag.
} 


$$
D_{i t}=D_{i}\left(z_{t}, t\right)+e_{i t} \quad \text { for } \quad i=1,2
$$

If we define $Y_{t, j}^{\psi}\left(d_{i}\right)$ as the value of $Y_{t+j}$ when $D_{i t}=\Psi(\cdot)=d_{i}$, that is to say the "potential outcome" of $Y_{t+j}$ for a specific realization of $D_{i t}$, then the Conditional Independence Assumption (CIA) can be formulated as:

$$
Y_{t, 1}^{\psi}\left(d_{i}\right), Y_{t, 2}^{\psi}\left(d_{i}\right), \ldots \perp D_{i t} \mid z_{t} \quad \forall d_{i}, \forall \psi \in \Psi, i=1,2
$$

In words, the CIA states that conditional on $z_{t}$, policies are independent of potential outcomes, or as good as randomly assigned. ${ }^{4}$ This critical assumption establishes the foundation based on which "regressions can also be used to approximate experiments in the absence of random assignment ${ }^{\prime .}$. This setting is particularly useful when counterfactual outcomes cannot be observed (e.g. what would have occurred if monetary authorities had not intervened, given that they did; and vice versa).

In the related literature, Romer and Romer (2004) use the intended Fed funds rate as their instrument variable $D_{t}$, the "Greenbook" forecasts, unemployment and inflation as exogenous variables in $X_{t}$ and industrial production growth as well as the producer's price index as outcome variables in $Y_{t}$. Another example is Wasserfallen and Kuersteiner (1994), who, in setting a Central Bank policy for the Swiss case use the money supply target as $D_{t}$ and nominal interest rates and exchange rates as $X_{t}$. Examples using foreign exchange purchases as $D_{t}$ with a GARCH methodology include Rincon and Toro (2010), Echavarria et al. (2009b), Kamil (2008), Toro and

\footnotetext{
${ }^{4}$ Equation (2) implies that $Y_{t, 1}^{\psi}\left(d_{i}\right), Y_{t, 2}^{\psi}\left(d_{i}\right), \ldots \perp \epsilon_{i t} \mid z_{t}$ since $\epsilon_{t}$ is the only random source of $D_{i t}$.

${ }^{5}$ Angrist and Pischke (2009), pg 18.
} 
Julio (2005) and Guimaraes and Karacadag (2004). Finally, estimations that follow the early works of Christiano et al. $(1996,1999)$ or Bernanke and Blinder (1992), use the effective Federal Funds Rate as $D_{t}$, and a set of real and nominal variables as $X_{t}$ to analyze the effects of monetary shocks with the use of VARs. Examples of these studies include Christiano et al. (2010), Kim and Roubini (2000), Bagliano and Favero (1998), Clarida and Gertler (1997) and Sims and Zha (2006).

A methodological complication that arises when measuring the impact of policy in Colombia is the fact that the $\mathrm{CBoC}$ does not target a single policy instrument, as is the case for most of US monetary policy. Rather, it employs two separate policy instruments $\left(F X I_{t}\right.$ and $\left.I R I_{t}\right)$ to achieve its targets. In a fully fleshed-out structural model, such as SVAR, implementing this dual strategy is potentially complicated. Also, "a monetary policy innovation (in VARs) reflects both the effect of the initial innovation and the effect of the predictable subsequent moves in the policy measure". ${ }^{6}$ Other drawbacks include the numerous disentangling restrictions needed to identify structural shocks and the fact that "spurious result(s) of in-sample data fitting (or of serially correlated omitted variables)"7 can reduce the variation of monetary shocks, which is necessary to identify causal effects.

This paper avoids these issues by focusing on the process that determines monetary policy with a parametric model, while leaving the response of the economy unspecified (and estimated with a non-parametric procedure). Modeling thus concentrates on the decisions of the central bank, which in principle are observable and non-linear.

\footnotetext{
${ }^{6}$ Romer and Romer (2004), pg 1078.

${ }^{7}$ See Rudebusch (1998), pg 919.
} 


\subsection{Data And Context}

\subsubsection{DATA}

There are two crucial steps needed to identify policy shocks. The first step consists of explicitly analyzing policy instruments. Failing to observe the exact decisions of monetary authorities can lead to an endogenous relationship between economic conditions and the policy's measurement error. This, for example, is the case for some studies that use changes in international reserves to implicitly derive FXI (in the absence of official data). ${ }^{8}$ The problem with using this measure is that it does not only capture the different mechanisms of FXI, but also valuation effects driven by exchange rate and interest rate differentials. In addition, monetary authorities can accumulate reserves for a variety of reasons, including self-insurance against sudden stops or financial shocks. The resulting policy effects would thus reflect a combination of factors (i.e. different intervention mechanisms, valuation effects, etc.) with no way of separating individual effects.

The second step consists of capturing the relevant information that monetary authorities use when setting their policy decisions, or in other words, being able to see what they see. In the potential outcomes framework described in section 2, this would be equivalent to finding out what variables should be included in $X_{t}$. In the present context, the internal forecasts of the central bank are ideal candidates. The CBoC (like many other central banks) has entire divisions in charge of forecasting key variables such as inflation, exchange rates, unemployment and output growth so that policymakers can make more informed decisions. Analogous to what the Federal Reserve's Greenbook Forecasts used to be for the US, the CBoC has its own internal

\footnotetext{
${ }^{8}$ See for example Dominguez et al. (2012) or Adler and Tovar (2011).
} 
forecasts that feed into the board's discussions whenever they meet to decide over FXI or IRI. These include:

- Exchange Rate Misalignment Forecasts: Seven "in house" structural models are estimated by the Observatorio de Tasa de Cambio Real (CBoC division) and results regarding the forecasted equilibrium exchange rate are presented monthly to the board of directors. Specifically, two models are based on the purchasing power parity condition (PPP), two models are based on Structural Vector Error Correction (SVEC) methodologies, two models are based on the current account equilibrium and one model simply uses Hodrick and Prescott filters. The average forecast of all seven models is depicted in Figure 1.1. Exchange rate misalignments, measured as the log-difference of the exchange rate minus the average forecasted equilibrium value, $\left(e_{t}-\right.$ Forecast $\left.\left(e_{t}\right)\right)$, constitute a key variable used to capture most of the deterministic component of $D\left(z_{t}, t\right)$ as presented in equation (1).

- Monetary Transmission Mechanism Forecasts: Inflation forecasts are estimated by the Departamento de Modelos Macroeconomicos (CBoC department). Since 2001, the $\mathrm{CBoC}$ adopted a model proposed by Gomez and Julio (2001) to forecast future inflation. This model includes 9 equations that govern prices, aggregate demand, wages, an interest rate rule, the uncovered interest rate parity condition, foreign real interest rates, risk premium, terms of trade and policy rates. The difference between forecasted inflation and the yearly target rate $\left(\right.$ Forecast $\left.\left(\pi_{t}\right)-\pi_{t}^{\text {Target }}\right)$, depicted in Figure 1.2, is also a key variable within $X_{t}$.

- Long Term GDP (PATACON) Forecasts: The GDP gap is also estimated by the Departamento de Modelos Macroeconomicos and is particularly relevant for the board's discussions since a long term equilibrium value of GDP is extremely sensitive to the applied methodology. This DSGE model (PATACON) incorporates nominal and real rigidities with the use of 5 main equations: cascade of Calvo pricing, staggered wages, 
endogenous depreciation, external habits in consumption, and investment costs. The forecasted GDP gap $\left(y_{t}-\right.$ Forecast $\left.\left(y_{t}\right)\right)$ is depicted in Figure 1.3.

The remainder of my data set is described in Appendix A.

\subsubsection{The Colombian Context}

Colombia adopted an inflation-targeting scheme with a floating exchange rate in October of 1999 during the aftermath of the strongest economic crisis of its history. ${ }^{9}$ Prior to this date, pre-announced exchange rate bands were established dating back to 1994. After 1999, however, the CBoC continued to conduct widespread FXI in spite of having a "free floater" status.

During 1999-2012, the nominal exchange rate between the Colombian peso (COP) and the US dollar (USD) underwent severe appreciation and depreciation episodes that doubled and halved the value of each currency. Peak values ranged from 1,542 $(C O P / U S D)$ in January 1999 to 2, 969 in February 2003, and to 1,652 in June 2008. During this period, inflation dropped from $15.4 \%$ to $3.6 \%$, and inflation targets set forth by the $\mathrm{CBoC}$ were, to some extent, able to anchor inflation expectations as depicted in Figure 1.5. ${ }^{10}$

The period of 2006-2008 was particularly interesting since it exhibited high inflation and a strong appreciation of the exchange rate in an overheated economy. Specifically, inflation was well above the target rate (by more than $3 \%$ during the second semester of 2008), the COP gained $37 \%$ of its value and the GDP gap was close to $2.8 \%$ during most of 2008. This combination of factors led to what can be thought of as a "Perfect Storm" for central bankers: objectives consisting of lowering inflation,

\footnotetext{
${ }^{9}$ See Echavarria and Villamizar (2006).

${ }^{10}$ The credibility of the $\mathrm{CBoC}$ concerning its ability to achieve its targets remained high amongst surveyed agents, in spite of the $\mathrm{CBoC}$ not being able to meet its inflation targets during 1999, 2001, 2002, 2006, 2007, and 2008.
} 
depreciating the currency and expanding economic output conflicted. ${ }^{11}$ During this time, the $\mathrm{CBoC}$ raised interest rates by 400 basis points and simultaneously purchased over 7.5 billion dollars in what later became a controversial set of policies. This period also coincided with the first presidential reelection in the country, after the Uribe administration amended the constitution of 1991. As a result, the board of directors of the $\mathrm{CBoC}$ (entity in charge of all monetary and exchange rate policy) went from having 3 out of 7 board members appointed by the president in 2002 to 5 out of 7 members in $2006 .^{12}$

\subsubsection{Monetary Policy through FXI}

From 1999 to 2012, the CBoC officially claimed to be an advocate of FXI with the goal of stemming exchange rate and output volatility. ${ }^{13}$ Additional reforms were implemented throughout the years to include objectives that sought an "adequate" level of international reserves and to hinder "excessive" depreciation/appreciation trends in the exchange rate. However, interventions were not symmetric. Purchases of USD totaled 28.5 billion whereas sales amounted to only 2.6 billion. ${ }^{14}$ Also, international reserves more than quadrupled: from 8 billion USD in January 1999 to 34 billion USD in September 2012.

\footnotetext{
${ }^{11}$ According to the Mundell-Fleming model, an increase in interest rates can lower future inflation but appreciates domestic currency. The conflict arises when trying to lower inflation and, at the same time, depreciate the exchange rate.

${ }^{12}$ In accordance with chapter 6 of the Colombian constitution of 1991, the board of directors of the $\mathrm{CBoC}$ is comprised of seven members that include: The minister of finance, the Governor of the board (elected by the board), and five members (two of which are appointed by the president).

${ }^{13}$ See Appendix B for a list of selected fragments of reports that were presented to the Colombian Congress.

${ }^{14}$ More than $80 \%$ of international reserves were invested in AAA securities (mostly in US treasury bonds).
} 
Purchases of USD can be further sub-categorized into 3 groups: discretionary interventions conducted in the spot market (22.8 billion), discretionary interventions through foreign exchange rate options (3.3 billion) and rule-based volatility options (2.4 billion). In this paper, FXI consists of the first two groups since volatility options are deterministic in nature and exclude any part of the policy decision process. ${ }^{15}$ Sales of USD, on the other hand, were almost all conducted through volatility options (2.3 billion).

Figure 1.6 depicts the different methods of FXI as well as the COP/USD exchange rate. Discretionary interventions, which account for $73 \%$ of all interventions, were concentrated in two periods: 2005-2007 and 2010-2012. While the former period consisted of large, unexpected purchases of US currency, the latter period consisted of small (close to 20 million USD) purchases conducted daily since September of $2010 .^{16}$ The figure also shows that after March 2003, the exchange rate appreciated rapidly. In some episodes, such as the one from December 2006 to May 2007, exchange rate changes were so pronounced that Colombia was ranked as the country with the highest currency appreciation vis-à-vis the USD. ${ }^{17}$ Table 1.1 shows the total amount of FXI (excluding volatility options) as well as the number of intervention days. The years 2005 and 2007 were peak years of intervention with purchases of 4.6 and 4.5 billion USD, respectively. Intervention days were also highly concentrated in 2005 and 2011.

\footnotetext{
${ }^{15}$ This mechanism, which was introduced in October 2002 to smooth exchange rate volatility, was triggered whenever daily deviations (with respect to the moving average of the last 20 working days) were greater or equal to a specific threshold.

${ }^{16}$ Daily interventions after September 2010 were also excluded from $F X I_{t}$, as they also became deterministic.

${ }^{17}$ See Kamil (2008).
} 


\subsubsection{Monetary Policy through IRI}

Intervention interest rates drastically declined from $26 \%$ in January 1999 to $4.75 \%$ in September 2012, reaching its lowest value (3\%) in 2010 during the aftershocks of the financial world crisis. During 1999-2012 the board of directors met over 160 times to decide whether to change the intervention interest rate, effectively doing so in 62 occasions. In all of the minutes of the board's meetings and the official reports presented to Congress, inflation and output were stated as the main variables that the $\mathrm{CBoC}$ considered when deciding over IRI.

Figures 1.7a and 1.7b depict both the intervention and inter-bank interest rates. As can be observed, the inter-bank rate is more volatile than the intervention rate ${ }^{18}$ and is most likely subject to endogenous effects brought forth by liquidity demand. The intervention rate, on the other hand, is ideal for estimating monetary policy decisions as it exclusively captures the treatment undertaken by monetary authorities. The fact that the $\mathrm{CBoC}$ explicitly states its interest rate targets makes Colombia an ideal case study. In other countries (including the United States) a researcher has to sometimes infer the intended rate with the use of narrative records (see for example Romer and Romer, 2004).

Figure 1.7a shows that the intervention interest rate followed a similar path as that of inflation in Figure 1.5. This close and positive relationship can be misconstrued as evidence of the Price Puzzle in which monetary tightening is followed by an increase in price levels. However, a more consistent explanation is that the $\mathrm{CBoC}$ raised interest rates in periods of high inflation in order to lower price levels, and reduced interest rates in periods of low inflation to stimulate economic growth. The true negative

\footnotetext{
${ }^{18}$ This volatility can be explained by the 3,000 basis points difference between the maximum borrowing rate and the minimum lending rate, which was reduced to 800 basis points in the year 2000 .
} 
correlation between inflation and interest rates can only be uncovered by removing the systematic responses to inflation brought about by the Taylor rule or some other identification strategy.

\subsection{Methodology}

The CIA assumption, $Y_{t, 1}^{\psi}\left(d_{i}\right), Y_{t, 2}^{\psi}\left(d_{i}\right), \ldots \perp \epsilon_{i t} \mid z_{t}$, justifies the two-step procedure of first identifying exogenous monetary shocks and then estimating their effects on economic variables. Accordingly, the first step of the methodology consisted of modeling both policy rules in order to remove systematic responses to informative variables.

\subsubsection{Computation of Monetary Shocks}

If the two policy instruments were assumed to be conditionally independent (i.e. conditional on a set of variables in $z_{t}$ of equation (2), the observed value of one instrument does not alter the probability distribution of the other), then they would follow different univariate processes exemplified by equations (3) and (4):

$$
\begin{gathered}
F X I_{t}^{*}=x_{1 t}^{\prime} \beta_{1}+v_{t} \\
F X I_{t}=\max \left[0, F X I_{t}^{*}\right] \\
v_{t} \sim N\left(0, \sigma_{1}^{2}\right) \\
I R I_{t}=x_{2 t}^{\prime} \beta_{2}+\epsilon_{2 t}
\end{gathered}
$$

where $F X I_{t}^{*}$ is the unobserved latent foreign exchange intervention (which takes

positive and negative values), $x_{1 t}^{\prime} \beta_{1}$ and $x_{2 t}^{\prime} \beta_{2}$ are the deterministic components of 
policy corresponding to $D_{1}\left(z_{t}, t\right)$ and $D_{2}\left(z_{t}, t\right)$, and $v_{t}$ is assumed to be normally distributed with zero mean and variance $\sigma_{1}^{2}$. This setting, much like in the related literature, assumes $F X I_{t}$ to be left-censored at zero. ${ }^{19}$

Monetary shocks can be obtained by subtracting the conditional mean of policy from its observed value. While the conditional mean of IRI is linear (by construction), the conditional mean of FXI is not as straightforward given its non-linearity. To compute the conditional mean of $F X I$, I followed classic econometric textbooks such as Amemiya (1985), Green (2003) and Wooldridge (2010) or studies such as Amemiya (1973), Jensen (2000) and Schnedler (2005). The resulting monetary shocks $\left(\epsilon_{1 t}, \epsilon_{2 t}\right)$ are shown in equations (5) and (6):

$$
\begin{aligned}
\epsilon_{1 t} & =F X I_{t}-E\left[F X I_{t} \mid x_{1 t}\right] \\
& =F X I_{t}-\int_{F X I_{t}>0}\left(F X I_{t}\right) d F\left(F X I_{t} \mid x_{1 t}\right) \\
& =F X I_{t}-\Phi\left(\frac{x_{1 t}^{\prime} \beta_{1}}{\sigma_{1}}\right)\left[x_{1 t}^{\prime} \beta_{1}+\sigma_{1} \lambda\left(\frac{x_{1 t}^{\prime} \beta_{1}}{\sigma_{1}}\right)\right] \\
\epsilon_{2 t} & =I R I_{t}-E\left[I R I_{t} \mid x_{2 t}\right] \\
& =I R I_{t}-x_{2 t}^{\prime} \beta_{2}
\end{aligned}
$$

where $\phi(\cdot)$ and $\Phi(\cdot)$ correspond to the pdf and cdf of a standard normal distribution, respectively. The term $\Phi\left(\frac{x_{1+\beta}^{\prime} \beta_{1}}{\sigma_{1}}\right)$ of equation (5) corresponds to the probability of observing a positive intervention $\left(\operatorname{Pr}\left(F X I_{t}^{*}>0 \mid x_{1 t}\right)\right)$ and the last term in brackets

\footnotetext{
${ }^{19}$ The fact that interventions are bounded below justifies the adoption of a censored Tobit Type-I model.
} 
is the expected value of the latent variable $F X I_{t}^{*}$ (where the term $\lambda(\cdot)=\phi(\cdot) / \Phi(\cdot)$ corresponds to the inverse-mills ratio). In short, $\epsilon_{1 t}$ can be thought of as the censored residual of the FXI policy rule while $\epsilon_{2 t}$ of equation (6) is the linear residual of the IRI policy rule.

However, there is no reason a priori to believe that policy instruments were independent. After all, the board of the $\mathrm{CBoC}$ conducts monetary policy through both $F X I$ and $I R I$ and it is entirely plausible that decisions about one instrument affect decisions about the other. The following specification allows to parameterize and estimate this dependence:

$$
\begin{aligned}
& F X I_{t}^{*}=x_{1 t}^{\prime} \beta_{1}+v_{t} \\
& F X I_{t}=\max \left[0, F X I_{t}^{*}\right] \\
& I R I_{t}=x_{2 t}^{\prime} \beta_{2}+\epsilon_{2 t} \\
& \left(\begin{array}{c}
v_{t} \\
\epsilon_{2 t}
\end{array}\right) \sim N(0, \Sigma)
\end{aligned}
$$

The only difference with respect to the previous setting is that residuals $v_{t}$ and $\epsilon_{2 t}$ are now assumed to be jointly normal with zero mean and variance-covariance matrix $\Sigma=\left[\begin{array}{cc}\sigma_{1}^{2} & \sigma_{12} \\ \sigma_{12} & \sigma_{2}^{2}\end{array}\right]$. The construction of a maximum likelihood function for the bivariate process described in equation (7) is hence warranted in order to obtain estimates of all individual regressors as well as the estimated covariance between $v_{t}$ and $\epsilon_{2 t}$. The following steps follow the literature on truncated multivariate normal distributions such as Cohen (1949), Rosenbaum (1961), Barr et al. (1999), and Green (2003). 
If we define $A \equiv\left(\sigma_{1}^{2}-\frac{\sigma_{12}^{2}}{\sigma_{2}^{2}}\right)$ and $b \equiv\left(x_{1 t}^{\prime} \beta_{1}+\frac{\sigma_{12}}{\sigma_{2}^{2}}\left(I R I_{t}-x_{2 t}^{\prime} \beta_{2}\right)\right)$, then the maximum likelihood can be constructed in two stages:

- Stage 1: When $F X I_{t}>0 \quad\left(F X I_{t}=F X I_{t}^{*}\right)$

$$
\begin{aligned}
f\left(F X I_{t}, I R I_{t}\right) & =f\left(F X I_{t}^{*} \mid I R I_{t}, x_{1 t}, x_{2 t}\right) f\left(I R I_{t} \mid x_{1 t}, x_{2 t}\right) \\
& =\frac{1}{A^{1 / 2}} \phi\left(\frac{F X I_{t}^{*}-b}{A^{1 / 2}}\right) \frac{1}{\sigma_{2}} \phi\left(\frac{I R I_{t}-x_{2 t}^{\prime} \beta_{2}}{\sigma_{2}}\right)
\end{aligned}
$$

- Stage 2: When $F X I_{t}=0 \quad\left(F X I_{t}^{*} \leq 0\right)$

$$
\begin{aligned}
f\left(F X I_{t}, I R I_{t}\right) & =\operatorname{Pr}\left(F X I_{t}^{*} \leq 0 \mid I R I_{t}, x_{1 t}, x_{2 t}\right) f\left(I R I_{t} \mid x_{1 t}, x_{2 t}\right) \\
& =\left(1-\Phi\left(\frac{b}{A^{1 / 2}}\right)\right) \frac{1}{\sigma_{2}} \phi\left(\frac{I R I_{t}-x_{2 t}^{\prime} \beta_{2}}{\sigma_{2}}\right)
\end{aligned}
$$

The resulting Maximum Likelihood function, shown in equation (10), is then fully characterized by combining equations (8) and (9) for both censored and uncensored observations:

$$
\begin{aligned}
L_{n}(\theta) & =\prod_{F X I_{t}^{*} \leq 0} f\left(F X I_{t}, I R I_{t} \mid x_{1 t}, x_{2 t}\right) \prod_{F X I_{t}^{*}>0} f\left(F X I_{t}, I R I_{t} \mid x_{1 t}, x_{2 t}\right) \\
& =\left[\prod_{F X I_{t}^{*} \leq 0} 1-\Phi\left(\frac{b}{A^{1 / 2}}\right) \prod_{F X I_{t}^{*}>0} \frac{1}{A^{1 / 2}} \phi\left(\frac{F X I_{t}^{*}-b}{A^{1 / 2}}\right)\right]\left[\prod \frac{1}{\sigma_{2}} \phi\left(\frac{I R I_{t}-x_{2 t}^{\prime} \beta_{2}}{\sigma_{2}}\right)\right]
\end{aligned}
$$


Finally, under significant dependence between policy instruments, monetary shocks can be computed in vector form as shown in equation (11):

$$
\left[\begin{array}{c}
\epsilon_{1 t} \\
\epsilon_{2 t}
\end{array}\right]=\left[\begin{array}{c}
F X I_{t} \\
I R I_{t}
\end{array}\right]-\left[\begin{array}{c}
E\left(E\left[F X I_{t} \mid I R I_{t}, x_{1 t}, x_{2 t}\right] \mid x_{1 t}, x_{2 t}\right) \\
E\left(I R I_{t} \mid x_{1 t}, x_{2 t}\right)
\end{array}\right]
$$

Where the last term can be expressed as:

$$
\begin{aligned}
& {\left[\begin{array}{c}
E\left(E\left[F X I_{t} \mid I R I_{t}, x_{1 t}, x_{2 t}\right] \mid x_{1 t}, x_{2 t}\right) \\
E\left(I R I_{t} \mid x_{1 t}, x_{2 t}\right)
\end{array}\right]=} \\
& \operatorname{Pr}\left(F X I_{t}^{*}>0 \mid x_{1 t}\right) E\left[\begin{array}{l}
F X I_{t} \mid F X I_{t}^{*}>0, x_{1 t}, x_{2 t} \\
I R I_{t} \mid F X I_{t}^{*}>0, x_{1 t}, x_{2 t}
\end{array}\right]+ \\
& \operatorname{Pr}\left(F X I_{t}^{*} \leq 0 \mid x_{1 t}\right) E\left[\begin{array}{l}
F X I_{t} \mid F X I_{t}^{*} \leq 0, x_{1 t}, x_{2 t} \\
I R I_{t} \mid F X I_{t}^{*} \leq 0, x_{1 t}, x_{2 t}
\end{array}\right] \\
& =\Phi\left(\frac{x_{1 t}^{\prime} \beta_{1}}{\sigma_{1}}\right)\left[\begin{array}{l}
x_{1 t}^{\prime} \beta_{1}+\sigma_{1} \lambda\left(\frac{x_{1 t}^{\prime} \beta_{1}}{\sigma_{1}}\right) \\
x_{2 t}^{\prime} \beta_{2}+\frac{\sigma_{12}}{\sigma_{1}} \lambda\left(\frac{x_{1}^{\prime} \beta_{1}}{\sigma_{1}}\right)
\end{array}\right]+\left(1-\Phi\left(\frac{x_{1 t}^{\prime} \beta_{1}}{\sigma_{1}}\right)\right)\left[\begin{array}{c}
0 \\
x_{2 t}^{\prime} \beta_{2}+\frac{\sigma_{12}}{\sigma_{1}} \lambda\left(\frac{x_{1 t}^{\prime} \beta_{1}}{\sigma_{1}}\right)
\end{array}\right]
\end{aligned}
$$

Note that some steps are based on the fact that if $\left(v_{t}, \epsilon_{2 t}\right)$ are jointly normal, then $\epsilon_{2 t}$ equals $\frac{\sigma_{12}}{\sigma_{1}} v_{t}+\varsigma$, where the random variable $\varsigma$ is independent of $v_{t} \cdot{ }^{20}$ The resulting

\footnotetext{
${ }^{20}$ See Cameron and Trivedi (2005).
} 
monetary shocks, $\left(\epsilon_{1 t}, e_{2 t}\right)$, should be free of endogenous and anticipatory movements and should contain only the random component of monetary policy. In the related literature, this exogenous variation has been mostly interpreted as exogenous shocks to how policymakers value different targets or how their views are aggregated. Other interpretations include the pursuit of additional (temporary) objectives, changes in beliefs, operating procedures, strategic considerations on private agents' expectations, measurement error and technical factors. ${ }^{21}$

\subsubsection{EXPLANATORY VARIABLES IN $X_{t}$}

An important part of this paper consisted of correctly specifying the relevant variables in $X_{t}$. The main challenge was to model the undertakings of monetary authorities as closely as possible so as to avoid a potential omitted variable bias. As such, the internal forecasts of the central bank were ideal candidates since they fed into the board's discussions whenever they met to decide over FXI or IRI.

In addition to the internal forecasts, the board of directors could have examined other variables. To account for some of these responses, a set of control variables was also included in $X_{t}$ based on the official reports of the CBoC that were presented to the Colombian Congress (Informes de la Junta Directiva al Congreso de la Republica) and the minutes of the board of director's meetings. ${ }^{22}$ Table 1.3 shows three specifications of $x_{1 t}: x_{1 t}(1), x_{1 t}(2), x_{1 t}(3)$, and four specifications of $x_{2 t}: x_{2 t}(1), x_{2 t}(2), x_{2 t}(3), x_{2 t}(4)$, that were used in order to purge the corresponding instruments of their deterministic component. Section 5.3 proposes a heuristic exercise to determine which of these specifications is subject to misspecification. Also, lagged policy instruments $\left(F X I_{t-1}\right.$

\footnotetext{
${ }^{21}$ See Hamilton (1997), Christiano et al. (1999), Romer and Romer (1994), Bernanke and Mihov (1998), Ball (1995) and Chari et al. (1997).

${ }^{22}$ These reports include macroeconomic results, different targets set by the board of directors, and explicit monetary procedures and regulations that the $\mathrm{CBoC}$ followed for different periods.
} 
and $\left.I R I_{t-1}\right)$ were considered in order to capture persistence effects, a common feature of intervention clusters.

All variables were included in either levels or changes based on the stationarity properties of the Elliot-Rothenberg-Stock test for a unit root, presented in Table 1.2. For example, $I R I_{t}$ was included in changes $\left(\Delta I R I_{t}\right)$ due to a significant time trend in $I R I_{t}$. Since all variables used in the estimations were stationary, conventional asymptotics were implied. Finally, all control variables in period " $t$ " contained information up until the close-of-business day previous to the policy change. Otherwise, interventions and explanatory variables would simultaneously determine each other, creating a bias in the policy estimates. ${ }^{23}$

\subsubsection{Impact of Policy on OUtcome VARiables}

The second step of the methodology consisted of estimating the effects of $\epsilon_{1 t}$ and $\epsilon_{2 t}$ on the different outcome variables in $Y_{t}$. This was achieved by estimating either equation (12), which follows Romer and Romer's (2004) methodology, or equation (13), which

follows Jorda's (2005) methodology. Both equations should be interpreted as being different representations of the same object, provided that shocks are independent. This result is corroborated in the next section.

$$
Y_{i t}=\gamma_{0}+\sum_{j=0}^{h} \gamma_{j} \epsilon_{1 t-j}+\sum_{k=0}^{h} \gamma_{k} \epsilon_{2 t-k}+\varsigma_{i t}
$$

\footnotetext{
${ }^{23}$ This postulation is entirely reasonable given that board meetings were generally held before noon (very little information could be gained from the time markets closed until the next day's meeting).
} 


$$
Y_{i t+s}=\eta_{0}^{s}+\eta_{1}^{s} \epsilon_{1 t}+\eta_{2}^{s} \epsilon_{2 t}+\vartheta_{i t+s} \text { for } s=0,1, \ldots, h
$$

While Romer and Romer's proposed regression is conceptually straightforward, the resulting standard errors are subject to misspecification (and thus a need for bootstrapping). Jorda's method of local projections avoids this problem by estimating sequential regressions in which the endogenous variable is shifted at each forecasting period. The tradeoff, however, is that Jorda's approach does not control for the possible correlation between the different lags of the policy shock.

For this reason, I estimated Impulse Response Functions (IRFs) for variables with a monthly frequency according to Jorda's methodology (equation 13). In this case, the correlation between lags disappears since shocks are summed up into monthly observations. Conversely, I estimated IRFs for variables with a daily frequency according to Romer and Romer's methodology (equation 12). ${ }^{24}$ Coefficients and standard errors (bootstrapped) were summed up every period in order to obtain the cumulative effect across time. ${ }^{25}$ Finally, equations (12) and (13) were also estimated with only one monetary shock at a time $\left(\epsilon_{1 t}\right.$ or $\left.\epsilon_{2 t}\right)$. The inclusion of one or two shocks yielded almost identical results which suggest that policy instruments were, in fact, conditionally independent (the next section specifically addressed this issue).

\footnotetext{
${ }^{24}$ Monte Carlo methods consisted of 500 draws from a multivariate normal distribution with mean and variance-covariance matrix given by the regression's point estimates.

${ }^{25}$ The number of lags varied depending on the frequency of the outcome variable $(\mathrm{h}=24$ if monthly, $\mathrm{h}=45$ if daily).
} 


\subsection{Estimation and Results}

\subsubsection{Parametric Dependence of Monetary Shocks}

Estimation results for the Maximum Likelihood function of equation (10) are reported in Table 1.4. Values correspond to the covariance between $v_{t}$ and $\epsilon_{2 t}$ for the different specifications of $X_{t}$ (see Table 1.3). As can be observed, none of the covariances are statistically significant. This finding indicates that, under the assumptions of the model, the board's decisions about one instrument did not alter the probability distribution of the other. This is mostly due to the inclusion of internal forecasts as control variables. Additional estimations (not reported) suggest that the covariance is significant when these forecasts are not included.

As such, this finding justifies the estimation of equations (3) and (4) in order to derive the monetary shocks. Additional evidence is shown in Table C.1 (Appendix C) where the cross-correlogram of the shocks is always close to zero. However, this result does not mean that policies did not react to similar targets. In fact, many control variables that were included in $x_{1 t}$ were also included in $x_{2 t} .{ }^{26}$ Independence, in this case, is conditional on the set of control variables.

\subsubsection{Policy Functions}

\section{$F X I_{t}$ Policy Function}

The $F X I_{t}$ policy function of equation (3) was estimated by using a censored regression (Tobit) model and results are reported in Table 1.5. Estimates show that the impact of $F X I_{t-1}$ is significant and less than unity for all specifications. Also, the effects of internal forecasts of both exchange rate misalignments $\left(e_{t-1}-\right.$ Forecast $\left.\left(e_{t-1}\right)\right)$ and

\footnotetext{
${ }^{26}$ An example is lagged interest rate interventions $\left(I R I_{t-1}\right)$, which were included in specification $x_{1 t}(3)$ as part of the FXI policy rule.
} 
GDP gap $\left(y_{t-1}-\right.$ Forecast $\left.\left(y_{t-1}\right)\right)$ are significant and have the expected sign. That is, the CBoC tried to depreciate domestic currency by purchasing USD whenever the exchange rate appreciated (relative to its forecasted equilibrium value) and whenever the GDP gap decreased. On the other hand, inflation forecasts $\left(\right.$ Forecast $\left(p_{t-1}\right)-$ $\left.\operatorname{Target}\left(p_{t-1}\right)\right)$ and the Net position of the $\mathrm{CBoC}\left(D_{N e t P_{t-1}}\right)$ were not statistically significant.

Other variables that significantly affected $F X I_{t}$ include: exchange rate volatility $\left(V O L_{t-1}\right)$, Brazil's exchange rate changes Brazil $\left(\Delta e_{t-1}\right),{ }^{27}$ meeting dates of the board of directors (BoardMeet $\left.t_{-1}\right)$, biweekly exchange rate changes $\left(\Delta e_{t-1,10}\right)$, industrial production growth $\left(\Delta I n d_{t-1}\right)$ and periods in which capital controls were enforced by the $\mathrm{CBoC}\left(D_{\operatorname{tax}}\right)$. The negative sign of $D_{\operatorname{tax}}$ suggests that capital controls acted as substitutes for $F X I_{t}$ (rather than complements) as they significantly restrained inflows of foreign assets.

\section{$I R I_{t}$ POLICY FUNCTION}

The $I R I_{t}$ policy function of equation (4) was estimated using OLS (around meeting dates of the board of directors) and results are reported in Table $1.6 .^{28}$ Lagged interventions $\left(I R I_{t-1}\right)$ were included both in levels and first differences in order to capture tendencies toward mean reversion in the board's behavior. ${ }^{29}$ Also, this setting (like in Romer and Romer 2004) assumes that unemployment acts through the measure of GDP gap (Okun's Law).

\footnotetext{
${ }^{27}$ Brazil's exchange rate was included to capture similarities within the region, as suggested in Loaiza and Melo (2012).

${ }^{28}$ Board meetings of the $\mathrm{CBoC}$ were pre-established at the beginning of each year and therefore the board conducted policy on IRI only over the assigned dates. This setting is similar to Romer and Romer (2004).

${ }^{29}$ The inclusion of $I R I_{t-1}$ (levels) in specifications $x_{2 t}(2)$ and $x_{2 t}(4)$ was motivated by Romer and Romer's (2004) methodology, as presented in equation (1) of their paper.
} 
Coefficients of $I R I_{t-1}$ are significant but close to zero which is evidence that the board conducted gradual changes in policy rather than an immediate one-time adjustment. Estimates also show that all internal forecasts have a significant impact and the expected sign (except for exchange rate misalignments in specification 10a). Namely, the board conducted expansionary policy whenever the GDP gap decreased and whenever the exchange rate appreciated. Conversely, the board conducted contractionary policy whenever forecasted inflation increased (relative to the yearly target). Other variables that prompted policy adjustments through $I R I_{t}$ included: inflationary surprises $\left(\pi_{t-1}-\pi_{t-1}^{e}\right)$, biweekly exchange rate changes $\left(\Delta e_{t-1,10}\right)$, 1-day yield spreads between Colombia and the United States $\left(i_{t-1}^{1 d a y}-i_{t-1}^{* 1 d a y}\right), 1$-year Treasury bond yield changes $\left(\Delta i_{t-1}^{1 \text { year }}\right)$ and industrial production growth $\left(\Delta I n d_{t-1}\right)$.

Finally, the 1-year Treasury bond's yield had a negative effect on $I R I_{t}$ when considering the sub-sample of 2006-2008 $\left(D_{\Delta i_{t-1}^{1 \text { year }}}\right)$. In normal circumstances, different maturity yields tend to move in the same direction, almost as if exhibiting a parallel shift. For this particular period, however, the board of directors seemed to have expected the yield curve to flatten out (probably in anticipation of the economic downturn or deflation episodes that later followed).

\subsubsection{POLICY SHOCKS}

Figure 1.8 depicts the resulting monetary shocks $\left(\epsilon_{1 t}, \epsilon_{2 t}\right)$ compared to the observed policy instruments $\left(F X I_{t}, I R I_{t}\right)$. To improve readability, data points were summed into quarterly observations. The deterministic component of policy can be interpreted as the difference between the green (solid) line and each specific residual. As can be inferred from Figure 1.8a, the $\mathrm{CBoC}$ would have intervened less in the foreign exchange market had it not been for exchange rate misalignments, the GDP gap and the remaining variables presented in Table 1.5. In fact, explanatory variables were able 
to explain most interventions conducted in 2004-2006 and 2008. Also, specifications $x_{1 t}(1), x_{1 t}(2)$ and $x_{1 t}(3)$ were able to explain $39 \%, 76 \%$ and $78 \%$ of the pronounced intervention peak of 2007, respectively.

Policy residuals depicted in Figure $1.8 \mathrm{~b}$ also differ from what occurred with the observed $I R I_{t}$. The most marked difference occurred in 1999, where monetary shocks were in fact positive as opposed to the negative sign of the observed intervention. This is mainly due to the economic crisis of 1998-1999 and the urgency to lower inflation down to a one-digit level, which is captured in the deterministic component of policy. Other noticeable discrepancies can be observed in 2001-2002, 2006-2007 and 2009.

One important characteristic of correctly specified policy shocks is their unpredictability. In other words, information prior to the policy change should not have any predicting power over the estimated residuals. A heuristic exercise to test for this orthogonality condition can be expressed as $\epsilon_{i t} \perp \Omega_{t-1}$, where $\Omega_{t-1}$ represents the information set available before the policy change took place. Results of this test are presented in Table 1.7 where policy shocks are individually regressed against 16 variables, some of which are different from those specified in Table 1.3. ${ }^{30}$ All gaps in Table 1.7 imply that the variable (row) was used under that specification (column) and the shock is, by construction, orthogonal to that variable. Results show that specification (1) of policy shock $\epsilon_{1 t}$ and specifications (1), (3) and (4) of policy shock $\epsilon_{2 t}$ (columns 3, 5, 7 and 8) are the only correct specifications since they are not correlated with any variable in $\Omega_{t-1}$.

\footnotetext{
${ }^{30}$ Residuals were individually regressed in order to avoid cases in which correlation amongst covariates would yield insignificant estimates.
} 


\subsubsection{Impact ON OUtCOME VARIABLES}

The contemporaneous exchange rate $\left(e_{t}\right)$, exchange rate volatility $\left(V o l_{t}\right)$ and inflation $\left(\pi_{t}\right)$ are obvious candidates to test for the effectiveness of Central Bank intervention as they are explicit objectives of the CBoC. Nonetheless, the 1-year Treasury bond's yield $\left(\Delta i_{t}^{1 y e a r}\right)$, industrial production growth $\left(\Delta I n d_{t}\right)$ and aggregate demand ( $\triangle$ AggregateDemand) also shed some light on salient features of the Colombian monetary transmission mechanism. The Treasury bond's yield, for instance, can explain the behavior of a medium to long-term maturity yield (1-year) after a policy change takes place. On the other hand, industrial production and aggregate demand are key variables that will ultimately determine if monetary shocks have an effect on real output.

In all cases, the effects of both the estimated residuals $\left(\epsilon_{1 t}, \epsilon_{2 t}\right)$ and the observed policy instruments $\left(F X I_{t}, I R I_{t}\right)$ were computed. ${ }^{31}$ While the former consist of correctly specified monetary surprises, the latter are most likely biased by anticipatory movements in the economy. The comparison of both measures is thus useful in order to get a better sense of the direction and magnitude of the bias driven by observed interventions $\left(F X I_{t}\right.$ and $\left.I R I_{t}\right)$.

\section{INFLATION}

Figure 1.9 depicts the implied IRF of inflation minus yearly targets. While panel (a) shows that $F X I_{t}$ has a significant albeit small effect on $\pi_{t}-\operatorname{target}(\pi)$, panel (b) shows that $\epsilon_{1 t}$ has no significant effect at all, which is consistent with the fact that almost all interventions were fully sterilized. Panel (c) shows that an increase

\footnotetext{
${ }^{31}$ Specifications $x_{1 t}(2)$ and $x_{2 t}(3)$ were considered for all IRFs. $x_{1 t}(2)$ was the only correct specification of $x_{1} . x_{2 t}(3)$ was $i$ ) correctly specified, $\left.i i\right)$ had interest rate changes instead of levels $\left(\Delta I R I_{t}\right)$ and $\left.i i i\right)$ had relevant control variables that were mentioned in $\mathrm{CBoC}$ reports.
} 
of $1 \%$ in $\Delta I R I_{t}$ has a strong positive effect on inflation (of up to $1.5 \%$ ) that lasts for one year (12 periods) before the effect subsides. Taken at face value, this result is straightforward evidence of the "price puzzle" in which prices and interest rates are positively correlated. However, panel (d) shows that this bias is completely elimiated: an increase of $1 \%$ in $\epsilon_{2 t}$ lowers inflation by the same amount. Effects are significant after the first year (and remain significant for up to 2 years), which is consistent with most of the empirical findings for developed economies. ${ }^{32}$

\section{Industrial Production And Aggregate Demand}

Figure 1.10 depicts the implied IRF of industrial production growth. The main findings are seen in panels (c) and (d) where the effect on industrial output changes considerably. An increase of $1 \%$ in $\Delta I R I_{t}$ has an immediate positive impact on $\Delta I n d_{t}$ of more than $6 \%$, a strange result considering that the board is conducting monetary tightening. This result, however, is completely reversed in Panel $(\mathrm{d})$ where a $1 \%$ increment of the policy shock $\epsilon_{2 t}$ precedes a $2 \%$ reduction in $\Delta I n d_{t}$ (significant after the $10^{t h}$ month). This finding is similar to that of Romer and Romer (2004) and is evidence that interest rate incrementals, when properly controlled for, have a negative impact on output. Panels (a) and (b) show that neither $F X I_{t}$ nor $\epsilon_{1 t}$ have significant effects on $\Delta I n d_{t}$.

Results are very similar when considering changes in aggregate demand. While panel (c) of Figure 1.11 shows that a $1 \%$ increase in $\Delta I R I_{t}$ raises aggregate demand by $4 \%$, panel (d) shows that a $1 \%$ increase in $\epsilon_{2 t}$ reduces aggregate demand by up to $2 \%$.

\footnotetext{
${ }^{32}$ See for example Romer and Romer (2004), Angrist and Kuersteiner (2011) or Wasserfallen and Kuersteiner (1994) for evidence of the lag-delay that interest rates have on inflation.
} 


\section{Exchange Rate Changes and Volatility}

Panels (a) and (b) of Figure 1.12 show that neither $F X I_{t}$ nor $\epsilon_{1 t}$ had a significant impact on exchange rate changes. This means that foreign exchange interventions are not well equipped to modify the value of the Peso vis-à-vis the USD. On the other hand, while Panel (c) shows that $\Delta I R I_{t}$ does not have a significant effect on the exchange rate, Panel $(\mathrm{d})$ shows that a $1 \%$ increase in $\epsilon_{2 t}$ appreciates domestic currency by $0.5 \%$ and its effects last for approximately 3 weeks (16 periods).

Figure 1.13 depicts the implied IRF of exchange rate volatility. Panel (a) shows that observed purchases of foreign currency $\left(F X I_{t}\right)$ have no significant effect on $V_{o l}$. On the other hand, panels (c) and (d) show that, while $\Delta I R I_{t}$ has no significant impact over $V o l_{t}$, an increase of $1 \%$ in $\epsilon_{2 t}$ raises volatility by up to $2 \%$ (the effects subside after the first week). Finally, panel (b) shows that a 1 million USD purchase in $\epsilon_{1 t}$ reduces $V o l_{t}$ by up to $0.005 \%$ and its effect lasts for approximately 3 weeks. This confirms that foreign exchange interventions have a significant, albeit small, effect on reducing exchange rate volatility.

\section{1-YEAR TREASURY BOND'S YIELD}

Figure 1.14 depicts the implied IRF of the 1-year Treasury bond's yield only as a response to $I R I_{t}$ and $\epsilon_{2 t}$. Panels (a) and (b) show that a $1 \%$ increase in either $\Delta I R I_{t}$ or $\epsilon_{2 t}$ raises the $\Delta i_{t}^{1 \text { year }}$ by up to $0.2 \%$ and its effects last for approximately 6 weeks (30 periods).

Table 1.8 summarizes the effects of observed policy instruments $\left(F X I_{t}, I R I_{t}\right)$ and monetary policy shocks $\left(\epsilon_{1 t}, \epsilon_{2 t}\right)$ on all outcome variables. 


\subsubsection{COUnterfactual EXPERIMENTS}

It can be of interest to know what would have occurred if monetary authorities had not intervened, given that they did. In other words, to be able to compare the behavior of outcome variables with the alternative (passive) policy in which the central bank had chosen not to intervene. A caveat however, is that if monetary authorities had strayed from their modus operandi, different estimates would be obtained and policy effects would vary. The following exercise thus estimates alternative policy paths assuming that estimates are held constant.

As such, it is important to capture the effects of policy shocks turning off all other variation in the economy. This can be achieved without any further estimation. Coefficients from IRFs can be used to compute the cumulative effect of policy after every period. Formally, let $\eta_{i}^{h}$ be the impulse response coefficient " $h$ " periods after the shock " $i$ " takes place, like in equation (13). Similarly, $\eta_{i}^{h}=\sum_{t=0}^{h} \gamma_{i t}$ in the context of equation (12). The response of an outcome variable $y_{t}$, attributed exclusively to a monetary shock, is then computed as shown in equation (14):

$$
\sum_{h=1}^{t} \epsilon_{(i)(t-h+1)} \eta_{i}^{h}=y_{t} \text { for } i=1,2
$$

Where $\eta_{i}^{h}=0$ when $h>24$ or $h>45$ for variables with monthly or daily frequency, respectively. ${ }^{33}$ Also, $t=1$ denotes the first observation of $y_{t}$.

Figure 1.15a depicts industrial production growth compared to what would have happened in the event of no intervention. The $\mathrm{CBoC}$ expanded industrial output by up to $4 \%$ during Nov 01-Jun 03, Feb 06-Jun 08 and Aug 09-Jun 10 as a result of expansionary policies. Nonetheless, the 2008-2009 crisis would have been 3\% less severe if the $\mathrm{CBoC}$ had not conducted contractionary policies to control for inflation.

\footnotetext{
${ }^{33}$ Refer to footnote 24.
} 
Figure $1.15 \mathrm{~b}$ shows that the $\mathrm{CBoC}$ was able to effectively lower inflation by almost $2 \%$ during Feb 04-Aug 06, Feb 09-Feb 10, and Jan 11-Nov 11. However, it is possible that the CBoC could have avoided missing several of its targets had it decided to act sooner.

Figure 1.15c depicts exchange rate volatility compared to counterfactual outcomes in which the $\mathrm{CBoC}$ a) had not conducted FXI and b) had not conducted IRI. The figure shows that, for a few but highly marked episodes, volatility would have been higher without $F X I$. In particular, the average monthly volatility would have been 3.3\% higher in May 2006 if the CBoC had not intervened in the exchange market. Alternatively, if the $\mathrm{CBoC}$ had not intervened through $I R I$, volatility would have behaved only marginally differently. The same applies for the effect of $I R I$ on exchange rate changes, as shown in Figure 1.15d.

Finally, Figure 1.15e shows how the 1-year Treasury bond's yield responded to $I R I_{t}$. Namely, if the CBoC had not intervened, the 1-year yield would have been higher during Apr 05-Jul 07, and Nov 08-May 09 and lower during Nov 02-Mar 05, Aug 07-Oct 08 and Feb 11-Jul 11.

\subsection{Conclusions}

Many questions, critical to the design of effective policy regimes in emerging economies, have remained almost entirely unanswered. Some of these include: What are the effects of monetary policy when central banks have multiple instruments at their disposal? Are decisions about policy instruments independent? What alternative policy regimes can central banks adopt to better achieve their targets?

This paper addresses these questions within a non-standard framework of causal effects in a dynamic setting. The main findings indicate that: 
- Empirical anomalies that are found using actual intervention data, such as the price puzzle or the co-movement between output and interest rates, are completely eliminated when properly accounting for the systematic responses of policy.

- Foreign exchange interventions are not effective for the purposes of depreciating domestic currency. Moreover, they do not have a significant impact on industrial production, aggregate demand or other low frequency variables. However, they do have a significant, albeit small, effect on reducing exchange rate volatility.

- A $1 \%$ increase in the intervention interest rate raises the 1-year Treasury bond's yield by up to $0.25 \%$, confirming that policy has a positive impact on different maturity rates.

- There is a 10-12 month lag-delay regarding the effects of interest rate policy on inflation and industrial production growth.

- Conditional on a set of control variables (including the internal forecasts of the central bank), decisions about interest rate interventions did not alter the probability distribution of foreign exchange interventions, and vice-versa.

In light of this new evidence, monetary authorities should conduct most of their policy through the intervention interest rate. They should limit exchange rate interventions (if any) to scenarios of high exchange rate volatility. 


\subsection{Figures}

Figure 1.1: Exchange Rate Equilibrium Forecast

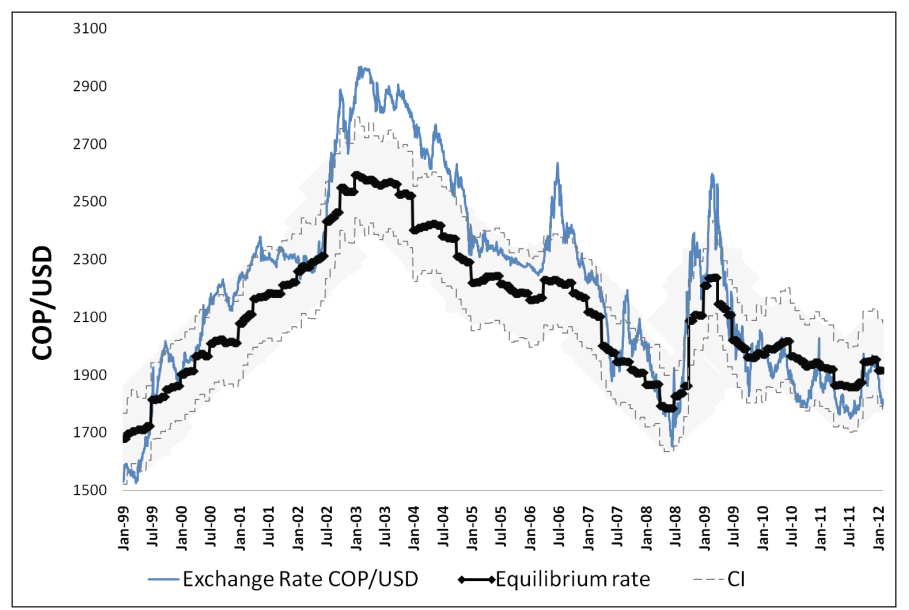

Figure 1.2: Inflation Forecast minus Yearly Target

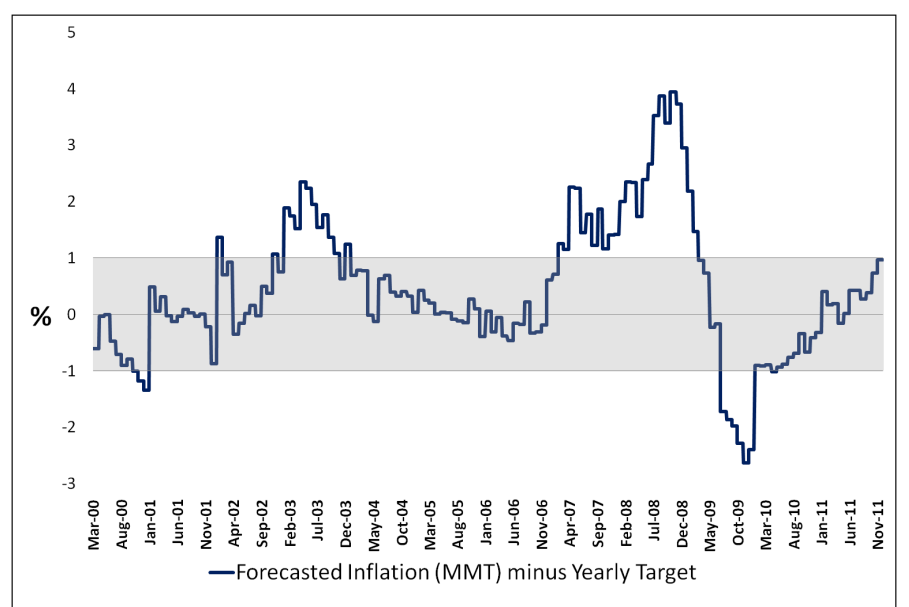


Figure 1.3: Forecasted GDP Gap

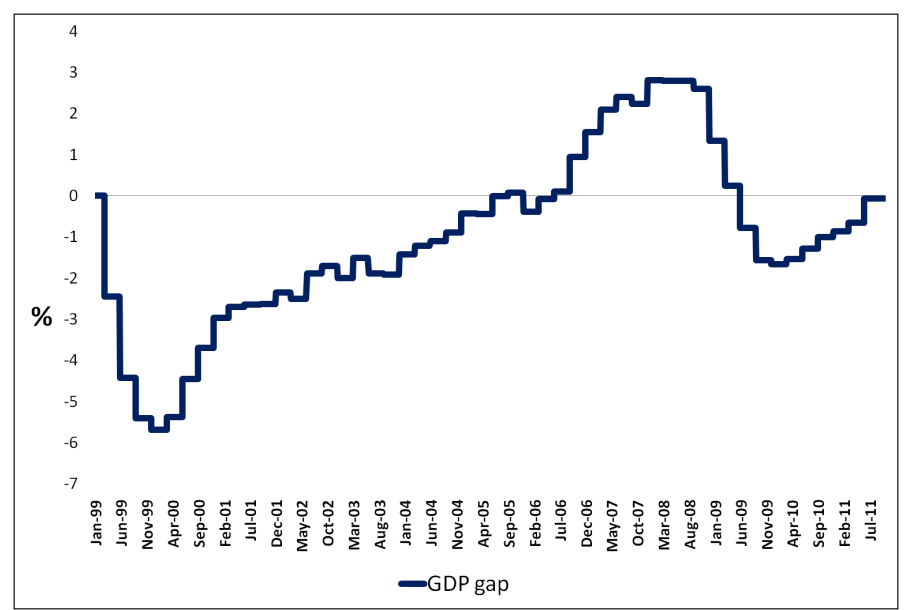

Figure 1.4: Net Position of CBoC

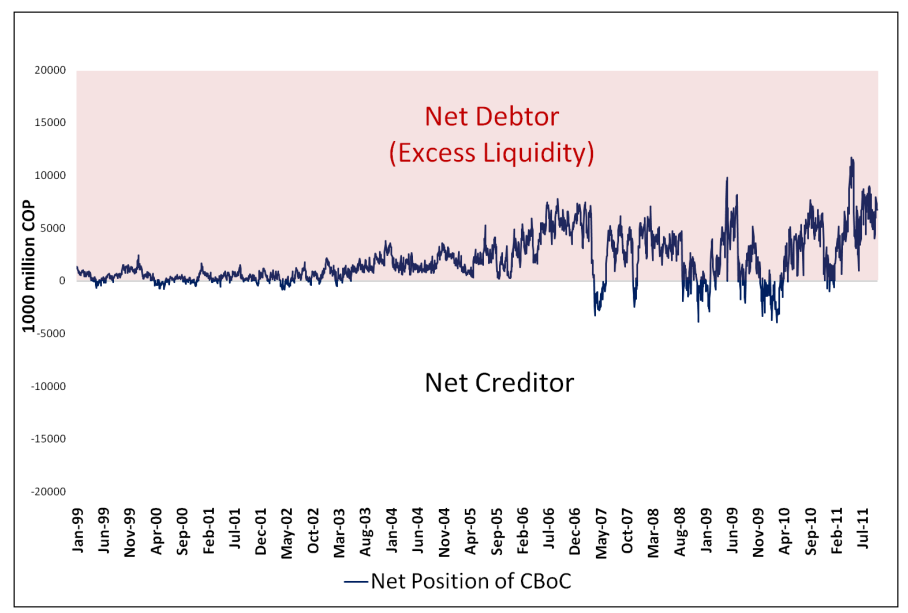


Figure 1.5: Inflation, Expected Inflation, and Inflation Target: 1999-2012

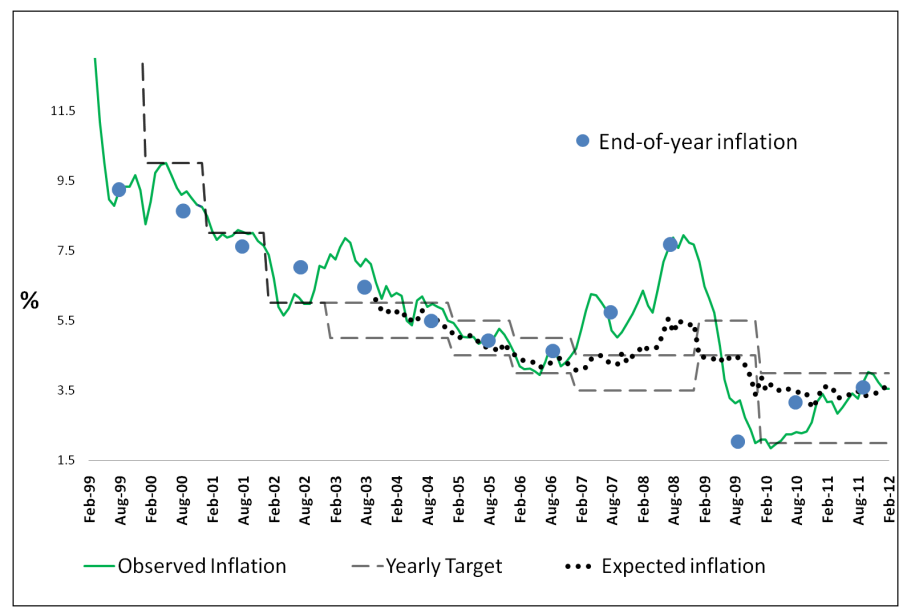

Figure 1.6: Different Mechanisms of Foreign Exchange Intervention: 1999-2012

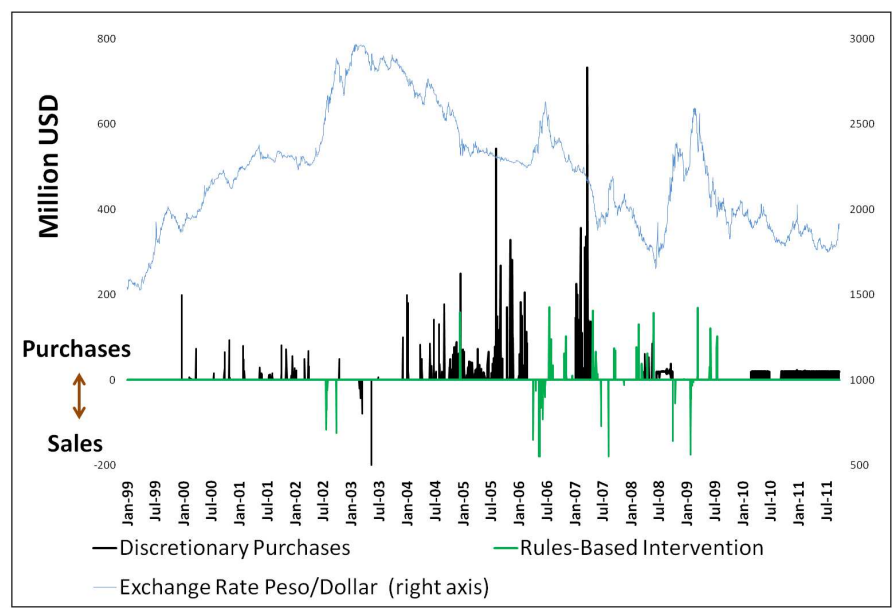


Figure 1.7: Interest Rate Intervention and Inter-Bank Rate of Central Bank: 19992012

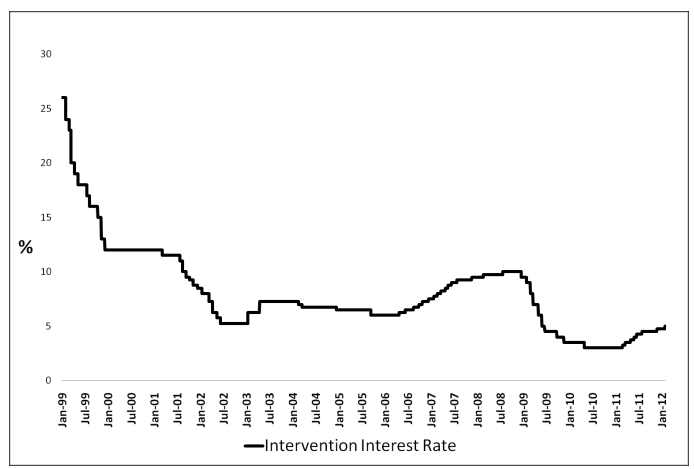

(a) $I R I$

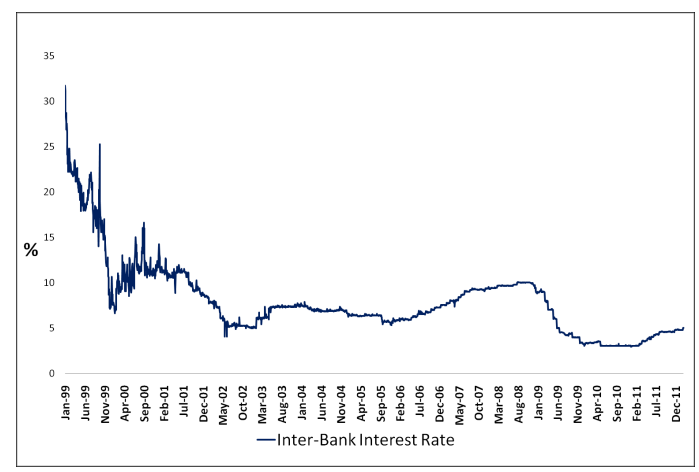

(b) Inter-Bank Rate

Figure 1.8: Observed Policy Instruments vs New Measures of Policy Shocks: 1999-2012

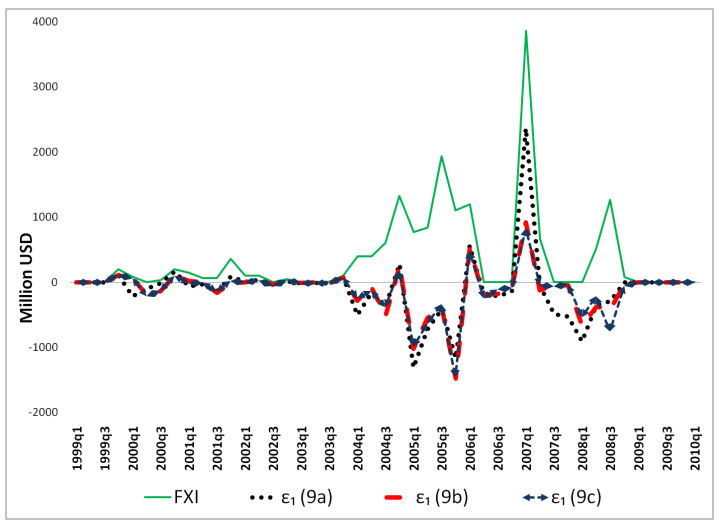

(a) FXI vs Tobit Residuals $\epsilon_{1 t}$

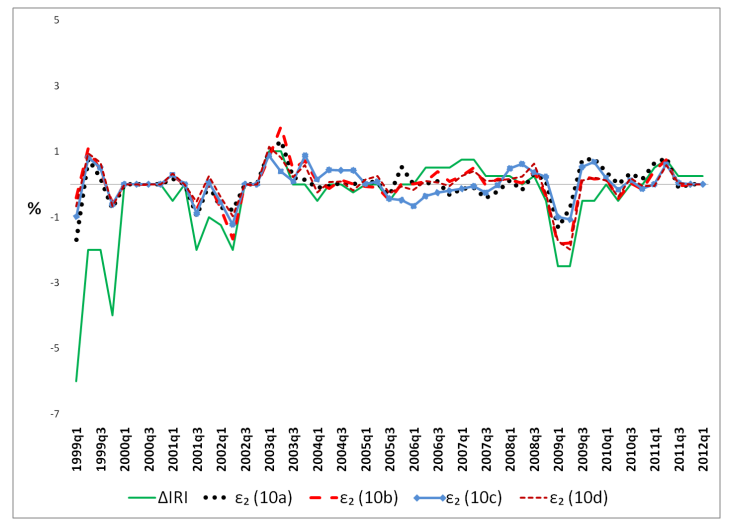

(b) $\Delta I R I$ vs OLS Residuals $\epsilon_{2 t}$ 
Figure 1.9: Implied IRFs of Inflation
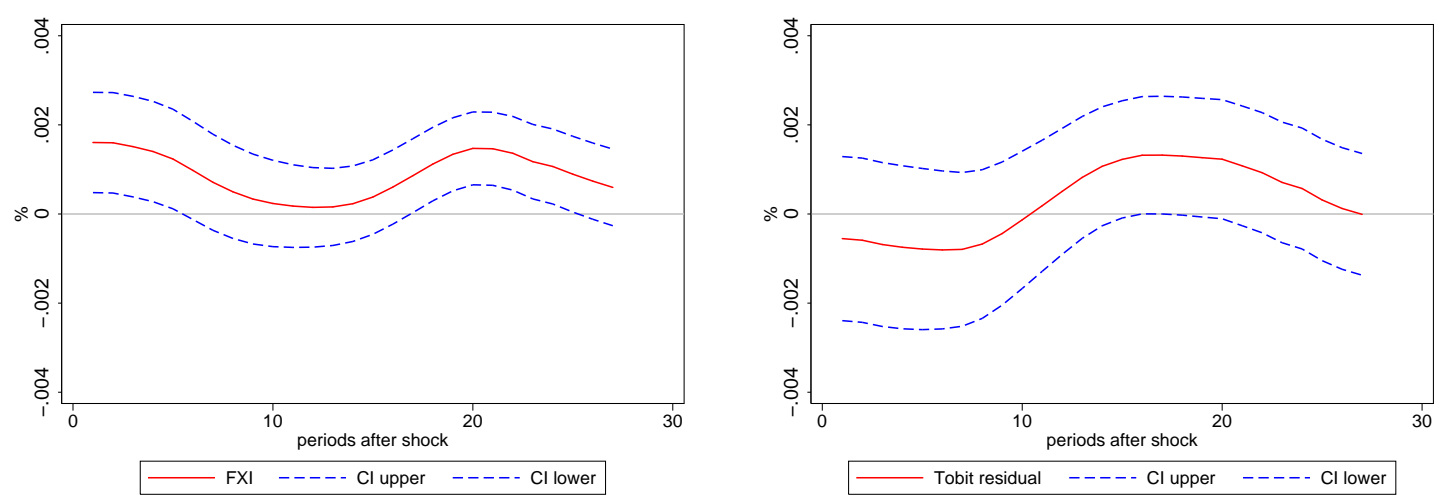

(a) Response to a 1 million USD purchase in (b) Response to a 1 million USD purchase in $F X I$

$\epsilon_{1 t}$
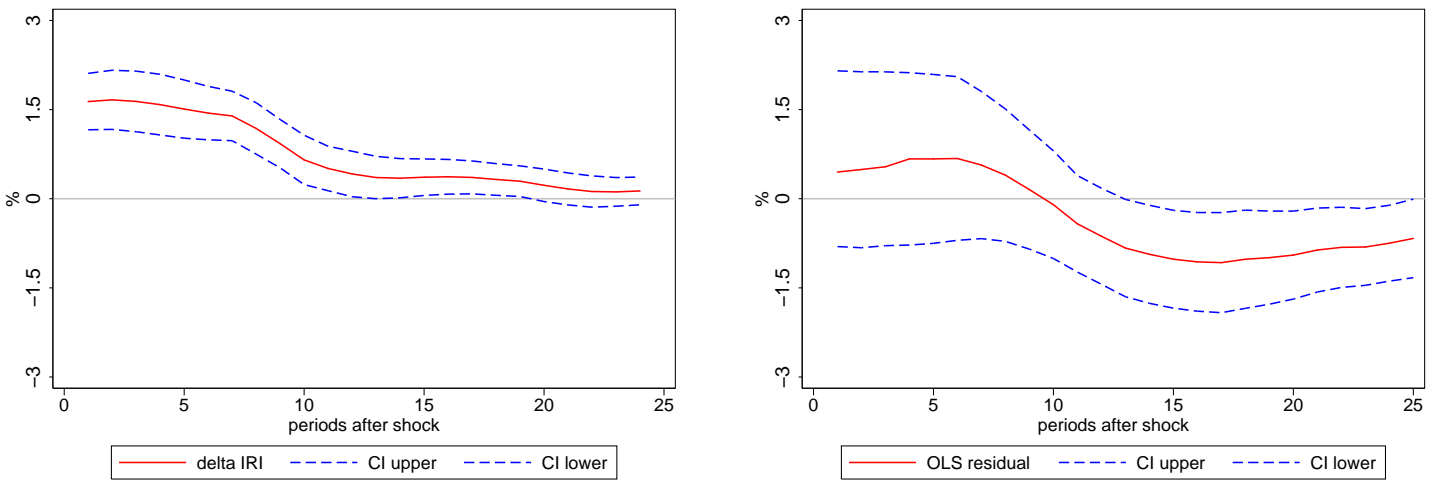

(c) Response to a $1 \%$ change in $\Delta I R I$

(d) Response to a $1 \%$ change in $\epsilon_{2 t}$ 
Figure 1.10: Implied IRFs of Industrial Production
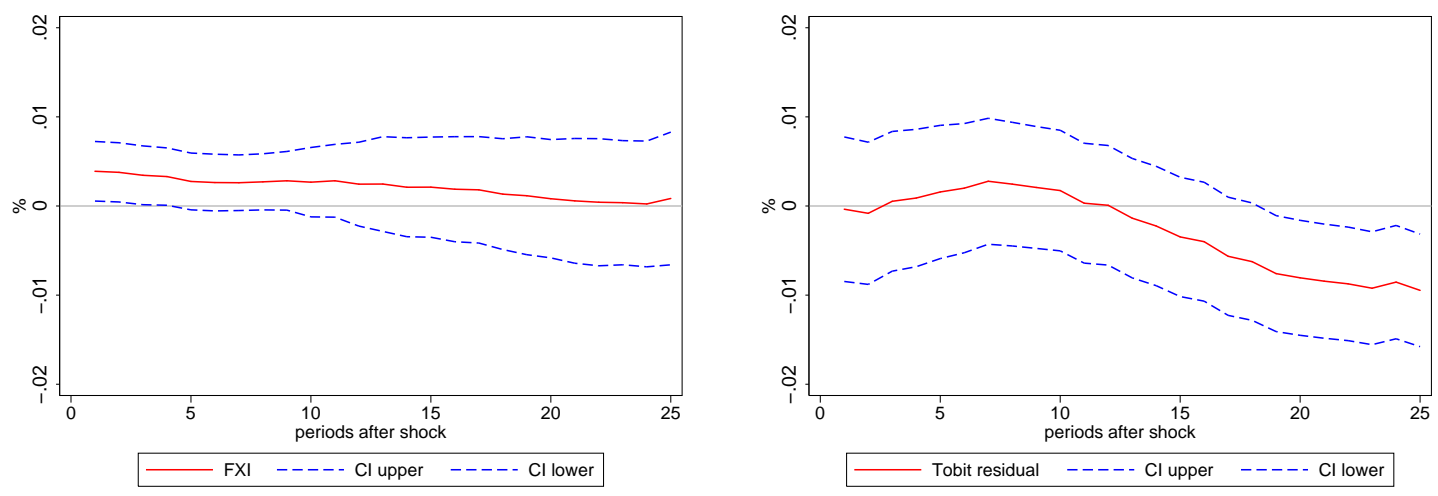

(a) Response to a 1 million USD purchase in (b) Response to a 1 million USD purchase in $F X I$

$\epsilon_{1 t}$
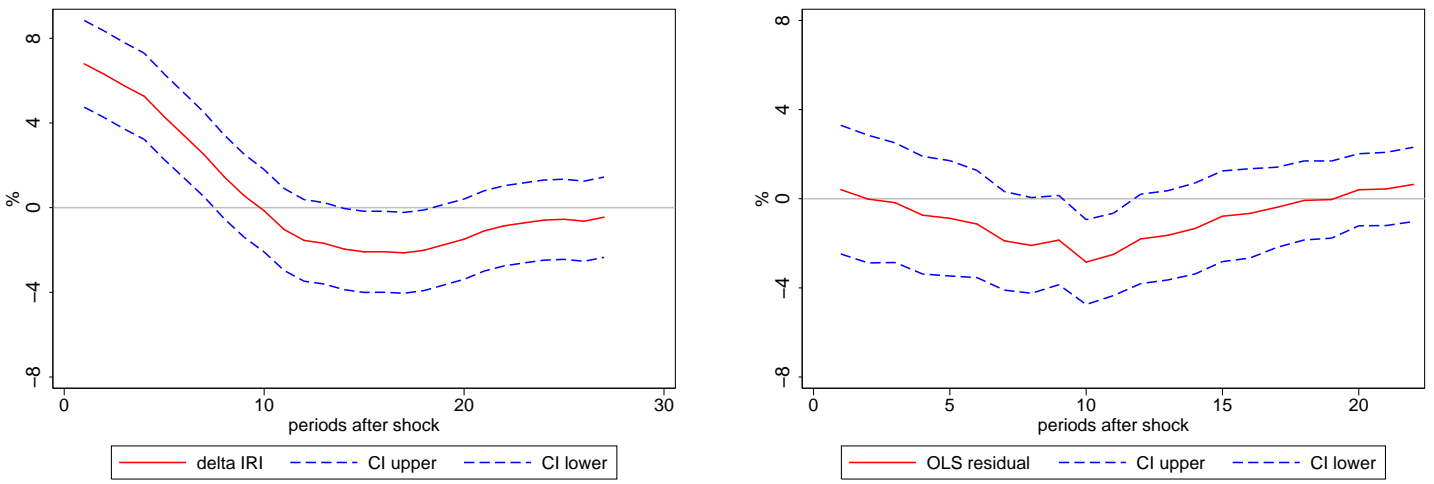

(c) Response to a $1 \%$ change in $\Delta I R I$ 
Figure 1.11: Implied IRFs of Aggregate Demand
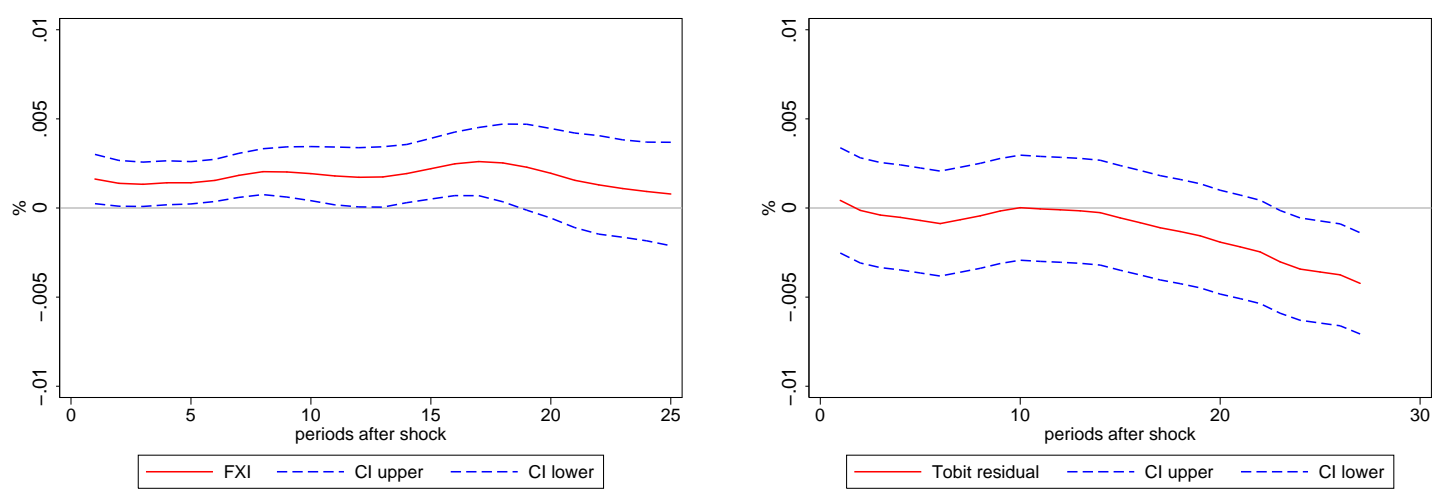

(a) Response to a 1 million USD purchase in (b) Response to a 1 million USD purchase in $F X I$

$\epsilon_{1 t}$
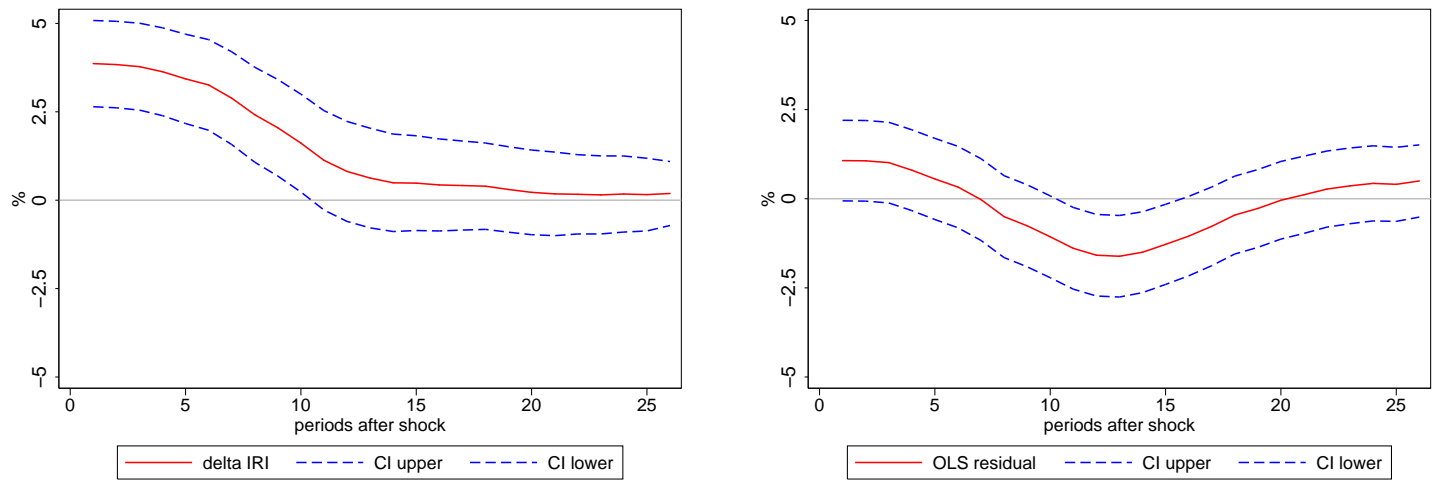

(c) Response to a $1 \%$ change in $\Delta I R I$

(d) Response to a $1 \%$ change in $\epsilon_{2 t}$ 
Figure 1.12: Implied IRFs of Exchange Rate Changes
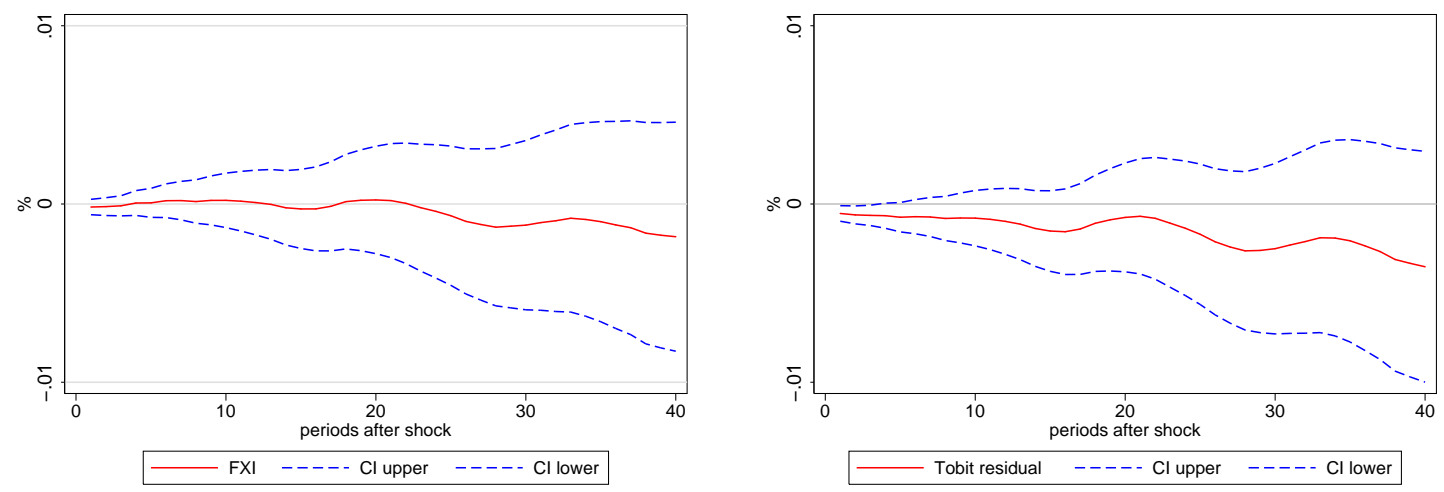

(a) Response to a 1 million USD purchase in (b) Response to a 1 million USD purchase in $F X I$

$\epsilon_{1 t}$
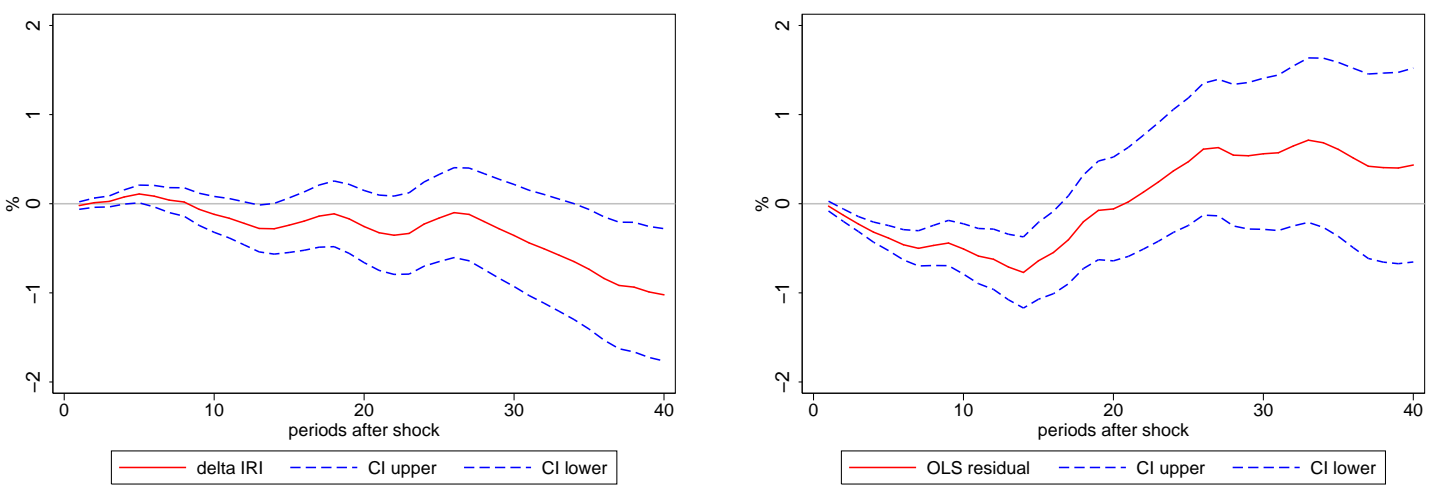

(c) Response to a $1 \%$ change in $\Delta I R I$ 


\section{Figure 1.13: Implied IRFs of Exchange Rate Volatility}
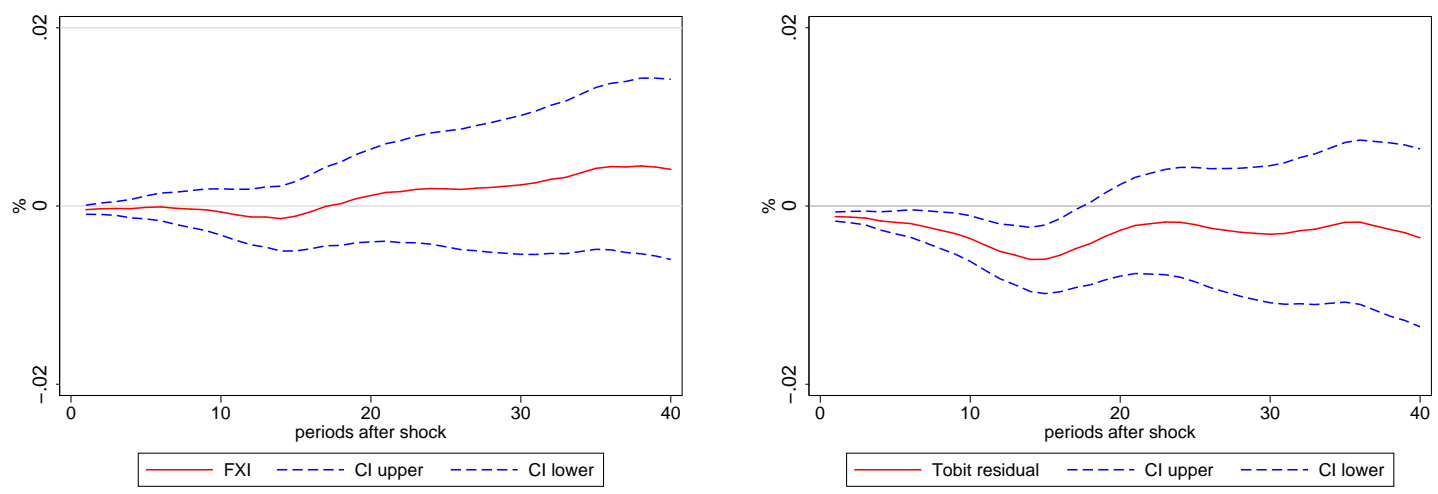

(a) Response to a 1 million USD purchase in (b) Response to a 1 million USD purchase in $F X I$

$\epsilon_{1 t}$
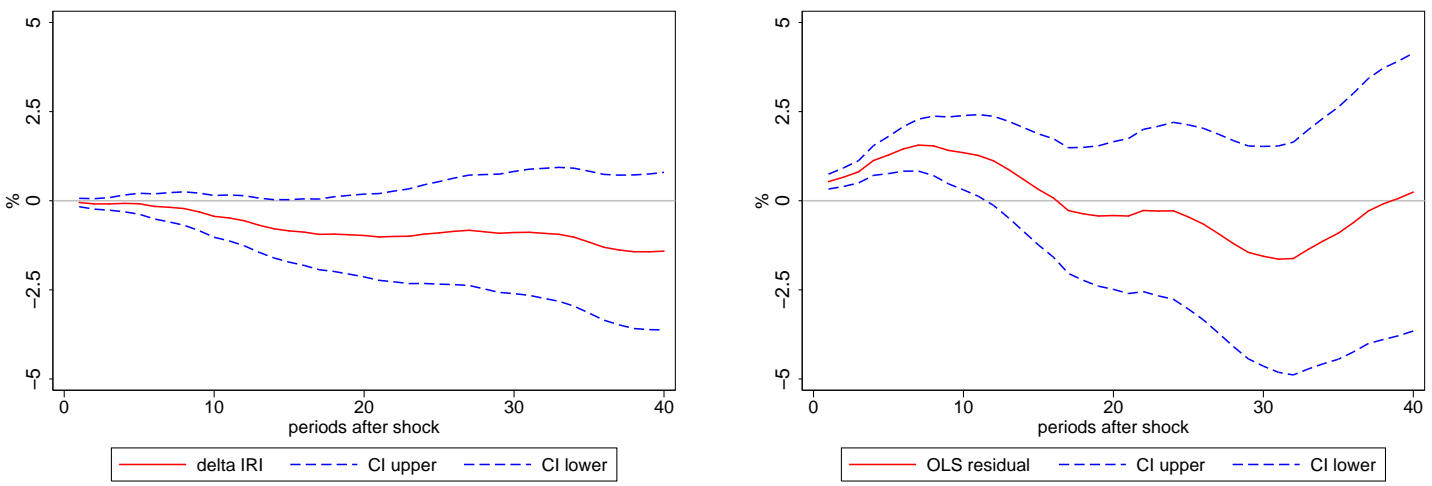

(c) Response to a $1 \%$ change in $\Delta I R I$

(d) Response to a $1 \%$ change in $\epsilon_{2 t}$ 
Figure 1.14: Implied IRFs of 1-year Treasury Bond's Yield

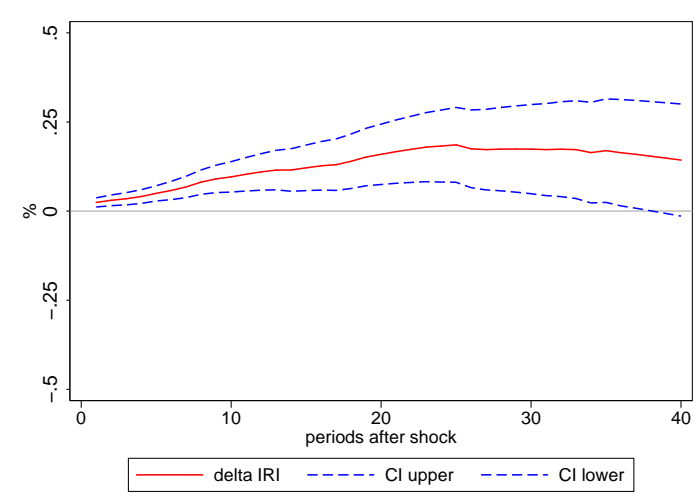

(a) Response to a $1 \%$ change in $\Delta I R I$

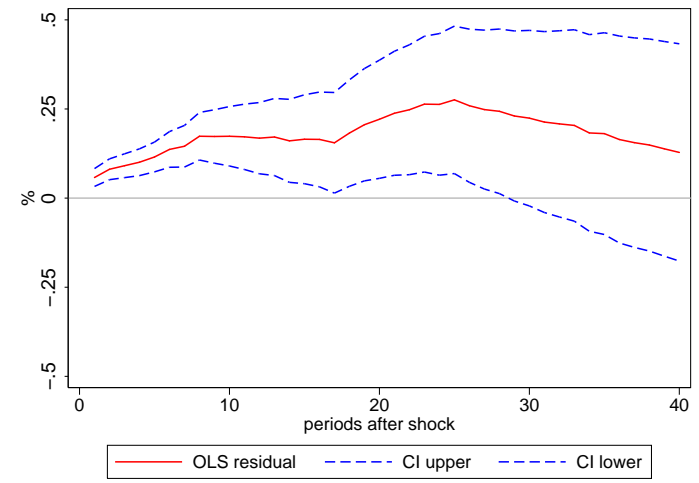

(b) Response to a $1 \%$ change in $\epsilon_{2 t}$ 
Figure 1.15: Counterfactual Outcomes

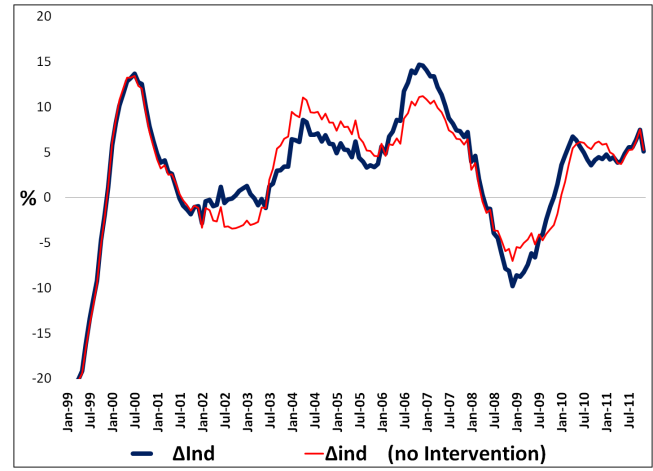

(a) Response of $\Delta I n d_{t}$

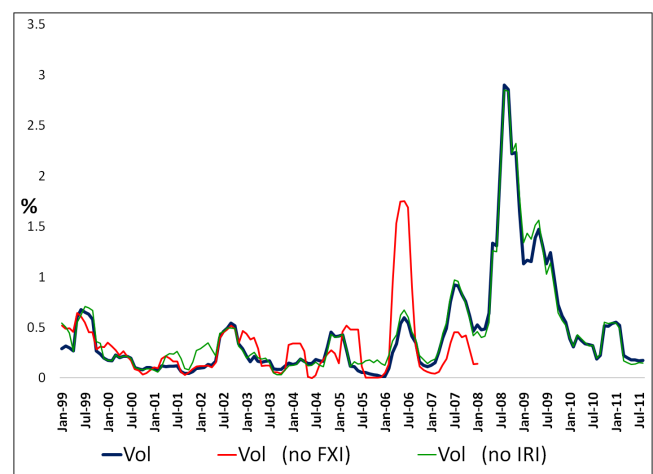

(c) Response of $\mathrm{Vol}_{t}$

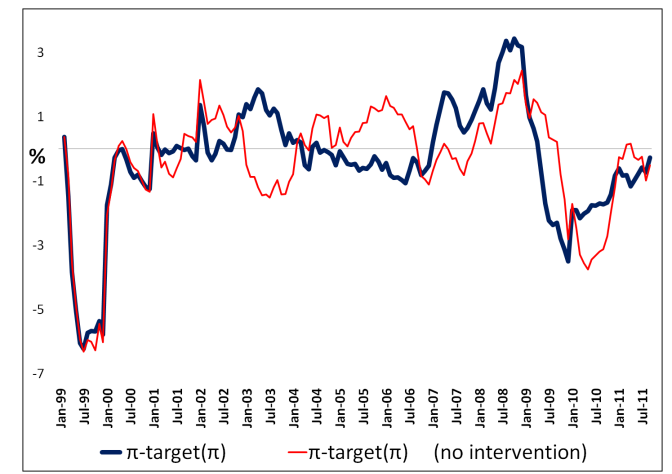

(b) Response of $\pi_{t}-\operatorname{target}\left(\pi_{t}\right)$

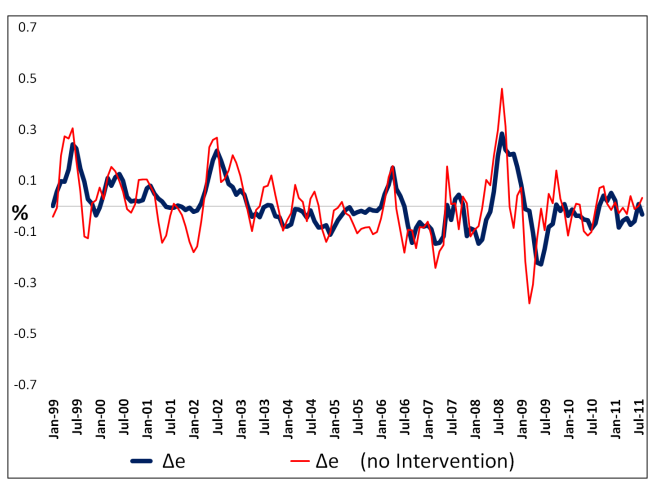

(d) Response of $\Delta e_{t}$

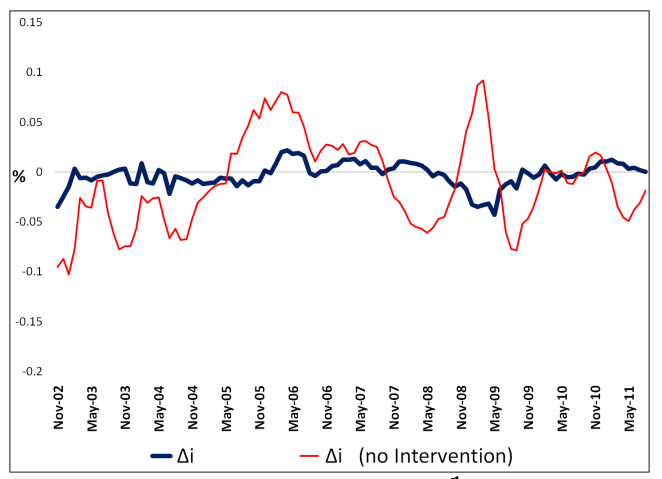

(e) Response of $\Delta i_{t}^{1 y e a r}$ 


\subsection{TABLES}

Table 1.1: Foreign Exchange Interventions 1999-2012 (Billion USD purchases)

\begin{tabular}{lcccccccccc}
\hline \hline USDPurchases & Total & $99-03$ & 04 & 05 & 06 & 07 & $08-09$ & 10 & 11 & 12 \\
\hline SPOT MARKET & 19.9 & 0.0 & 1.3 & 4.6 & 1.2 & 4.5 & 1.4 & 3.0 & 3.7 & 3.0 \\
OPTIONS MARKET & 3.3 & 1.5 & 1.4 & 0.0 & 0.0 & 0.0 & 0.5 & 0.0 & 0.0 & 0.0 \\
& & & & & & & & & & \\
Intervention days & & & & & & & & & & \\
$(\%$ of trading days) & & $5 \%$ & $32 \%$ & $70 \%$ & $13 \%$ & $18 \%$ & $18 \%$ & $62 \%$ & $75 \%$ & $83 \%$ \\
\hline \hline
\end{tabular}


Table 1.2: Elliott-Rothenberg-Stock Test for Unit Root

\begin{tabular}{lccc}
\hline \hline Variable (up to 28 lags) & t-statistic & $1 \%$ critical value & $10 \%$ critical value \\
\hline & & & \\
$F X I_{t}$ & -5.517 & -3.480 & -2.570 \\
$\Delta I R I_{t}$ & -6.157 & -3.480 & -2.570 \\
Vol & -8.413 & -3.480 & -2.570 \\
$\Delta e_{t}$ & -7.756 & -3.480 & -2.570 \\
$e_{t}-$ Forecast $\left(e_{t}\right)$ & -2.812 & -3.480 & -2.570 \\
Forecast $\left(\pi_{t}\right)-$ Target $\left(\pi_{t}\right)$ & -3.520 & -3.480 & -2.570 \\
$\pi_{t}-\pi^{e}$ & -2.696 & -3.480 & -2.570 \\
$D_{N e t P_{t}}$ & -6.131 & -3.480 & -2.570 \\
$y_{t}-F_{\text {orecast }}\left(y_{t}\right)$ & -4.069 & -3.480 & -2.570 \\
$\Delta$ Ind & -3.887 & -3.480 & -2.570 \\
Brazil $_{t}\left(\Delta e_{t}\right)$ & -11.398 & -3.480 & -2.570 \\
$\Delta i_{t}^{1 \text { year }}$ & -12.244 & -3.480 & -2.570 \\
$\Delta i_{t}^{*}$ & -3.827 & -3.480 & -2.570 \\
$\Delta$ Res $_{t}$ & -7.092 & -3.480 & -2.570 \\
\hline \hline
\end{tabular}

The minimum lag is determined using the modified akaike's information criterion (MAIC). All variables reject the null hypothesis of a unit root at the $1 \%$ level (except for the exchange rate deviation from the equilibrium forecast and deviations from expected inflation, which reject the null at the $10 \%$ level. 
Table 1.3: Different Specifications for $X_{t}$

\begin{tabular}{|c|c|}
\hline & Variables Included (In addition to the Central Bank's Internal Forecasts) \\
\hline & Variables in $X_{1}$ \\
\hline$x_{1 t}(1):$ & Exchange rate Volatility $\left(V O L_{t-1}\right)$ \\
\hline$x_{1 t}(2):$ & $\begin{array}{l}\text { Net Position of Central Bank }\left(D_{N e t P_{t-1}}\right) \text {, Brazil's Exchange rate }\left(\operatorname{Brazil}\left(\Delta e_{t-1}\right)\right) \text {, Board } \\
\text { Meetings }\left(\text { BoardMeet }_{t-1}\right) \text {, Industrial Production }\left(\Delta \operatorname{Ind_{t-1})} \text {, Capital Controls }\left(D_{t a x}\right)\right.\end{array}$ \\
\hline$x_{1 t}(3):$ & $\begin{array}{l}\text { All in } x_{1 t}(2)+\text { Exchange rate Volatility }\left(V O L_{t-1}\right) \text {, Biweekly Exchange rate }\left(\Delta e_{t-1,10}\right) \text {, } \\
\text { International Reserves }\left(\Delta \text { Res }_{t-1}\right) \text {, 1-Year Yield Spreads }\left(i_{t-1}^{1 \text { year }}-i_{t-1}^{* 1 \text { year }}\right) \text {, Lagged } \\
\text { Interest rate Interventions }\left(\Delta I R I_{t-1}\right)\end{array}$ \\
\hline & Variables in $X_{2}$ \\
\hline$x_{2 t}(1):$ & $\begin{array}{l}\text { Inflation Surprises }\left(\pi_{t-1}-\pi_{t-1}^{e}\right) \text {, Biweekly Exchange rate }\left(\Delta e_{t-1,10}\right) \text {, Industrial } \\
\text { Production }\left(\Delta I R I_{t-1}\right)\end{array}$ \\
\hline$x_{2 t}(2):$ & All in $x_{2 t}(1)+$ EMBI $\left(E M B I_{t-1}\right)$ \\
\hline$x_{2 t}(3):$ & All in $x_{2 t}(4)+$ Biweekly Exchange rate $\left(\Delta e_{t-1,10}\right), 1$-Day Yield Spreads $\left(i_{t-1}^{1 \text { day }}-i_{t-1}^{* 1 d a y}\right)$ \\
\hline$x_{2 t}(4):$ & $\begin{array}{l}\text { 1-Year Yield } \Delta i_{t-1}^{1 \text { year }} \text {, Dummy }(2006-2008) \text { for 1-Year Yield }\left(D_{\Delta i_{t-1}^{1 \text { year }}}\right) \text {, Industrial } \\
\text { Production }\left(\Delta I R I_{t-1}\right)\end{array}$ \\
\hline
\end{tabular}

See Appendix A for a detailed description of each variable. 
Table 1.4: Covariances of Bivariate Process

\begin{tabular}{lccc}
\hline \hline$x_{2 t} / x_{1 t}$ & $(1)$ & $(2)$ & $(3)$ \\
\hline \multirow{2}{*}{$(1)$} & -0.04 & -0.04 & -0.03 \\
& $(0.058)$ & $(0.061)$ & $(0.128)$ \\
Log-Likelihood & 67.06 & 110.69 & 122.26 \\
& & & \\
$(2)$ & -0.02 & -0.04 & -0.09 \\
& $(0.054)$ & $(0.058)$ & $(0.215)$ \\
Log-Likelihood & -172.51 & -128.99 & -117.23 \\
& & & \\
$(3)$ & -0.04 & -0.03 & -0.04 \\
& $(0.058)$ & $(0.061)$ & $(0.125)$ \\
Log-Likelihood & 61.94 & 105.35 & 117.11 \\
& & & \\
$(4)$ & -0.03 & -0.05 & -0.11 \\
& $(0.053)$ & $(0.055)$ & $(0.177)$ \\
Log-Likelihood & -339.41 & -295.87 & -283.78 \\
& & & \\
\hline \hline
\end{tabular}

Specifications $x_{1 t}(1-3)$ and $x_{2 t}(1-4)$ correspond to the different combinations of covariates presented in Table 2. All models consisted of 2,108 observations.*, **, ${ }^{* *}$ indicate significance at the $10 \%, 5 \%$ and $1 \%$ level, respectively. Standard errors are reported in parentheses. 
Table 1.5: Tobit Estimation for Foreign Exchange Interventions

\begin{tabular}{|c|c|c|c|}
\hline Variable & (1) & $(2)$ & $(3)$ \\
\hline$F X I_{t-1}$ & $\begin{array}{c}0.51^{* * *} \\
(0.058)\end{array}$ & $\begin{array}{c}0.36 * * * \\
(0.056)\end{array}$ & $\begin{array}{c}0.35^{* * *} \\
(0.058)\end{array}$ \\
\hline$e_{t-1}-$ Forecast $\left(\bar{e}_{t-1}\right)$ & $\begin{array}{c}-2.36 * * \\
(1.017)\end{array}$ & $\begin{array}{c}-4.63^{* * *} \\
(1.078)\end{array}$ & $\begin{array}{c}-6.69^{* * *} \\
(1.410)\end{array}$ \\
\hline $\operatorname{Forecast}\left(\pi_{t-1}\right)-\operatorname{Target}\left(\pi_{t-1}\right)$ & $\begin{array}{c}-7.41 \\
(7.965)\end{array}$ & $\begin{array}{c}-4.45 \\
(8.121)\end{array}$ & $\begin{array}{c}-5.81 \\
(8.045)\end{array}$ \\
\hline$y_{t-1}-$ Forecast $\left(\bar{y}_{t-1}\right)$ & $\begin{array}{c}-40.8^{* * *} \\
(11.901)\end{array}$ & $\begin{array}{c}-66.0^{* * *} \\
(12.322)\end{array}$ & $\begin{array}{c}-47.4^{* * *} \\
(13.390)\end{array}$ \\
\hline$D_{N e t P_{t-1}}$ & & $\begin{array}{c}4.17 \\
(11.563)\end{array}$ & $\begin{array}{c}3.48 \\
(11.580)\end{array}$ \\
\hline$V O L_{t-1}$ & $\begin{array}{c}1.96 \\
(1.502)\end{array}$ & & $\begin{array}{c}2.54^{*} \\
(1.498)\end{array}$ \\
\hline $\operatorname{Brazil}\left(\Delta e_{t-1}\right)$ & & $\begin{array}{c}-8.43^{* * *} \\
(3.222)\end{array}$ & $\begin{array}{c}-8.08 * * \\
(3.169)\end{array}$ \\
\hline BoardMeet $_{t-1}$ & & $\begin{array}{c}-19.6^{* * *} \\
(12.084)\end{array}$ & $\begin{array}{c}-20.5^{*} \\
(12.244)\end{array}$ \\
\hline$\Delta I n d_{t-1}$ & & $\begin{array}{l}-1.25^{*} \\
(0.706)\end{array}$ & $\begin{array}{c}-0.87 \\
(0.715)\end{array}$ \\
\hline$D_{\operatorname{tax}}$ & & $\begin{array}{c}-164.8^{* * *} \\
(19.140)\end{array}$ & $\begin{array}{c}-164.6^{* * *} \\
(20.192)\end{array}$ \\
\hline$\Delta e_{t-1,10}$ & & & $\begin{array}{c}-4.68 * * \\
(2.249)\end{array}$ \\
\hline$\Delta R e s_{t-1}$ & & & $\begin{array}{c}-0.33 \\
(2.644)\end{array}$ \\
\hline$i_{t-1}^{1 \text { year }}-i_{t-1}^{* 1 \text { year }}$ & & & $\begin{array}{c}-1.97 \\
(3.869)\end{array}$ \\
\hline$\Delta I R I_{t-1}$ & & & $\begin{array}{c}-43.1 \\
(51.000)\end{array}$ \\
\hline
\end{tabular}

Specifications $x_{1 t}(1-3)$ correspond to the different combinations of covariates presented in Table 2. All models consisted of 2,108 observations. Pseudo $R^{2}=0.08,0.10$ and 0.11 for Tobit specifications $1-3 . *, * *, * * *$ indicate significance at the $10 \%, 5 \%$ and $1 \%$ level, respectively. Standard errors are reported in parentheses. Constant and time dummies are not reported (estimations without dummies yield similar results). 
Table 1.6: OLS Estimation for Interest Rate Interventions

\begin{tabular}{|c|c|c|c|c|}
\hline Variable & (1) & (2) & (3) & (4) \\
\hline$\Delta I R I_{t-1}$ & $\begin{array}{c}0.36 * * * \\
(0.093)\end{array}$ & & $\begin{array}{c}0.19^{*} \\
(0.110)\end{array}$ & \\
\hline$I R I_{t-1}$ & & $\begin{array}{c}-0.06^{* * *} \\
(0.015)\end{array}$ & & $\begin{array}{c}-0.07^{* * *} \\
(0.012)\end{array}$ \\
\hline$e_{t-1}-$ Forecast $\left(\bar{e}_{t-1}\right)$ & $\begin{array}{c}0.00 \\
(0.006)\end{array}$ & & & $\begin{array}{c}0.01^{* * *} \\
(0.005)\end{array}$ \\
\hline $\operatorname{Forecast}\left(\pi_{t-1}\right)-\operatorname{Target}\left(\pi_{t-1}\right)$ & & & $\begin{array}{c}0.07^{* * *} \\
(0.023)\end{array}$ & \\
\hline$y_{t-1}-$ Forecast $\left(\bar{y}_{t-1}\right)$ & & $\begin{array}{c}0.08 * * * \\
(0.025)\end{array}$ & & $\begin{array}{c}0.08 * * * \\
(0.015)\end{array}$ \\
\hline$E M B I_{t-1}$ & & $\begin{array}{c}0.04^{*} \\
(0.021)\end{array}$ & & \\
\hline$\pi_{t-1}-\pi_{t-1}^{e}$ & $\begin{array}{c}0.05^{* *} \\
(0.024)\end{array}$ & $\begin{array}{c}0.02 \\
(0.031)\end{array}$ & & \\
\hline$\Delta e_{t-1,10}$ & $\begin{array}{l}0.02^{* *} \\
(0.010)\end{array}$ & $\begin{array}{l}0.02^{* *} \\
(0.011)\end{array}$ & $\begin{array}{c}0.02^{* *} \\
(0.008)\end{array}$ & \\
\hline$i_{t-1}^{1 d a y}-i_{t-1}^{* 1 d a y}$ & & & $\begin{array}{c}-0.07^{* * *} \\
(0.025)\end{array}$ & \\
\hline$\Delta i_{t-1}^{1 \text { year }}$ & & & $\begin{array}{c}0.63^{* * *} \\
(0.217)\end{array}$ & $\begin{array}{c}0.76^{* * *} \\
(0.229)\end{array}$ \\
\hline$D_{\Delta i_{t-1}^{1 \text { year }}}$ & & & -0.33 & $-0.62^{*}$ \\
\hline$\Delta I n d_{t-1}$ & $\begin{array}{c}0.020^{* * *} \\
(0.007)\end{array}$ & $\begin{array}{c}0.014^{* * *} \\
(0.004)\end{array}$ & $\begin{array}{c}(0.427) \\
0.004 \\
(0.005)\end{array}$ & $\begin{array}{c}(0.360) \\
0.008^{*} \\
(0.004)\end{array}$ \\
\hline
\end{tabular}

Specifications $x_{2 t}(1-4)$ correspond to the different combinations of covariates presented in Table 2. All models consisted of 161 observations. $R^{2}=0.54,0.64,0.64$ and 0.67 for OLS specifications $1-4 . *, * *, * * *$ indicate significance at the $10 \%, 5 \%$ and $1 \%$ level, respectively. Robust standard errors are reported in parentheses. Constant is not reported. Time dummies were not included. 
Table 1.7: Policy Shocks' Orthogonality Condition

\begin{tabular}{|c|c|c|c|c|c|c|c|}
\hline \multirow{2}{*}{$\begin{array}{l}\text { Policy Shocks } \\
\text { Variable }\end{array}$} & \multicolumn{3}{|c|}{ FXI $\left(\epsilon_{1 t}\right)$} & \multicolumn{3}{|c|}{ IRI $\left(\epsilon_{2 t}\right)$} & \multirow[b]{2}{*}{ (4) } \\
\hline & $(1)$ & $(2)$ & (3) & (1) & $(2)$ & (3) & \\
\hline$\Delta I n d_{t-1}$ & $\begin{array}{c}\mathbf{0 . 3} \text { *** } \\
(0.129)\end{array}$ & & & & & & \\
\hline BoardMeet $_{t-1}$ & $\begin{array}{c}-5.7^{* * *} \\
(1.451)\end{array}$ & & & & & & \\
\hline$D_{N e t P_{t-1}}$ & $\begin{array}{c}\mathbf{2 . 5}^{*} \\
(1.261)\end{array}$ & & & $\begin{array}{c}0.002 \\
(0.067)\end{array}$ & $\begin{array}{c}-0.05 \\
(0.079)\end{array}$ & $\begin{array}{c}0.001 \\
(0.064)\end{array}$ & $\begin{array}{c}-0.03 \\
(0.067)\end{array}$ \\
\hline $\operatorname{Brazil}\left(\Delta e_{t-1}\right)$ & $\begin{array}{l}-\mathbf{- 1 . 6 * *} \\
(0.787)\end{array}$ & & & $\begin{array}{c}0.000 \\
(0.015)\end{array}$ & $\begin{array}{c}0.016 \\
(0.019)\end{array}$ & $\begin{array}{c}0.006 \\
(0.016)\end{array}$ & $\begin{array}{c}0.008 \\
(0.018)\end{array}$ \\
\hline$D_{\operatorname{tax}}$ & $\begin{array}{c}-5.6^{* * *} \\
(1.145)\end{array}$ & & & $\begin{array}{c}-0.08 \\
(0.079)\end{array}$ & $\begin{array}{c}0.06 \\
(0.063)\end{array}$ & $\begin{array}{c}0.031 \\
(0.070)\end{array}$ & $\begin{array}{c}0.07 \\
(0.064)\end{array}$ \\
\hline$\Delta \operatorname{Res}_{t-1}$ & $\begin{array}{c}-0.61 \\
(0.902)\end{array}$ & $\begin{array}{c}-0.43 \\
(0.779)\end{array}$ & & $\begin{array}{l}-0.003 \\
(0.016)\end{array}$ & $\begin{array}{l}-0.006 \\
(0.014)\end{array}$ & $\begin{array}{l}-0.005 \\
(0.014)\end{array}$ & $\begin{array}{c}-0.01 \\
(0.013)\end{array}$ \\
\hline$i_{t-1}^{1 \text { year }}-i_{t-1}^{* 1 \text { year }}$ & $\begin{array}{c}-0.24^{*} \\
(0.127)\end{array}$ & $\begin{array}{c}-0.07 \\
(0.125)\end{array}$ & & $\begin{array}{c}0.007 \\
(0.011)\end{array}$ & $\begin{array}{c}0.000 \\
(0.009)\end{array}$ & $\begin{array}{c}0.014 \\
(0.010)\end{array}$ & $\begin{array}{c}0.001 \\
(0.009)\end{array}$ \\
\hline$\pi_{t-1}-\pi_{t-1}^{e}$ & $\begin{array}{c}-0.02 \\
(0.872)\end{array}$ & $\begin{array}{c}-0.50 \\
(0.839)\end{array}$ & $\begin{array}{l}-0.58 \\
(0.841)\end{array}$ & & & $\begin{array}{l}-0.003 \\
(0.019)\end{array}$ & $\begin{array}{l}-0.005 \\
(0.019)\end{array}$ \\
\hline$E M B I_{t-1}$ & $\begin{array}{c}0.002 \\
(0.003)\end{array}$ & $\begin{array}{c}0.004 \\
(0.003)\end{array}$ & $\begin{array}{c}0.004 \\
(0.003)\end{array}$ & $\begin{array}{c}0.000 \\
(0.000)\end{array}$ & & $\begin{array}{c}0.000 \\
(0.000)\end{array}$ & $\begin{array}{c}0.000 \\
(0.000)\end{array}$ \\
\hline$\Delta e_{t-1,20}$ & $\begin{array}{c}-0.04 \\
(0.183)\end{array}$ & $\begin{array}{l}-0.005 \\
(0.176)\end{array}$ & $\begin{array}{l}-0.33^{*} \\
(0.180)\end{array}$ & $\begin{array}{c}-0.02 \\
(0.127)\end{array}$ & $\begin{array}{l}-0.004 \\
(0.139)\end{array}$ & $\begin{array}{c}0.02 \\
(0.112)\end{array}$ & $\begin{array}{c}0.19 \\
(0.145)\end{array}$ \\
\hline$\Delta \pi_{t-1}$ & $\begin{array}{c}3.58 \\
(2.505)\end{array}$ & $\begin{array}{c}0.21 \\
(2.391)\end{array}$ & $\begin{array}{c}0.47 \\
(2.382)\end{array}$ & $\begin{array}{c}0.13 \\
(0.129)\end{array}$ & $\begin{array}{c}0.12 \\
(0.106)\end{array}$ & $\begin{array}{c}0.010 \\
(0.110)\end{array}$ & $\begin{array}{c}0.11 \\
(0.104)\end{array}$ \\
\hline$\Delta i_{t-1}^{* 1 d a y}$ & $\begin{array}{c}-6.4 \\
(5.306)\end{array}$ & $\begin{array}{c}-5.7 \\
(5.316)\end{array}$ & $\begin{array}{c}-4.8 \\
(5.382)\end{array}$ & $\begin{array}{c}0.08 \\
(0.188)\end{array}$ & $\begin{array}{c}0.05 \\
(0.152)\end{array}$ & $\begin{array}{c}0.09 \\
(0.161)\end{array}$ & $\begin{array}{c}0.07 \\
(0.141)\end{array}$ \\
\hline$\Delta G D P_{t-1}^{\text {Tradables }}$ & $\begin{array}{l}-0.23 \\
(0.355)\end{array}$ & $\begin{array}{c}-0.37 \\
(0.334)\end{array}$ & $\begin{array}{l}-.040 \\
(0.332)\end{array}$ & $\begin{array}{c}0.01 \\
(0.012)\end{array}$ & $\begin{array}{c}\mathbf{0 . 0 2 *} \\
(0.011) \\
\end{array}$ & $\begin{array}{c}0.008 \\
(0.010)\end{array}$ & $\begin{array}{c}0.017 \\
(0.010) \\
\end{array}$ \\
\hline
\end{tabular}

Specifications $x_{1 t}(1-3)$ and $x_{2 t}(1-4)$ correspond to the different combinations of covariates presented in Table 2. All models consisted of 2,108 observations. *, **,*** indicate significance at the $10 \%, 5 \%$ and $1 \%$ level, respectively. Standard errors (robust for OLS) are reported in parentheses. 
Table 1.8: Effects of Observed Policy Instruments and Policy Shocks

\begin{tabular}{lcc}
\hline \hline Summary & FXI Shocks $\left(\epsilon_{1 t}\right)$ & IRI Shocks $\left(\epsilon_{2 t}\right)$ \\
\hline Inflation & 0 & $-(\geq 1$ year $)$ \\
Industrial Production & 0 & $-\quad$ (months: $10-12)$ \\
Aggregate Demand & 0 & $-\quad$ (months: $11-15)$ \\
Exchange Rate & 0 & $-(\leq 15$ days $)$ \\
Exchange Rate Volatility & $-(\leq 16$ days $)$ & $+(\leq 11$ days $)$ \\
1-year TB's yield &
\end{tabular}


CHAPTER 2

Great Expectations? Evidence from Colombia's Exchange Rate SURVEY

\subsection{INTRODUCTION}

The amount of foreign exchange that is traded daily is far in excess of what is required for trade in goods and services. According to Jongen et al. (2008) and Froot and Thaler (1990), it seems that the foreign exchange market is a market "on its own" and, because of its volume, very liquid and efficient. On the other hand, most theoretical models would agree that expectations play a central role in the determination of the exchange rate, and for some authors "little else matters" (Woodford, 2003).

The Mundell-Fleming model assumes that expectations are static so that international arbitrage equates domestic and foreign interest rates. Some authors like Friedman (1953) argue that expectations must be stabilizing since destabilizing speculators will be driven out of the market, but Nurkse (1944) considers that expectations could be highly volatile and unstable, and that the influence of psychological factors may, at times, be overwhelming. This destabilizing pattern of expectations is commonly known as bandwagon and has been described in detail by Frankel and Rose (1994) and by Takagi (1990). Bandwagon expectations could produce extremely volatile exchange rates, negatively affecting investment and international trade, 
increasing protectionist pressures, and hindering the development of the financial sector. ${ }^{1}$

Most recent theoretical models assume that expectations are rational, where agents are able to predict future exchange rates (plus a random error). This implies that any additional information available at the time of the survey cannot improve agents' forecasts. Also, few models incorporate a measure of a risk premium that can be produced when foreign and domestic currencies are imperfect substitutes. Finally, most models in the related literature assume homogeneous expectations. But the empirical literature shows again and again that these assumptions do not hold. In fact, there is a long history of evidence pioneered by Dominguez (1986), Frankel (1979), and Frankel and Froot (1987) or even more recent works like Frankel (1997), Cavaglia et al. (1998), Menkhoff (1998), Chinn and Frankel (2002), and De Grauwe et al. $(2006,2013)$ that show a systematic bias in exchange rate expectations. Also, Ito (1990) and Allan and Taylor (1990) find empirical evidence of heterogeneity in expectations amongst market participants. ${ }^{2}$ There are also numerous studies such as Bekaert (1996), Lewis (1995), Mark and Wu (1998), Carlson (1998), and Meredith and Ma (2002) that find statistical evidence of currency risk premiums.

This paper contributes to the existing strand of the literature by using a novel (and proprietary) survey data set from the Central Bank of Colombia. In particular, we find that the forward discount rate was generally different from future exchange rate changes due to the rejection of the unbiasedness condition and to a time-varying risk premium. This suggests that the rational expectations hypothesis does not hold. We also find a high degree of heterogeneity in exchange rate expectations.

\footnotetext{
${ }^{1}$ See Villa (2011) and Rigobon (2008).

${ }^{2}$ Ito (1990) uses biweekly panel data collected by the Japan Center for International Finance. It includes 44 financial institutions. Allan and Taylor (1990) use data from the foreign exchange market in London.
} 
This paper is organized as follows: Section II reviews the accuracy of forecasts, and the relative importance of rational expectations and risk premium associated with the explanation of the so called forward puzzle. Section III presents different models of how expectations are formed and determines if they are stabilizing or destabilizing. In this section we also compare agents' forecasts with a simple random walk process and explore if the use of information available at the time of the survey could have potentially improved the accuracy of forecasts. Section IV shows that expectations are highly heterogeneous due to the use of different forecasting techniques and contrasts the forecasting accuracy of chartists vs. fundamentalists. Finally, Section V concludes.

\subsection{Forecasts, Forwards AND THE Risk PREMIUM}

Survey data have been widely used in the international finance literature. Examples include interest rate surveys to test for term premiums and rational expectations, and surveys ranging from stock market rates, GNP deflators and even money aggregates. ${ }^{3}$ Survey data on exchange rates has been widely used to test for rationality and the presence of a risk premium without having to depend on forward or ex-post exchange rates as proxies of expectations.

However, there are obvious drawbacks of using survey data. For one, there is no guarantee that agents will disclose their true beliefs. As mentioned by Frankel and Froot (1987, pp. 134) "It is a cornerstone of positive economics that we learn more by observing what people do in the marketplace than what they say". Also, the timing of the forecast report might not coincide with the closing of the exchange rate market, which might give some agents additional hours of information for their predictions. Finally, as explained in Section IV, there is wide dispersion in the answers provided by different agents, so it is not always clear that the mean or median value captures all of

\footnotetext{
${ }^{3}$ See Jongen et al. (2008) for a more in-depth literature review
} 
the existing information. Nevertheless, exchange rate surveys can be less problematic than other surveys (i.e. GDP, prices, etc.) since investors or analysts responding to the survey are actively involved in trading in the foreign exchange market. They at least represent a clear improvement on the conventional methodology of assuming ex-post exchange rates as a proxy for exchange rate expectations.

We use the Central Bank Expectations Survey conducted monthly by the Central Bank of Colombia (October 2003 - August 2012) to commercial banks, stockbrokers and pension funds. The survey asks for the 1-month, end-of-year and the 1-year ahead exchange rates (Colombian peso/US dollar). The number of responses (i.e. financial institutions) varies from month to month, with a median number of 39 , a minimum of 27 (in August 2005, March 2007 and October 2007) and a maximum of 48 (in April 2010). Overall, the survey was conducted 107 times within our sample. ${ }^{4}$ Financial institutions were classified into three groups: 1) Commercial Banks (median of 15 per month), 2) Stockbrokers (median of 19 per month) and 3) Pension Funds (median of 5 per month). The resulting unbalanced panel data set contains 4,389 observations for each of the three variables (not all establishments participated every month). In total, 15 institutions answered the survey more than 90 times, and 41 institutions answered the survey more than 52 (with a median of 42 times and an average of 47 ). ${ }^{5}$ Additional exercises (not reported) and internal follow-ups suggest that there was no systematic reason for financial institutions not to participate in every survey. In this sense, we believe that missing observations were in fact random, or at least not correlated to the underlying covariates in each of the estimated models.

\footnotetext{
${ }^{4}$ Our data set is large when compared to the 12,38 and 47 observations for the three surveys used by Frankel and Froot (1987).

${ }^{5}$ Even if survey respondents comprise economic analysts rather than traders, Villa (2011) shows that their projection techniques are very similar to the ones used by market participants.
} 


\subsubsection{How Accurate Are Agents' Forecasts?}

It appears as an empirical regularity in the literature that the expected exchange rate does not equal the observed future rate, often even missing the direction of change. For example, Wikita (1989) and Ito (1990) find industry-specific bias in expectations. Also, Mussa (1979) and Frankel and Froot (1987) find constant under-predictions of exchange rates and Lewis (1989) finds evidence of systematic forecast errors. ${ }^{6}$

Figure 2.1 presents the one-month and one year-ahead exchange rate (average) expectations. Appreciations were generally followed by expectations of further appreciations in the short run, but by expectations of depreciations (reversals) in the long run. In the related literature, this pattern has been referred to as a twist in expectations and partially explains the stabilizing nature of expectations that we find in Section III. It could also explain why many Colombian exporters were reluctant to insure themselves in the forward exchange market. This pattern is also very similar to the one found by Takagi (1990), Chart 3, for the yen-dollar exchange rate during 1985-1986. However, circumstances seemed to have changed in 2011 and 2012 when agents were finally predicting that the 1-year exchange rate would remain constant or even fall. Figure 2.1 also exhibits some degree of short term under-prediction of the 1-month exchange rate, in the sense that expected appreciations were lesser in magnitude than observed appreciations (and vice-versa for depreciations).

Expectations considered over the sample period behaved poorly in terms of accuracy. Figure 2.2 presents forecast errors for 1-month and 1-year expectations, measured as the difference between the expected and observed future rate. Expecta-

\footnotetext{
${ }^{6}$ The finding of biases in expectations does not necessarily preclude them from being formed rationally. Agents could have anticipated (with a small probability) an event that would cause a large devaluation. This is the so-called peso problem, after the discount consistent with the massive depreciation of the Mexican peso in 1976. Forecast errors may also arise when the market gradually and rationally learns about the true process that generates expectations, or can even occur as a result of heterogeneous expectations.
} 
tions differed from the 1-month and 1-year ahead spot rate in up to 206 pesos/dollar (September 2007) and in up to 615 pesos/dollar (June 2007), respectively. As can be observed, 1- month forecast errors oscillate between negative and positive values, but the 1-year errors are for the most part positive, except during the second part of 2008 and the first part of 2009 when the exchange rate presented strong depreciations. The fact that yearly forecast errors were generally positive indicates, once again, a systematic bias towards expected depreciations, exacerbated during periods of sharp exchange rate appreciations.

Figure 2.3 shows the percentage of establishments that correctly predicted the exchange rate change direction (i.e. positive or negative variations). Again, there are marked differences between short and long-term expectations. Financial institutions were able to correctly predict the direction of the exchange rate in $67 \%$ of cases for the 1-month horizon, but only in $40 \%$ of cases for the 1-year horizon (i.e. a fair coin would have outperformed the 1-year direction forecasts, invoking any law of large numbers). Levels of accuracy were particularly low in 2004 (and in some months of 2005-2007), and high during episodes of steady appreciation (Jan 2005 - Apr 2006, Nov 2007 - Jun 2008). Similarly, Figure 2.4 depicts forecast errors larger than $\$ 100$ Pesos ( \pm 50 pesos / dollar) and shows that in many months, not a single entity was able to predict the 1-year ahead rate within that range. Only in some months of 2005 and 2011 were there more than $30 \%$ of institutions able to do so. Again, results for the 1-month forecasts yield more accurate results, but even in that case there were many months with a low percentage of answers falling within the specified range.

\subsubsection{The Forward Discount and the Risk Premium}

Forward exchange rates have been widely used in the literature, not only to test for covered interest parity, but also to test for the effectiveness of sterilized foreign 
exchange intervention or the existence (absence) of a risk premium. For the case of Colombia, Echavarria et al. (2008) show that the covered interest rate parity condition holds (on average) at all horizons considered, a result that is consistent with most of the international literature.

Equations (2.1) and (2.2) show the covered and uncovered interest rate parity conditions, respectively, as presented in MacDonald and Taylor (1992), McCallum (1994), Engel (1996), or Chinn (2007):

$$
\begin{aligned}
F_{t}^{t+k}-S_{t} & =i_{t}-i_{t}^{*} \\
E_{t}\left[S_{t+k}\right]-S_{t} & =i_{t}-i_{t}^{*}-r p_{t}
\end{aligned}
$$

Where $F_{t}^{t+k}$ is the log forward exchange rate (to be exercised in period $t+k$ ), $S_{t}$ is the $\log$ spot exchange rate at time $t, E_{t}$ is the expected value operator and $i_{t}$ and $i_{t}^{*}$ correspond to the domestic and foreign interest rates, respectively. By substituting equation (2.1) into (2.2), we obtain equation (2.3) where the forward discount $\left(F_{t}^{t+k}-\right.$ $S_{t}$ ) can be expressed in terms of the expected depreciation and the risk premium $\left(r p_{t}\right)$. The second part of equation (2.3) also suggests that the forward discount can be expressed as the sum of the forecast errors $\left(E_{t}\left[S_{t+k}\right]-S_{t+k}\right)$, ex-post devaluations $\left(S_{t+k}-S_{t}\right)$, and the risk premium.

$$
\begin{aligned}
F_{t}^{t+k}-S_{t} & =E_{t}\left[S_{t+k}\right]-S_{t}+r p_{t} \\
& =\left(E_{t}\left[S_{t+k}\right]-S_{t+k}\right)+\left(S_{t+k}-S_{t}\right)+r p_{t}
\end{aligned}
$$


Most of the literature has found that the forward discount is not equal (on average) to the observed exchange rate change. For example, Fama (1984) as well as Hodrick and Srivastava (1984), assume that expectations are rational and give prominence to a risk premium in their explanation. The authors argue that the variance of the risk premium is greater than the variance of the expected depreciation. Similarly, Dominguez and Frankel (1993) show that, for imperfect substitutes, an increase in the amount of an asset results in either an increase of the required return or an increase of the risk premium. Additionally, some of the earliest empirical findings that reject unbiasedness of forward rates as predictors of future spot exchange rates include Levich (1979), Hansen and Hodrick (1980), Bilson (1981), Hsieh (1982), Hansen and Hodrick (1983), and Hodrick and Srivastava (1986).

Intuitively, the risk premium in equation (2.3) can be thought of as the difference between a risk-free investment (in this case hedged by the forward rate) and a risky investment subject to unexpected exchange rate changes. Thus, in the case of risk-neutral agents, the certainty equivalent would equal the return's expected value, eliminating the risk premium. If agents are risk averse, the risk premium should take positive values in order to compensate for the increased uncertainty of the risky asset.

Figure 2.5 shows both the forward and expected exchange rates. The figure suggest that the 1-month forward rate follows the expected rate very closely (unlike the case for 1-year expectations). The figure also shows that in periods of exchange rate appreciation, the 1-year forward rate is lower than the expected rate, suggesting the existence of a negative risk premium (and vice versa for depreciations). Similarly, Tables 2.1 and 2.2 show the forward discount, the expected future depreciation, forecast errors, and the risk premium $\left(r p_{t}\right)$ which are all part of equation (2.3). Table 2.1 shows that the difference between the forward discount and the observed exchange rate change is relatively small for 1 -month forecasts (with an average of $0.5 \%$ and 
a maximum value of $1.6 \%$ in 2004). On the other hand, Table 2.2 shows that this difference is large for 1-year forecasts (with an average of $8.7 \%$ and a maximum value of $19.4 \%$ in 2003). Table 2.2 also shows that 1-year forecast errors are large (average of $8.4 \%$ and a maximum value of $19.9 \%$ in 2004), especially when compared with a relatively small risk premium (average of $0.3 \%$ and a maximum value of $3.9 \%$ in 2012).

\subsubsection{Risk PREmium and the Rational Expectations Hypothesis}

The use of forward rates to predict future spot exchange rates is attributed to the efficient market hypothesis (EMH), which precludes high above-normal profits through arbitrage in the forward market. This in turn, encompasses the joint hypothesis that expectations are formed rationally and that market participants are risk neutral. That is, the efficient market hypothesis can fail as a result of non-rational expectations or the existence of a time-varying risk premium, or both (See Hodrick, 1987 and Engel 1996 for a description on empirical surveys).

In the related literature, Frenkel (1976) was one of the first to test for the unbiasedness of forward rates as predictors of future exchange rates (both variables measured in levels). However, the non-stationarity of these variables present a potential spurious regression problem that has been thoroughly addressed in Garbers (1987), Crowder (1994), Baillie et al. (1996), and Maynard and Phillips (2001). In fact, some authors like Kaminsky and Peruga (1993) and Baillie et al. (1996) have included an unobservable time-varying risk premium in their models to account for differences in statistical properties when regressing interest rate spreads on exchange rate changes.

The conventional methodology for testing the existence of a risk premium (as proposed by Fama, 1984) is to use ex-post exchange rates as a proxy for exchange rate expectations. The critical disadvantage to this approach is that it assumes rational 
expectations instead of testing it. Thus, you cannot determine whether evidence of a risk premium is in fact attributed to a time-varying risk or to the failure of rational expectations. Assuming that our survey data accurately represents agents' expectations, we can directly test for the presence of a risk premium without making any a-priori assumptions on rationality. Hence, to statistically test if the forward rate is an unbiased predictor of the expected exchange rate we estimate equation (2.4) as proposed by Macdonald and Torrance (1990) and Frankel and Froot (1989):

$$
E_{t}\left[S_{t+k}\right]-S_{t}=b_{0}+b_{1}\left(F_{t}^{t+k}-S_{t}\right)+e_{t}
$$

Where the expected future exchange rate, $E_{t}\left[S_{t+k}\right]$, is obtained from the Colombian Central Bank Survey, and $F_{t}^{t+k}-S_{t}$ corresponds to the forward discount. In this setting, " $i "$ corresponds to the different financial institutions. A constant is also added to account for the convexity term arising from Jensen's inequality. ${ }^{7}$

Table 2.3 presents the estimated coefficients $b_{0}$ and $b_{1}$, a t-test for the null hypothesis $H_{0}: b_{1}=1$, and a Wald test for the joint hypothesis $b_{0}=0$ and $b_{1}=1$. Results are presented for OLS regressions (cross section with dummies for each institution, less one), for panel data, and for panel data with robust standard errors. Results are similar for all regressions: The null $H_{0}: b_{1}=1$ is not rejected for 1-month horizons, but it is rejected for 1 -year horizons. ${ }^{8}$ These results are contrary to those of Froot and Frankel (1989) who reject the null for 1-month forecasts, but do not reject the null for 3-month, 6-month and 1-year horizons. ${ }^{9}$

All estimations were tested for fixed and random effects to control for both establishment and time-specific characteristics that could potentially be correlated with the

\footnotetext{
${ }^{7}$ See Macdonald and Torrance, 1990.

${ }^{8}$ The joint hypothesis $b_{0}=0$ and $b_{1}=1$ is rejected for both 1 -month and 1-year horizons. ${ }^{9}$ See also Takagi (1990)
} 
probability of an agent's participation in the survey, as well as for any possible correlation with residuals of the various estimations conducted in this paper. Seemingly Unrelated Regressions (SUR) were also considered to allow for the error terms of each equation to be potentially correlated (cross-equation contemporaneous correlations), all yielding very similar results. Adjustments on the total number of counts were made when calculating variances and F-tests. We also tested one-way and two-way unbalanced fixed effects models (not reported) which also produced similar results as those reported in each table.

In addition to the presence of a risk premium, it is of interest to test for rational expectations so as to validate (or not) the use of ex-post exchange rates as proxies of exchange rate expectations. In order to determine if expectations are rational they must: 1) be unbiased predictors of the ex-post future exchange rate (unbiasedness), and 2) contain all useful information available at the time when they are formed (orthogonality). Although the first result alone would be sufficient to reject rational expectations, we also test for the orthogonally condition in order to shed additional light on whether expectations capture the impact of news and some selected fundamentals.

Table 2.4 presents estimations for the unbiasedness condition as proposed by Allen and Taylor (1990), Frankel and Froot (1990b) and Macdonald and Torrance (1990). In this setup, expectations are unbiased if $E_{t}\left[S_{t+k}\right]=S_{t+k}$. Results show that the joint hypothesis $\beta_{0}=0$ and $\beta_{1}=1$ is rejected in all cases. However, using ex-post values of the exchange rate as explanatory variables will most likely lead to an endogenous relationship (i.e. conditional on ex-post rates, the expected value of the error term will most likely be different than zero). For this reason, we also estimate the effects 
of average expectations (cross-section) on future exchange rate changes. ${ }^{10}$ Table 2.5 shows that in this case the null $H_{0}: \beta_{1}=1$ is rejected for 1 -year horizons but not for 1-month horizons.

We also test for the orthogonality condition in order to shed some additional light on whether expectations capture the impact of news and some selected fundamentals. That is, when agents use all available information efficiently, any variable from their information set should be orthogonal to the forecast error. Dominguez (1986), Macdonald and Torrance (1990) and Benassy-Quere, Larribeau, and Macdonald (2003) find that rejection of the null hardly ever occurs at 1-week and 2-weeks ahead forecasts. Rejection of the null is more frequent at the 1-month horizon, and becomes strongest when the forecast horizon is larger than 3 months. At 1 year-horizons rejection becomes an empirical regularity.

We considered four key fundamentals to regress (individually) against agent's forecast errors. The first (dummy) variable, MeetBoard, captures whether the Board of Directors of the Colombian Central Bank officially met to decide over the shortterm interest rate. These meetings and the decision of any change regarding the overnight interest rate are immediately published and are then known to investors. We also considered the intervention interest rate $\left(I R I_{t}\right)$, corresponding to the minimum overnight lending interest rate. Other variables considered include the forward discount $\left(F_{t}^{t+k}-S_{t}\right)$ and past exchange rate changes $\left(S_{t}-S_{t-k}\right)$.

Table 2.6 shows that the forward discount and past devaluations are significant for the three methodologies at both 1-month and 1-year, and also the dummy for MeetBoard (except for one of the 6 cases considered). Only the intervention interest rate is not significant for the different methodologies or horizons. Consistently, the last

\footnotetext{
${ }^{10}$ The caveat however, is that the average of agent's forecasts might not be a representative statistic given the high degree of heterogeneous expectations in the survey.
} 
row (F-test) suggests that we can reject the null that all coefficients are zero. To our surprise, these results suggest that agents (on average) could improve their forecasting accuracy of the exchange rate by simply looking at variables like the forward discount or the previous variations of the exchange rate, or recognizing that the meetings of the Board of Directors of the Central Bank generally have an impact on the exchange rate. For some reason, agents are failing to do so. The negative coefficients for the 1-month horizon mean that in the short run, an increase in any of the covariates leads to a systematic under-prediction of the exchange rate (with the opposite results for 1-year horizons). This constitutes additional evidence that there is a structural difference on how agents react in the short and long run.

\subsection{Stabilizing - Destabilizing Expectations}

Many models of exchange rate determination have made the simplifying assumption that expectations are static. In other words, that expected depreciations are zero or that the exchange rate follows a random walk. For example, Meese and Rogoff (1983) show that a random walk performs as well as any model at one to twelve month horizons for a series of exchange rates (See also Frankel and Froot, 1987).

On the other hand, it has been a concern of critics of floating exchange rates that bandwagon expectations would make the system unstable. For Nurkse (1944, pp.118):

"SPeculative] anticipations are apt to bring about their own realization. Anticipatory purchases of foreign exchange tend to produce or at any rate to hasten the anticipated fall in the exchange value of the national currency, and the actual fall may set up or strengthen expectations of a further fall ... Exchange rates under such circumstances are bound to become highly unstable, and the influence of psychological factors may at times be overwhelming" 
Finally, Friedman's (1953) advocacy for floating exchange rates was based on the stabilizing effect of expectations. That is, if current or past appreciations (of domestic currency) induce agents to expect future depreciations, then they will seek to sell domestic currency and hence mitigate much of the current appreciation. Following Frankel and Froot (1986), Takagi (1990) and Frankel and Rose (1994) we consider three main processes of expectation formation, in order to compare the forecasting accuracy of each, as well as to shed some light on the stabilizing or destabilizing effect that they might have over the short and long-term exchange rate. The discussion is based on the general form of equation (3.1):

$$
E_{t}\left[S_{t+k}\right]=\beta x_{t}+(1-\beta) S_{t}
$$

Where $x_{t}$ is a variable from the investors' information set. Expectations can thus be seen as the weighted average of the contemporaneous spot rate and some other variable at time $t$. In the related literature, there are three main candidates for $x_{t}$ : past exchange rates, past expected exchange rates and long term equilibrium values of the exchange rate. They correspond to the so called extrapolative, adaptive, and regressive expectations, respectively. By substituting these candidates in equation (3.1) we obtain equations (3.2-3.4).

$$
\begin{aligned}
& E_{t}\left[S_{t+k}\right]-S_{t}=-\beta_{e x}\left(S_{t}-S_{t-k}\right) \\
& E_{t}\left[S_{t+k}\right]-S_{t}=-\beta_{a d}\left(S_{t}-E_{t-k}\left[S_{t}\right]\right) \\
& E_{t}\left[S_{t+k}\right]-S_{t}=-\beta_{r e g}\left(S_{t}-\bar{S}_{t}\right)
\end{aligned}
$$


Where, as a proxy for the long run equilibrium exchange rate $\left(\bar{S}_{t}\right)$, we used the arithmetic average of 7 in house models estimated at the Colombian Central Bank. ${ }^{11}$

In sum, extrapolative expectations involves forecasting with past movements of the exchange rate: past variations are used to forecast the next period's variation. Under adaptive expectations investors use current forecast errors to predict future exchange rates. Intuitively, if an agent expected the exchange rate to be significantly higher than what is observed ex-post, then he/she will "correct" new forecasts by lessening his expectation of next period's exchange rate change (i.e. an agent will adapt to new changes given his past mistakes). Finally, regressive expectations incorporates deviations of the exchange rate with respect to its long-run equilibrium value, in order to forecast future exchange rate changes. This process implicitly assumes that the exchange rate "regresses" (at speed $\beta_{r e g}$ ) towards this long-run value which can take the form of a constant, moving average, or Purchasing Power Parity rate, among others (See Dornbusch, 1976).

The processes described in equations $(3.2$ - 3.4) are stabilizing when agents believe that a large appreciation (depreciation) in the past will be followed by a smaller depreciation (appreciation) in the future. In other words, when the coefficients of $\beta_{e x}$, $\beta_{a d}$, and $\beta_{\text {reg }}$ are negative and less than unity (in absolute terms). The (alternative) hypothesis of static expectations (i.e. random walk) will occurr when coefficients equal zero. In the literature, Frankel and Froot (1990a) and Cavaglia et al. (1993) find positive values for $\beta_{e x}, \beta_{a d}$, and $\beta_{\text {reg }}$ when considering 1-month horizons, suggesting that short run expectations exhibit bandwagon or destabilizing effects. However, for horizons longer or equal than 3 months, the authors find stabilizing effects (negative

\footnotetext{
${ }^{11}$ Two of these models are based on the Purchasing Power Parity (PPP) condition, 2 are based on VectoError Correction (VEC) methodologies and one model simply uses a Hodrick and Prescott filter.
} 
coefficients lower than unity in absolute terms), which implies that the most recent price trend is expected to be reversed in the future.

Results for equations $(3.2-3.4)$ are presented in Table 2.7. They show that expectations are stabilizing in all cases, with negative coefficients between 0 and -1 , except for the case of regressive expectations at the 1 -year horizon. ${ }^{12}$ All results are significant at the $5 \%$ significancelevel (most are significant at the $1 \%$ level). These results are partially related with the "Twist" in expectations presented in Figure 2.1. The observed exchange rate fell most of the time but investors expected a reversal at the 1-year horizon. This was especially marked in the period of 2003-2010.

It is also interesting to know the type of mechanism that better resembles actual expectations. The coefficient of determination $\left(R^{2}\right)$ is low in all cases, but it is higher in the case of adaptive expectations. Values of the Bayesian Information Criterion (BIC, now shown) also suggest that adaptive expectations come closest at explaining expected depreciations. Villa (2011) reproduces the previous exercise at the financial institution level and finds that expectations are stabilizing for nearly $85 \%$ of them when considering extrapolative and adaptive expectations, and for more than $95 \%$ for regressive expectations. Institutions which are destabilizing account for less than $1.5 \%$ of the foreign exchange market.

\subsubsection{The Random WALK Benchmark}

There is a long literature on the unpredictability of exchange rates, where studies often compare the accuracy of linear models with a random walk process (used as benchmark). Most of these studies have generally followed the methodology presented

\footnotetext{
${ }^{12}$ For the case of extrapolative 1-year expectations, the absolute value of the coefficient is different from zero at the $1 \%$ significance level and less than 1 , with a confidence interval between -0.165 and -0.105 .
} 
in the seminal work of Meese and Rogoff (1983) but some earlier works include Nelson (1972), Christ (1975), Litterman (1979) and Fair (1979).

To date, most studies have failed to reject the null hypothesis that exchange rates are unpredictable. However some exceptions are found in the literature. Evans and Lyons (2005), for example, use order flows as a successful determinant of future exchange rates. Cheung et al. (2005) find that models that incorporate productivity differentials outperform the random walk and the Purchasing Power Parity (PPP) benchmark for some periods and currencies. Gourinchas and Rey (2007) are also able to outperform a random walk with a model that uses the trade balance and the valuation of net foreign assets. ${ }^{13}$

Following the classic paper of Meese and Rogoff (1983) or even more recent ones like Rogoff (2009), in this section we set forth five competing models to assess how well they perform relative to a zero mean martingale difference (i.e. a random walk). Like in Meese and Rogoff (1983), we constructed Mean Squared Prediction Errors (MSPEs) for each model as well as for a driftless random walk, as shown in equation $(3.5)$ :

$$
M S P E=\sum_{i=0}^{N-1} \frac{\left[\left(E\left[S_{t+k+i} \hat{i}\right]-S_{t+i}\right)-\left(E\left[S_{t+k+i}\right]-S_{t+i}\right)\right]^{2}}{N}
$$

Where $(\wedge)$ corresponds to the estimated value of the forecast error $\left(E\left[S_{t+k}\right]-S_{t}\right)$, and " $N$ " corresponds to the number of rolled-over forecast periods.

When conducting inference for nested models, it is important to control for an existing upward shift of the predicted sample errors. We account for this by following Clark and West's (2006) methodology. That is, we construct MSPE-adjusted statistics in which, under the null hypothesis that models follow a martingale difference, the

\footnotetext{
${ }^{13}$ Studies that find predictable models for stock market returns are more abundant and include Keim and Stambaugh (1986), Fama and French (1987) and Lo and MacKinlay (1988).
} 
sample MSPE can be equal to that of the null. ${ }^{14}$ We proceed as follows: first we define our in-sample period to be from Oct 2003 to May 2005, we then estimate the corresponding models and make 1-period out of sample forecasts before rolling over the sample by one period. Finally we construct MSPE-adjusted statistic for each model.

Results are presented in Table 2.8. The first column shows the different competing models (i.e. unrestricted models) that consist of extrapolative, adaptive, and regressive processes (described in the previous Section), the forward discount $\left(F_{t}^{t+k}-S_{t}\right)$, and expected depreciations $\left(E_{t}\left[S_{t+k}-S_{t}\right]\right)$ from our survey. We considered expectations from all participants but also individually categorized commercial banks, stockbrokers and pension funds (rows 7-9). Columns 2 and 3 show results for the $\left(M S P E_{r}-M S P E_{u}\right)$ adjusted statistic, using the methodology presented in Clark and West (2006). Positive values are good predictors of the exchange rate since they outperform a random walk (lower MSPEs).

Results for 1-month horizon show that expectations stated in the survey are much better predictors than the three models (extrapolative, adaptive or regressive) or the forward discount. In fact, they outperform the random walk, with positive and significant numbers for $\left(M S P E_{r}-M S P E_{u}\right)$. But results are almost the opposite for 1-year forecasts. In fact, traders and analysts answering the survey would do much better following the extrapolative, adaptive or regressive models than following the strategy they pursue today. For 1-year horizons, the statistic $\left(M S P E_{r}-M S P E_{u}\right)$ is not significant for agent's forecasts (rows 6-9), but it is for the case of extrapolative, adaptive, regressive, and even the forward discount. Overall this exercise suggests

\footnotetext{
${ }^{14}$ See Granger and Newbold (1977) and Ashley et al. (1980) for a list of methods on comparing MSPEs. Other studies such as Meese and Rogoff (1988), Christiano (1989), West et al. (1993), and Diebold and Mariano (1995) offer more general procedures for forecast evaluation.
} 
that 1 ) the exchange rate behaves very differently at different time horizons, and 2) agents do exceptionally well in forecasting 1-month horizons but should reconsider their 1-year forecasts. Also, by following simple models presented in rows (1-4) agents could improve their forecasting accuracy.

\subsection{Heterogeneous Predictions}

The analysis of expectations presented in the previous section assumed that market participants had homogeneous expectations. However, responses to surveys are highly heterogeneous. In fact, the heterogeneity in agents' expectations appears useful in explaining some characteristics of the exchange market, such as the very large amount of trading (when compared, for example, with the amount required for trade in goods and services) and some of the anomalies found in the foreign exchange literature. ${ }^{15}$

Frankel and Froot (1990b), for example, show that the dispersion of expectations Granger causes both volatility of the exchange rate and the volume of trading, and Chionis and Macdonald (1997) also find reverse Granger causality from volatility to dispersion. Beine et al. (2007) show that heterogeneity in forecasts increases as a result of central bank interventions in the foreign exchange market. On the other hand, Beine et al. (2003) assess the extent of herding behavior in foreign exchange markets. The authors find that agents' forecasts are related to each other through leader and imitation patterns, though there is no evidence of sequential herding. They also find that leaders do not appear to be selected based on their past forecast performance.

\footnotetext{
${ }^{15}$ Frankel and Froot (1990a) show that in 1989, exchange rate trading activity represented 20 times that of US GDP and 39 times the amount of world trade in goods and services. They authors also find that approximately $95 \%$ of exchange rate trading takes place among financial firms, rather than importers or exporters. In Colombia, this relations are much lower (the relation between exchange rate trading and trade in goods and services could be close to two).
} 
Finally, the available evidence seems to suggest that heterogeneity increases when agents try to forecast the long run, as shown by Jongen et al. (2008).

Figure 2.6 shows standard deviations for 1-month and 1-year expectations of the central bank survey. As suspected, dispersion is greater for 1-year (average of $\$ 105$ pesos) than for 1-month expectations (average of $\$ 33$ pesos) although less than the expected 12 times if the variance had remained constant over time horizons. Of particular interest are the periods of exchange rate appreciation corresponding to Dec 2007 - Jun 2008 and Mar 2009 - Oct 2009 which generated great discrepancy amongst the surveyed agents. In contrast, agents seemed to agree more (forecasts converged to similar values) in periods of exchange rate depreciation and in periods with low volatility. Discrepancies were also low in 2011 and 2012 when most agents seemed to have agreed that the exchange rate was not going to depreciate in the coming 1 or 12 months.

Finally, Table 2.9 shows the answers given by commercial banks, stockbrokers, and Pension Funds to the same question considered in Figures 2.3 and 2.4. Close to $65 \%$ correctly guess the direction of exchange rate changes (depreciation or appreciation) when considering 1-month expectations. The figure is much lower for 1-year expectations, with important differences among agents. Pension funds (49\%) and stockbrokers (43\%) more accurate than commercail banks (35\%). These outcomes may well be attributed to differences in information, strategic behavior or wishful thinking, but they are remarkably low in all cases. The last two columns show that the percentage of establishments with correct predictions within the range of \pm 50 pesos is even lower, especially for 1-year forecasts ( $9 \%, 15 \%$ and $20 \%$, respectively). 


\subsection{CONCLusions}

Expectations play a key role in determining economic variables and, according to some authors like Woodford (2003), "little else matter". Expectations are even more relevant in the determination of the exchange rate when markets are liquid and when prices are flexible. However, there is a wide disagreement on the behavior of exchange rate expectations, with radically different implications for economic policy. Markets are inherently stabilizing for some, since destabilizing agents are driven out of the market. But according to Dornbusch (1976), expectations could be rational and still produce high exchange rate volatility in the presence of rigid prices of goods and services.

Following the important practice pioneered by Dominguez (1986), Frankel (1979) and Frankel and Froot (1987), in this paper we use the Expectations Survey conducted monthly by the Central Bank of Colombia during the period of October 2003 - August 2012. We find that exchange rate appreciations were generally followed by expectations of further appreciation in the short run, but by expectations of depreciation in the long run (a pattern commonly known as a twist in expectations). The latter explains another important finding of this paper, namely that extrapolative, adaptive and regressive expectations are stabilizing both at 1-month and 1-year horizons.

We also find that the forward discount is different from future exchange rate changes. This is partly due to the rejection of the unbiasedness condition (i.e. expectations are not unbiased predictors of future exchange rates). Also, for 1-year horizons, expectations exhibit a significant time-varying risk premium. In terms of accuracy, expectations differed from the 1-month and 1-year ahead spot rate in up to $\$ 206$ pesos (September 2007) and in up to $\$ 615$ pesos/dollar (June 2007), respectively. In some months, not a single establishment was able to predict the 1-year ahead rate within 
a \pm 50 pesos range. Also, less than half of financial institutions correctly guessed the direction of change for the 1-year ahead exchange rate. To our surprise, agents could have improved their forecasting accuracy by looking at variables like the forward discount or the previous variations of the exchange rate, or by recognizing that the meetings of the Board of Directors of the Central Bank generally have an impact on the exchange rate.

Finally, we set forth five competing strategies in order to assess how well actual expectations performed relative to a random walk process. We find that 1-month expectations are much better predictors than extrapolative, adaptive or regressive models, or the forward discount. In fact, they even outperform a random walk process (with lower mean squared prediction errors). But results are almost the opposite for 1-year forecasts where expectations do not outperform a random walk. In this case, traders and analysts answering the survey could have actually performed much better by following extrapolative, adaptive or regressive models than by following the strategy that they pursue today. 


\subsection{Figures}

Figure 2.1: Twist in Exchange Rate Expectations

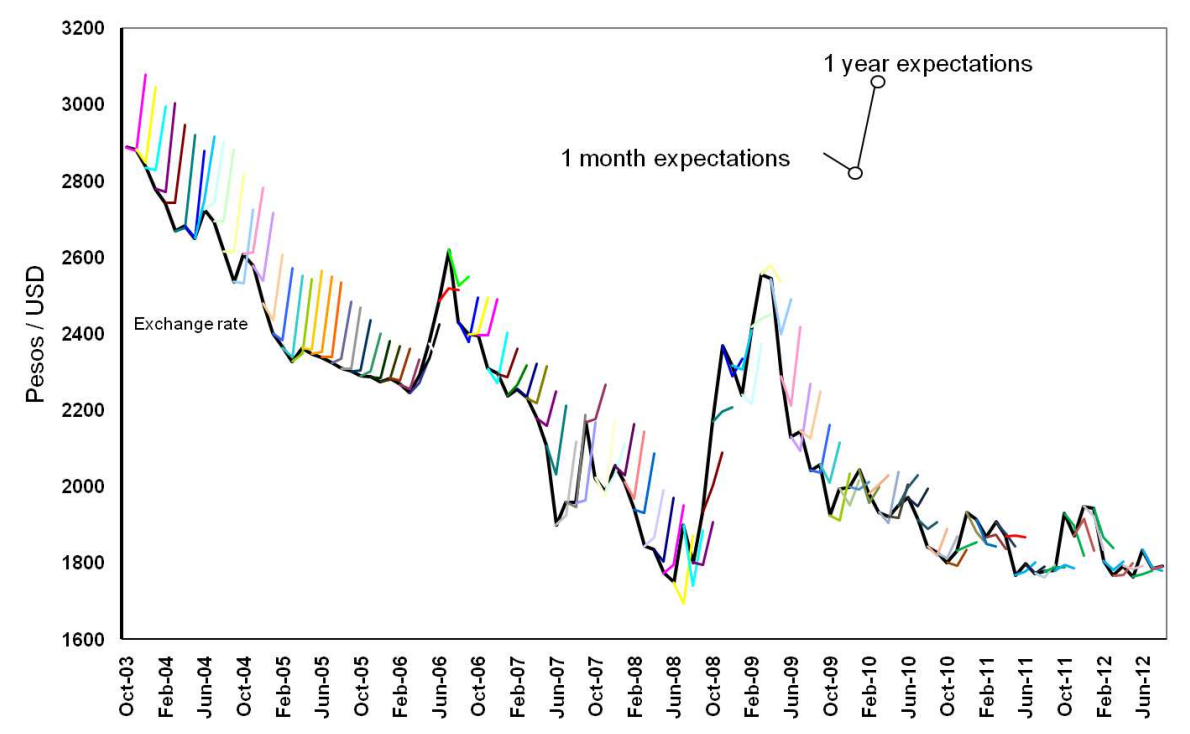

Figure 2.2: Forecast Errors

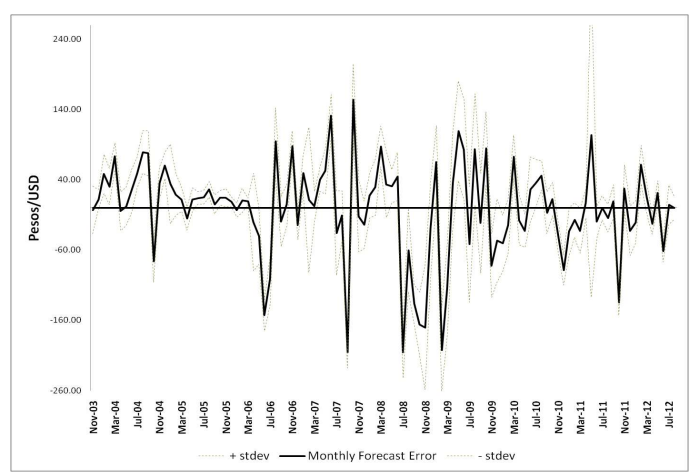

(a) 1-month Forecast Errors

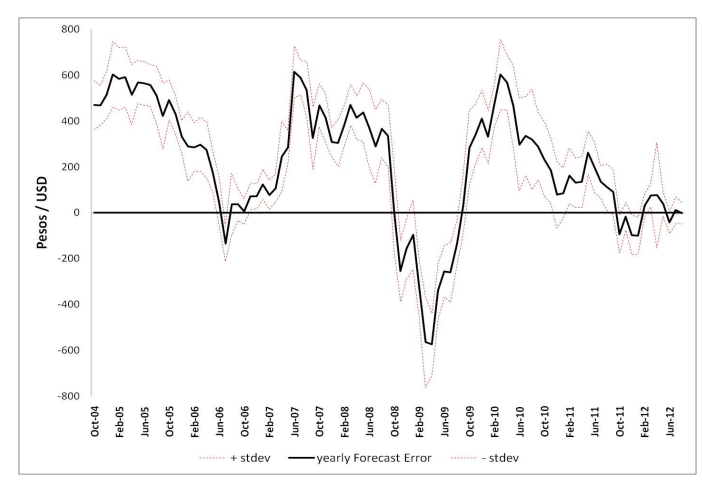

(b) 1-year Forecast Errors 
Figure 2.3: \% of Institutions with Correct Exchange Rate Change Direction

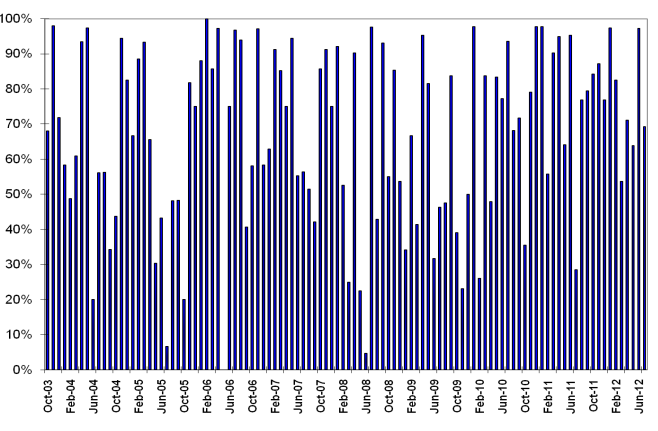

(a) 1-month Forecasts

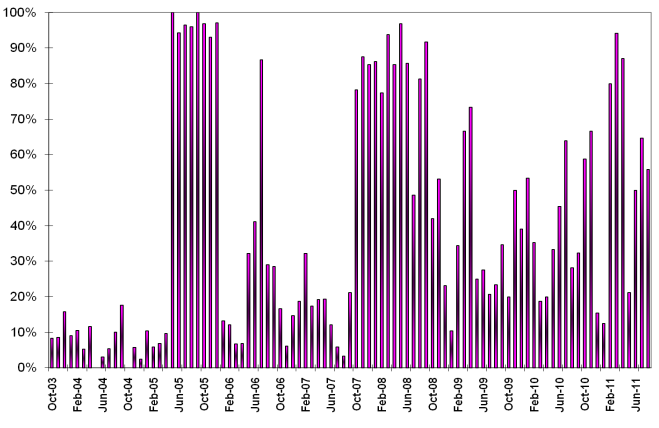

(b) 1-year Forecasts

Figure 2.4: \% of Institutions with Expectations falling within \pm 50 Pesos

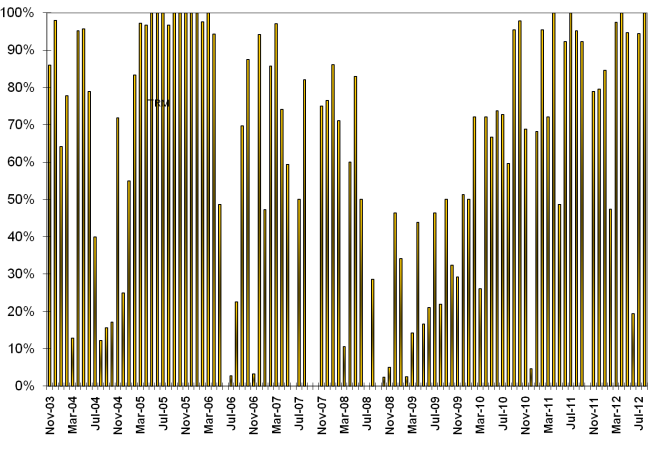

(a) 1-month Forecasts

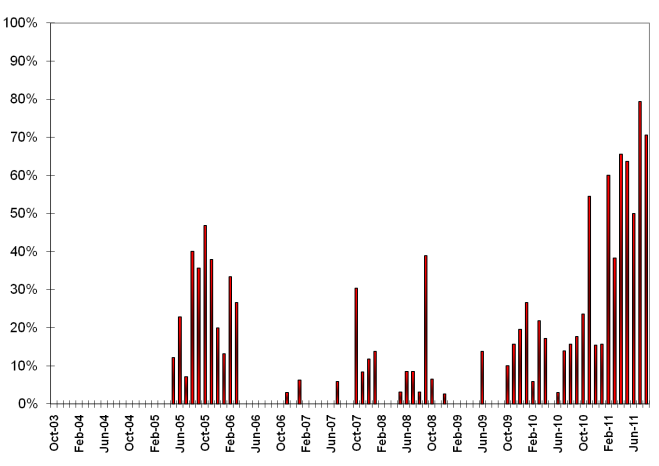

(b) 1-year Forecasts 
Figure 2.5: Forward vs. Expected Exchange Rates

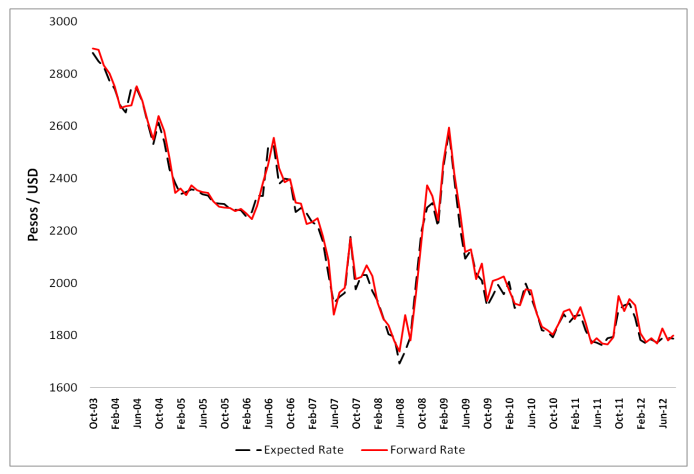

(a) 1-month Horizon

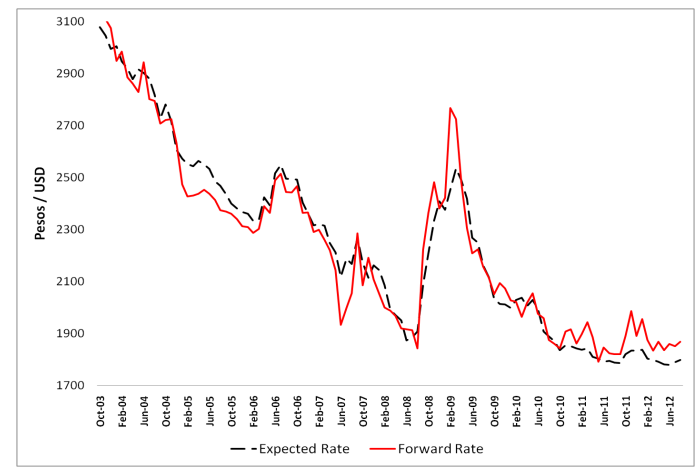

(b) 1-year Horizon

Figure 2.6: Dispersion (Standard Deviation of Forecasts)

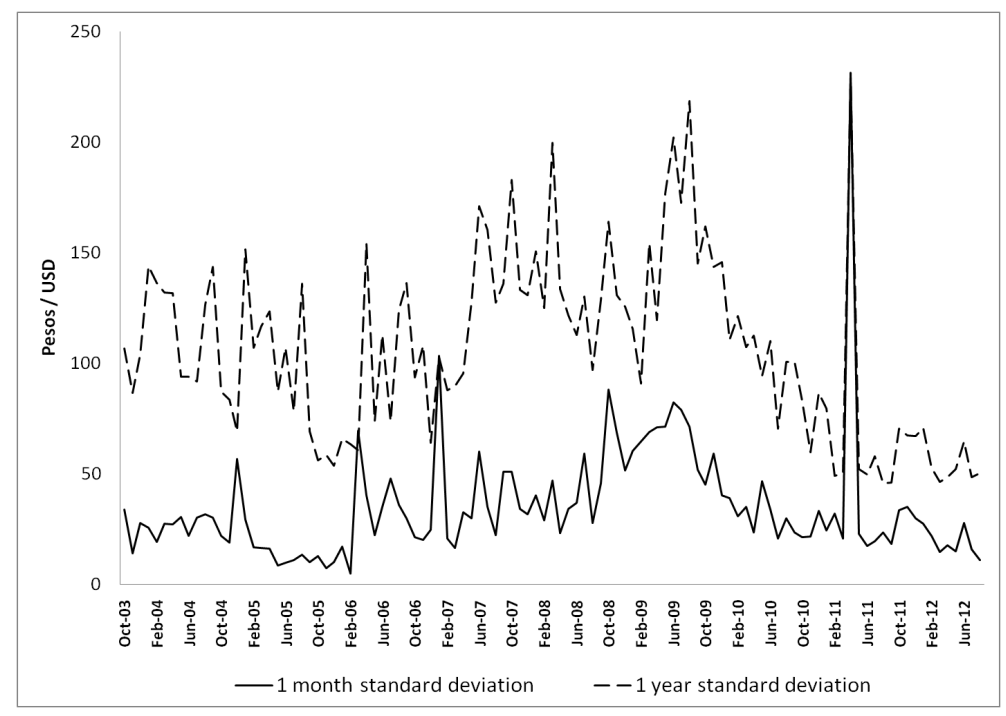




\subsection{TABLES}

Table 2.1: Individual components of equation 2.3. (1-Month horizon)

\begin{tabular}{lccccc}
\hline \hline Year & $\begin{array}{c}\text { Forward } \\
\text { Discount }\end{array}$ & $\begin{array}{c}\text { Future } \\
\text { Depreciation }\end{array}$ & $\begin{array}{c}\text { Forecast } \\
\text { Error }\end{array}$ & $\begin{array}{c}\text { Risk } \\
\text { Premium }\end{array}$ & $\begin{array}{c}\text { Expected } \\
\text { Depreciation }\end{array}$ \\
\hline & & & & & \\
2003 (Oct-Dec) & 0.2 & -1.3 & 0.7 & 0.8 & -0.6 \\
2004 & 0.4 & -1.2 & 1.2 & 0.4 & 0.0 \\
2005 & 0.0 & -0.4 & 0.4 & 0.0 & 0.0 \\
2006 & -0.3 & -0.2 & -0.3 & 0.2 & -0.5 \\
2007 & 0.1 & -0.9 & 0.5 & 0.5 & -0.4 \\
2008 & 0.1 & 0.9 & -2.0 & 1.2 & -1.1 \\
2009 & -0.2 & -0.8 & -0.6 & 1.2 & -1.4 \\
2010 & -0.4 & -0.5 & -0.2 & 0.4 & -0.8 \\
2011 & -0.1 & 0.1 & -0.8 & 0.6 & -0.7 \\
2012 (Jan-Aug) & -0.1 & -1.2 & 0.2 & 0.8 & -0.9 \\
Average & 0.0 & -0.5 & -0.1 & 0.6 & -0.6 \\
\hline \hline
\end{tabular}

SOURCE: Central Bank Data and author's calculations (mean values). See Section 2.2. 
Table 2.2: Individual components of equation 2.3. (1-Year horizon)

\begin{tabular}{lccccc}
\hline \hline Year & $\begin{array}{c}\text { Forward } \\
\text { Discount }\end{array}$ & $\begin{array}{c}\text { Future } \\
\text { Depreciation }\end{array}$ & $\begin{array}{c}\text { Forecast } \\
\text { Error }\end{array}$ & $\begin{array}{c}\text { Risk } \\
\text { Premium }\end{array}$ & $\begin{array}{c}\text { Expected } \\
\text { Depreciation }\end{array}$ \\
\hline & & & & & \\
2003 (Oct-Dec) & 7.8 & -11.6 & 17.4 & 2.0 & 5.8 \\
2004 & 6.3 & -12.8 & 19.9 & -0.8 & 7.1 \\
2005 & 3.2 & 1.6 & 5.0 & -3.5 & 6.6 \\
2006 & 1.2 & -12.6 & 15.2 & -1.4 & 2.7 \\
2007 & 3.2 & -6.2 & 12.2 & -2.9 & 6.1 \\
2008 & 5.5 & 10.9 & -5.7 & 0.3 & 5.1 \\
2009 & 4.7 & -13.4 & 16.5 & 1.7 & 3.0 \\
2010 & 2.0 & -3.3 & 4.8 & 0.5 & 1.5 \\
2011 & 1.1 & 0.0 & -0.5 & 3.0 & -1.9 \\
2012 (Jan-Aug) & 3.2 & 0.0 & -0.7 & 3.9 & -0.7 \\
Average & 3.8 & -4.9 & 8.4 & 0.3 & 3.5 \\
\hline \hline
\end{tabular}

SOURCE: Central Bank Data and author's calculations (mean values). See Section 2.2.

Table 2.3: Risk Premium

\begin{tabular}{lcccccc}
\hline \hline & \multicolumn{3}{c}{ 1-month } & \multicolumn{3}{c}{ 1-year } \\
Coefficient & OLS & PANEL & PANEL $^{1}$ & OLS & PANEL & PANEL $^{1}$ \\
\hline \multirow{3}{*}{$\beta_{0}$} & & & & & & \\
& $-.014^{* * *}$ & $-.006^{* * *}$ & $-.006^{* * *}$ & $.069^{* * *}$ & $.012^{* * *}$ & $-.012^{* * *}$ \\
$\beta_{1}$ & $(0.003)$ & $(0.000)$ & $(0.000)$ & $(0.011)$ & $(0.003)$ & $(0.003)$ \\
& $1.05^{* * *}$ & $1.05^{* * *}$ & $1.05^{* * *}$ & $0.63^{* * *}$ & $0.63^{* * *}$ & $0.63^{* * *}$ \\
$t: \beta_{1}=1$ & $(0.038)$ & $(0.038)$ & $(0.041)$ & $(0.031)$ & $(0.030)$ & $(0.040)$ \\
& 1.90 & 2.34 & 2.06 & $140.5^{* * *}$ & $139.6^{* * *}$ & $83.6^{* * *}$ \\
Wald $: \beta_{0}=0 \beta_{1}=1$ & $(0.168)$ & $(0.126)$ & $(0.152)$ & $(0.000)$ & $(0.000)$ & $(0.000)$ \\
& $11.97^{* * *}$ & $278.7^{* * *}$ & $154.1^{* * *}$ & $79.5^{* * *}$ & $139.8^{* * *}$ & $85.4^{* * *}$ \\
& $(0.000)$ & $(0.000)$ & $(0.000)$ & $(0.000)$ & $(0.000)$ & $(0.000)$ \\
\hline \hline
\end{tabular}

SOURCE: Authors' calculations. ${ }^{1}$ Corresponds to PANEL with robust standard errors. Standard errors are in parenthesis. $* * *, * *,{ }^{*}$ correspond to significance levels of $1 \%, 5 \%$ and $10 \%$, respectively. Total number of Obervations: 4,100 for 1-month horizon and 3,443 for 1-year horizon. 
Table 2.4: Unbiasedness Condition

\begin{tabular}{lcccccc}
\hline \hline & & 1-month & & \multicolumn{3}{c}{ 1-year } \\
Coefficient & OLS & PANEL & PANEL $^{1}$ & OLS & PANEL & PANEL $^{1}$ \\
\hline \multirow{3}{*}{$\beta_{0}$} & & & & & & \\
& $-.013^{* * *}$ & $-.005^{* * *}$ & $-.005^{* * *}$ & $0.10^{* * *}$ & $0.04^{* * *}$ & $0.04^{* * *}$ \\
$\beta_{1}$ & $(0.003)$ & $(0.000)$ & $(0.000)$ & $(0.012)$ & $(0.003)$ & $(0.003)$ \\
& $0.23^{* * *}$ & $0.26^{* * *}$ & $0.26^{* * *}$ & $0.07^{* * *}$ & $0.07^{* * *}$ & $0.07^{* * *}$ \\
$t: \beta_{1}=1$ & $(0.009)$ & $(0.009)$ & $(0.010)$ & $(0.008)$ & $(0.008)$ & $(0.013)$ \\
& $6276^{* * *}$ & $6260^{* * *}$ & $5419^{* * *}$ & $11009^{* * *}$ & $11169^{* * *}$ & $5102^{* * *}$ \\
Wald $: \beta_{0}=0 \beta_{1}=1$ & $(0.000)$ & $(0.000)$ & $(0.000)$ & $(0.000)$ & $(0.000)$ & $(0.000)$ \\
& $3144^{* * *}$ & $6289^{* * *}$ & $6602^{* * *}$ & $5521^{* * *}$ & $11846^{* * *}$ & $6576^{* * *}$ \\
& $(0.000)$ & $(0.000)$ & $(0.000)$ & $(0.000)$ & $(0.000)$ & $(0.000)$ \\
\hline \hline
\end{tabular}

SOURCE: Authors' calculations. ${ }^{1}$ Corresponds to PANEL with robust standard errors. Standard errors are in parenthesis. ${ }^{* *}, * * *$, correspond to significance levels of $1 \%, 5 \%$ and $10 \%$, respectively. Total number of Obervations: 4,063 for 1-month horizon and 3,090 for 1-year horizon. 
Table 2.5: Unbiasedness Condition II

\begin{tabular}{lcc}
\hline \hline Coefficient & 1-month & 1-year \\
\hline \multirow{2}{*}{$\beta_{0}$} & & \\
& 0.003 & $-0.136^{* * *}$ \\
$\beta_{1}$ & $(0.422)$ & $(0.000)$ \\
& $1.15^{* * *}$ & $1.63^{* * *}$ \\
$: \beta_{1}=1$ & $(0.000)$ & $(0.001)$ \\
& 0.42 & $3.67^{*}$ \\
\hline \hline
\end{tabular}

SOURCE: Authors' calculations. Estimations correspond to OLS regressions with with robust standard errors (in parenthesis). $* * *, * *, *$ correspond to significance levels of $1 \%, 5 \%$ and $10 \%$, respectively. Total number of Obervations: 93 for 1-month horizon and 82 for 1-year horizon.

Table 2.6: Orthogonality Condition

\begin{tabular}{lcccccc}
\hline \hline \multirow{2}{*}{ Variable } & \multicolumn{3}{c}{ 1-month } & \multicolumn{3}{c}{ 1-year } \\
& OLS & PANEL & PANEL $^{1}$ & OLS & PANEL & PANEL $^{1}$ \\
Board Meetingst & & & & & & \\
& $-0.03^{* *}$ & $-0.01^{*}$ & $-0.01^{*}$ & $0.29^{* * *}$ & $0.308^{* * *}$ & $0.308^{* * *}$ \\
Intervention Interest Rate & $(0.014)$ & $(0.014)$ & $(0.006)$ & $(0.050)$ & $(0.049)$ & $(0.032)$ \\
& -0.0004 & -0.0005 & -0.0005 & 0.004 & 0.003 & 0.003 \\
Forward Discount $t$ & $(0.002)$ & $(0.002)$ & $(0.002)$ & $(0.007)$ & $(0.007)$ & $(0.008)$ \\
& $-0.55^{* * *}$ & $-0.52^{* * *}$ & $-0.52^{* * *}$ & $0.22^{* * *}$ & $0.24^{* * *}$ & $0.24^{* * *}$ \\
Past Exchange Change $t$ & $(0.062)$ & $(0.062)$ & $(0.040)$ & $(0.066)$ & $(0.066)$ & $(0.076)$ \\
& $-0.08^{* * *}$ & $-0.08^{* * *}$ & $-0.08^{* * *}$ & $0.45^{* * *}$ & $0.44^{* * *}$ & $0.44^{* * *}$ \\
F Test & $(0.015)$ & $(0.015)$ & $(0.014)$ & $(0.019)$ & $(0.018)$ & $(0.021)$ \\
& $26.7^{* * *}$ & $139.9^{* * *}$ & $287.9^{* * *}$ & $142.2^{* * *}$ & $1035.6^{* * *}$ & $1268.1^{* * *}$ \\
& $(0.000)$ & $(0.000)$ & $(0.000)$ & $(0.000)$ & $(0.000)$ & $(0.000)$ \\
\hline \hline
\end{tabular}

SOURCE: Authors' calculations. ${ }^{1}$ Corresponds to PANEL with robust standard errors. Standard errors are in parenthesis. ***,**,* correspond to significance levels of $1 \%, 5 \%$ and $10 \%$, respectively. Total number of Obervations: 4,063 for 1 -month horizon and 3,090 for 1-year horizon. 
Table 2.7: Stabilizing / Destabilizing Expectations

Type of Expectation $\quad$ 1-month 1 1-year

Extrapolative

$E_{t}\left[S_{i, t+k}\right]-S_{t}=\beta_{0}+\beta_{1}\left(S_{t}-S_{t-k}\right)+\epsilon_{t}$

$\beta_{1}=-0.03^{* *}$

$\beta_{1}=-0.14^{* * *}$

(0.013)

Adaptive

$E_{t}\left[S_{i, t+k}\right]-S_{t}=\alpha_{0}+\alpha_{1}\left(S_{t}-E_{t-k}\left[S_{t}\right]\right)+\nu_{t}$

$\alpha_{1}=-0.07 * * *$

$\alpha_{1}=-0.17^{* * *}$

$(0.015)$

Regressive

$E_{t}\left[S_{i, t+k}\right]-S_{t}=\gamma_{0}+\gamma_{1}\left(S_{t}-\bar{S}_{t}\right)+\eta_{t}$

$$
\begin{array}{cc}
\gamma_{1}=-0.03^{* * *} & \gamma_{1}=0.13^{* * *} \\
(0.005) & (0.027)
\end{array}
$$

SOURCE: Authors' calculations. All estimations correspond to PANEL regressions with robust standard errors. Standard errors are in parenthesis. ${ }^{* *},{ }^{* *}, *$ correspond to significance levels of $1 \%, 5 \%$ and $10 \%$, respectively.

Total number of Obervations: 4,063 for 1-month horizon and 3,090 for 1-year horizon. 
Table 2.8: Out-of-Sample Forecasts: Competing Models vs. a Random Walk

\begin{tabular}{lcc}
\hline \hline \multirow{2}{*}{ Model } & 1-month & 1 -year \\
& $\left(M S P E_{r}-M S P E_{u}\right)$ & $\left(M S P E_{r}-M S P E_{u}\right)$ \\
\hline \multirow{2}{*}{ Extrapolative } & -0.0006 & $0.18^{* * *}$ \\
\multirow{3}{*}{ Adaptive } & $(0.001)$ & $(0.042)$ \\
& -0.0004 & $0.20^{* * *}$ \\
Regressive & $(0.001)$ & $(0.045)$ \\
Forward Discount & $0.003^{* * *}$ & $0.09^{* * *}$ \\
& $(0.001)$ & $(0.030)$ \\
& $0.003^{* *}$ & $0.03^{* *}$ \\
& $(0.002)$ & $(0.016)$
\end{tabular}

Surveyed Expectations

$\begin{array}{lcc}\text { All Participants } & 0.009^{* * *} & 0.01 \\ & (0.002) & (0.013) \\ \text { Commercial Banks } & 0.009^{* * *} & 0.01 \\ & (0.002) & (0.015) \\ \text { Stockbrokers } & 0.009^{* * *} & 0.01 \\ & (0.002) & (0.012) \\ \text { Pension Funds } & 0.009^{* * *} & 0.00 \\ & (0.003) & (0.018)\end{array}$

SOURCE: Authors' calculations. All estimations correspond to OLS rolling regressions. $M S P E_{r}$ and $M E S P E_{u}$ correspond to "restricted" (Random Walk) and "unrestricted" (competing strategies) models. Methodology follows that of Clark and West (2006). Standard errors are in parenthesis. $* * *, * *, *$ correspond to significance levels of $1 \%, 5 \%$ and $10 \%$, respectively.

Table 2.9: Accuracy of 1-month and 1-year forecasts

\begin{tabular}{lccccc}
\hline \hline Institution & Median & $\begin{array}{c}\text { Direction } \Delta S_{t} \\
\text { 1-month }\end{array}$ & $\begin{array}{c}+/-50 \text { pesos } \\
\text { 1-month }\end{array}$ & $\begin{array}{c}\text { Direction } \Delta S_{t} \\
\text { 1-year }\end{array}$ & $\begin{array}{c}+/-50 \text { pesos } \\
\text { 1-year }\end{array}$ \\
\hline Commercial Banks & 15 & $66 \%$ & $64 \%$ & $35 \%$ & $9 \%$ \\
Stockbrokers & 19 & $65 \%$ & $61 \%$ & $43 \%$ & $15 \%$ \\
Pension Funds & 5 & $65 \%$ & $66 \%$ & $49 \%$ & $20 \%$ \\
\hline \hline
\end{tabular}

SOURCE: Authors' calculations. 


\section{CHAPTER 3}

The Impact of Foreign Exchange Intervention in Colombia: An Event STUDY APPROACH

\subsection{INTRODUCTION}

In the context of discretionary central bank intervention, monetary authorities systematically react to informative variables when setting their policy decisions, i.e. the timing and magnitude of interventions are driven by market behavior in order to meet explicit or implicit policy objectives. As such, researchers usually assume functional forms of both the policy rule and the process determining the economy in order to estimate causal effects. However, since most of these studies purely rely on structural models to address identification problems (see Christiano et al. 2011) then the validity of results largely depends on how accurate the assumptions are in describing the full extent of the underlying economy.

To date, there is still great controversy as to which exchange rate model should be used (stock, monetary, micro-structure, etc.) or which monetary channel should be considered (signaling, portfolio, or expectations) when measuring the effects of policy. Moreover, the Colombian case poses additional methodological challenges since there have been multiple mechanisms of foreign exchange rate intervention. A better understanding of these mechanisms and their effects is hence warranted, without imposing restrictive parametric assumptions or without the need to adopt a fullblown structural model. 
In this paper we compare the effects of $i$ ) discretionary purchases in the spot exchange market, $i i$ ) discretionary purchases through exchange rate options (intended for reserve accumulation), and $i i i$ ) a rule-based mechanism of exchange rate options for volatility control, using an event study approach. This paper is complementary to the work of Echavarria et al. (2013) which focuses on pre-announced interventions. Following the methodology presented in Frankel (1994), Fatum and Hutchison (2003) and Humpage (1996), we define four criteria to evaluate a successful intervention: 1) Direction, 2) Reversal, 3) Smoothing, and 4) Matching. Our main finding indicates that volatility options had the strongest effect across the different criteria. Results are robust when using different windows sizes and counterfactual exercises.

This paper is organized as follows: Section II provides a general overview of the Colombian foreign exchange rate intervention. Parts of this section are taken from Echavarria et al. (2013). Section III describes the event study methodology and Section IV presents the results. Finally, section V concludes.

\subsection{Foreign Exchange Interventions}

Foreign exchange interventions for the Colombian case during the period 2000-2012 are summarized in Graph 3.1. Average yearly purchases were close to US $\$ 2.2$ billion, much larger than average sales (US $\$ 571$ millions). Purchases were especially high in 2005 and 2007, and also during 2010-2012. ${ }^{1}$ Yearly purchases represented $0.12 \%$ of (yearly) market transactions in 2003, and $4.06 \%$ in 2005, with an average of $1.70 \%$ in 2000-2012. They represented $1.0 \%$ of the average stock of international reserves in

\footnotetext{
${ }^{1}$ There were some sales of US dollars to the government in 2004-2006, intended to repay external debt.
} 
2003 and $33 \%$ in 2005 , with an average of $11.86 \%$ in $2000-2012 .{ }^{2}$ In total, there were 723 days of discretionary purchases, 80 days of reserve accumulation (USD purchases), and 41 days of volatility option purchases.

According to Ramirez (2005), exchange rate interventions in Colombia have been relatively transparent. Exchange rate options are announced on the same day that they are exercised and the amount of intervention is announced each week. Very often the Board of Directors pre-announced the total amount of dollars to be purchased/sold during the next months. For example, the Board announced an intervention of US $\$ 1$ billion during the last three months of 2004, and on June 20, 2008 the Board announced the new US $\$ 20$ million daily interventions, with an amount of US\$2.4 billion to be purchased between July and December.

To date, there is still a general lack of consensus within the literature regarding the effects of monetary policy. This, in part, is the result of the different methodologies employed. For example, studies for Colombia show very different results in terms of significance and duration of policy effects. While Echavarria et al. (2009a, 2009b) find a significant effect of foreign exchange intervention on the exchange rate for durations of 1-6 months, studies such as Kamil (2008), Rincon and Toro (2010), and Adler and Tovar (2011) find no significant effects. Other authors like Toro and Julio (2005) and Vargas et al. (2013) find significant results but only for a duration of a few days.

In the international literature, methodologies vary from 1) Vector Autoregressions (VARs) (see Christiano et al. (1996, 1998), Bernanke and Blinder (1992)), 2) GARCH models (see Kamil (2008), Guimaraes and Karacadag (2004), Humala and Rodriguez (2009), Rincon and Toro (2010), Echavarria et al. (2009b), and Toro and Julio (2005)), and 3) through a direct estimation of policy shocks on outcome variables, leaving the

\footnotetext{
${ }^{2}$ Daily transactions in the market were close to US $\$ 1000$ million at the end of the sample, and to US $\$ 320$ million in 2001-2004 (average). The stock of international reserves was close to US $\$ 33,000$ million at the end of the sample and to US $\$ 10,611$ in 2001-2004.
} 
response of the economy unspecified (see Romer and Romer (2004), Wasserfallen and Kuersteiner (1994), and Angrist and Kuersteiner (2011)).

While most of these studies depend on parametric assumptions to model the behavior of monetary authorities, there is also a large strand of the literature that uses non-parametric procedures. Such is the case for event studies which were originally applied in the area of finance (MacKinlay, 1997), but in recent years they have also been used in areas as diverse as: the impact of different local factors on financial crisis (IMF, 2007, pp.124-132), the relationship between the development of capital markets and the environment in emerging countries (Dasgupta et al. 1997), the effects of fiscal policy in the process of disinflation (Celasum et al. 2004), and even the impact of the merits of the Central Bank Governor on financial markets (Kuttner and Posen, 2007).

Event studies have also been used to analyze the effect of central bank interventions. For example, Humpage (1996), Fatum and Hutchison (2003, 2008), and Fratzscher (2012) show that interventions had a significant impact on the exchange rate, even when considering a 15-day window (the longest period considered by most of them). For Fratzscher (2012, pp.739) "there is overwhelming evidence that both actual and oral intervention events for the G3 economies have been successful", and the success rate remains relatively stable when extending the time window to 40 days. Egert (2007) finds, for the case of the Czech Republic, Hungary, Romania, Slovakia and Turkey, that interventions are effective only in the short-run, when they are able to ease appreciation pressures. Similarly, Payne and Vitale (2003) find that interventions have short-run effects on the exchange rate for the Swiss case.

Finally, event studies have also been used to examine the most recent monetary policies undertaken by the US Federal Reserve and the Bank of England. Swanson (2011) for example, uses an event study analysis of Operation Twist and finds sig- 
nificant effects of 4 out of 6 Fed announcements. Bauer and Rudebusch (2013) find that bond purchases by the Federal Reserve have a significant signaling effect over expected short term interest rates. Krishnamurthy and Vissing-Jorgensen (2011) use intra-day data and find that purchases of long term Treasuries and bonds lead to a large drop in nominal interest rates of both medium and long-term assets. Finally, for the case of the United Kingdom, Joyce et al. (2011) finds that securities purchased by the Bank of England had a significant impact in reducing medium to long-term government bond yields.

\subsection{Methodology: An Event Study Approach}

There are some limitations when using a non-parametric approach to estimate the effects of policy. One of these drawbacks consists of a certain degree of subjectivity when choosing the window size of the pre-event window, event and post-event window. While we refer to standard cross-validation techniques and allow for multiple window sizes for robustness, it is usually the case that large windows over-smooth the density of the underlying data structure. On the other hand, small bandwidths might reduce the bias but at the expense of obtaining a larger variance in the estimates. Also, the longer the event window is defined, the fewer events are found within the sample. Finally, long pre and post estimation windows increase the likelihood of exogenous shocks (foreign and domestic) that might affect the exchange rate (always expressed as Pesos per Dollar). Bearing these limitations in mind, we believe that our event study approach holds clear advantages over the bulk of the literature that uses restrictive parametric assumptions. 


\subsubsection{Definition of the Event Window}

In this section we compare the cumulative effect of the different types of foreign exchange intervention. ${ }^{3}$ In the methodology that follows, we focus on relatively short event windows to increase the likelihood of interventions being random (or at least independent of anticipatory movements). In other words, we reduce the time frame (to 5 days) in which interventions are exposed to market conditions. Additionally, we consider two control groups to verify the validity of this assumption. The first control group considers the evolution of the exchange rate in Brazil. ${ }^{4}$ The second control group considers cases in which rule-based interventions should have been triggered, but were not since the rule was no longer active.

The methodology starts with the definition of the event window comprised by: $a$ ) the pre-event window, $b$ ) the event, and $c$ ) the post-event window. Following Fatum and Hutchison (2003), Hutchison (2002) and Fratzscher (2012), we consider pre and post-event windows of 2, 5, 10 and 15 days and define the event as the cluster of foreign exchange intervention in which the Central Bank did not stop intervening for $2,5,10$ or 15 days. In other words, the event begins when the central bank first conducts purchases or sales in the foreign exchange market and ends when 2, 5, 10 or 15 consecutive days have elapsed without interventions.

We then follow Frankel (1994), Fatum and Hutchison (2003) and Humpage (1996) in defining the following four criteria to evaluate a successful intervention: 1) Direction, 2) Reversal, 3) Smoothing, and 4) Matching. They can be summarized as follows:

- The Direction criterion considers a successful event when the exchange rate depreciates (appreciates) after USD purchases (USD sales), without any regard

\footnotetext{
${ }^{3}$ We exclude day-to-day constant and pre-announced interventions from our analysis given the few events available.

${ }^{4}$ We choose the case of Brazil as a control group based on Loaiza and Melo (2012), who find a strong relation between the Peso and the Real.
} 
about the trend of the exchange rate before intervention. As Frankel (1994) argues, a successful intervention means that the exchange rate moves in the direction wanted by the central bank. In this sense, the Direction criterion does not take into account the behavior of the exchange rate before interventions take place. The central bank could simply be following a leaning-with-the-wind policy, with the behavior of the exchange rate probably dictated by market conditions.

- The Reversal criterion is more demanding, and success requires that the exchange rate depreciates (appreciates) after USD purchases (USD sales). The difference with the direction criterion is that it now requires the exchange rate to be appreciating (depreciating) before an intervention episode.

- The Smoothing criterion also considers the pre-intervention period, but it is less demanding. This criterion defines success when exchange rate appreciations (depreciations) are lesser in magnitude after USD purchases (USD sales).

- The Matching criterion is similar to the smoothing criterion but considers the magnitude of exchange rate changes as opposed to comparing the number of successful events. Hence, the matched sample test consists of verifying whether the behavior of the exchange rate experienced a significant variation between the pre and post-event windows.

The statistical analysis for the first three criteria (Direction, Reversal and Smoothing) consists of counting the number of successful events and comparing 
it with the total number of events. Specifically, we use a sign $t-t e s t$, based on a binomial distribution, to check if the probability of a successful event $(p)$ is greater or equal than 0.5 (or a given probability value). As for the Matched criterion, the analysis consisted of computing the difference between the corresponding pre and post event exchange rate values. And, by assuming that the variation of the exchange rate of both sub-samples is normally distributed, we use a $t$-test with $n-1$ degrees of freedom (" $\mathrm{n}$ " being the number of matched pairs).

The four criteria are shown in Tables 3.1 and 3.2, for the case of purchases and sales of foreign currency, respectively. $\Delta S_{t}$ corresponds to exchange rate changes, and the superscripts " - " and "+" correspond to the pre and post intervention periods, respectively. Overall, reversal is a more demanding criterion than direction since it does not consider the behavior of the exchange rate in the pre-event window. It is also more demanding than the smoothing criterion since it does not require the exchange rate to depreciate (appreciate) after USD purchases (USD sales).

\subsection{Results}

Tables 3.3-3.6 present results when the estimation window, the pre, and the post-event periods correspond to five days. Column (1) presents the different types of intervention which include $i$ ) Discretionary purchases in the spot exchange market, $i i$ ) Discretionary purchases through exchange rate options (intended for reserve accumulation), and $i$ ii) Rule-based exchange rate options for volatility control. We recognize that different types of foreign exchange intervention could have been motivated by different covariates and policy objectives. However, it might be of interest to know if they had a significant impact on the exchange rate, and specifically, over the smoothing, direction and reversal criteria. Column (2) shows the number of favorable cases (i.e. 
number of successful interventions) out of the total number of events and column (3) shows if the probability of a successful event $(p)$ is greater or equal than 0.5 (or a given probability value).

Results shown in Table 3.3 suggest that rule-based interventions were successful according to the Direction criterion, with p-values of 0.02 for sales, and 0.11 for purchases. However, results also shows that discretionary purchases (both through options and directly in the spot market) were not significant. Results are very similar when considering the Reversal or the Matching criteria shown in Tables 3.4 and 3.6. In fact, only sales of foreign currency through rule-based exchange rate options were significant (with a p-value of 0.02).

Results for the Smoothing criterion (Table 3.5), on the other hand, show that all types of intervention were successful, when considering the null hypothesis of $H_{0}: p \leq 0.5$. Taken at face value, this means that exchange rate appreciations were lesser in magnitude after purchases of foreign currency (vice-versa for sales). However, counterfactual exercises conducted for the case of Brazil also show significant results. ${ }^{5}$ This casts some doubts when considering the impact of interventions according to the Smoothing criterion. However, this is not the case when considering the null of $H_{0}: p \leq 0.8$, which is significant for the Colombian case but not significant for the case of Brazil.

\subsubsection{COUNTERFACTUALS}

In this section we also report the results for the same criteria, but now controlling for two alternative counterfactual scenarios. The first scenario considers the evolution of

\footnotetext{
${ }^{5}$ Discretionary purchases through exchange rate options and rule-based interventions were significant under the Smoothing criterion.
} 
the exchange rate in Brazil (with the underlying assumption that Brazil did not intervene simultaneously with Colombia). The second scenario considers cases in which rule-based interventions should have been triggered, but were not since the rule was permanently stopped.

\section{COUNTERFACTUAL I}

The first counterfactual exercise resembles a difference-in-difference estimation where the exchange rate in Brazil corresponds to the control group. In other words, the difference between the average effect in Colombia (i.e. treatment group) and the average effect in Brazil (i.e. control group) represents the effect of interventions on the exchange rate when controlling for similar macroeconomic trends. In a regressionbased setting this would amount to estimating equation (4.1), as presented in Betrand et al. (2004) but for the case of no control variables:

$$
S_{i t}=A_{i}+B_{t}+\beta I_{i t}+\epsilon_{i t}
$$

Where $S_{i t}$ would be the exchange rate change in country $i$ and for period $t . A_{i}$ and $B_{t}$ would correspond to the country-specific and time-specific intercepts and $I_{i t}$ would be a dummy for whether foreign exchange intervention affected country $i$ at period $t$.

As illustrated by Abadie et al. (2003), Betrand et al. (2004), Abadie (2005), Angrist and Pischke (2008) and Imbens and Wooldridge (2009), the coefficient $\beta$ can be interpreted as the treatment effect of interventions as long as some additional assumptions hold (See Angrist and Pischke, 2008 for an in-depth description).

Tables 3.7-3.9 show the event study estimation for the case of Brazil (i.e. control group). Specifically, they show results for discretionary interventions directly in the spot market (Table 3.7), discretionary interventions through exchange rate options 
(Table 3.8), and rule-based foreign exchange options (Table 3.9), when considering the same dates as for the Colombian case. All tables show the number of successful interventions according to the four criteria defined in Section 3. The main findings indicate that, under the null hypothesis of $H_{0}: p \leq 0.5$, discretionary interventions through exchange rate options were significant according to both the Smoothing and Direction criteria. Also, rule-based interventions were significant under the Smoothing criterion. However, these results do not longer hold when considering the null of $H_{0}: p \leq 0.8$. In this case, all of the interventions mechanisms were not statistically significant.

Table 3.10 shows results for the Difference-in-Difference estimation exercise. Columns 2 and 3 show the number of favorable cases for Colombia and Brazil, respectively and column 4 shows the difference between them. As can be seen, the treatment effect is not significant for either the Smoothing, Reversal or Direction criteria. This is mostly due to the small number of events. Nonetheless, these results cast some doubts on the successful criteria for rule-based interventions.

\section{COUnterfactual II}

The second counterfactual considered was related to the behavior of the Colombian exchange rate in periods in which rule-based volatility options should have been triggered if the rule were in place, but was not, simply because the board of the Central Bank decided to suspend interventions. In principle, monetary authorities may have chosen to suspend this particular intervention mechanism for reasons related to exchange rate movements, leading to an endogenous relationship. However, we consider a period of over 3 years (2010-2012) in which the rule was no longer in place. And, while exchange rate movements in 2009 might have influenced the decision to 
permanently terminate this type of interventions, it is very unlikely that this relationship persisted for more than a few months (certainly not for years after the decision was taken). Given the small number of events available, we only considered the case of a 2-day event window, pre and post event.

Results for this exercise are shown in Table 3.11. Rule-based interventions are significant only under the Smoothing criterion. ${ }^{6}$

\subsubsection{Robustness Checks}

Graphs 3.2-3.5 show additional robustness checks for our proposed criteria: Direction (Figure 3.5), Reversal (Figure 3.6), Smoothing (Figure 3.7), and Matching (Figure 3.8). For each type of intervention, we computed the percentage of successes and p-values of each test for different window sizes. The main results indicate that: 1) volatility options are successful according to all criteria and for all window sizes considered, and 2) all intervention mechanisms are successful when considering only the smoothing criteria and for window sizes of less than 12 days.

\subsection{CONCLUSiOnS}

In this paper we compare the effects of $i$ ) Discretionary purchases in the spot exchange market, ii) Discretionary purchases through exchange rate options (intended for reserve accumulation), and $i$ ii) Rule-based exchange rate options for volatility control, using an event study approach. Following the methodology presented in Frankel (1994), Fatum and Hutchison (2003) and Humpage (1996), we define four criteria to evaluate a successful intervention: 1) Direction, 2) Reversal, 3) Smoothing, and 4) Matching. We also conduct two counterfactual exercises: $i$ ) we consider the evolution

\footnotetext{
${ }^{6}$ The difference-in-difference estimation was not conducted for this exercise due to the small number of events.
} 
of the Brazilian exchange rate in periods corresponding to pre and post Colombian interventions and $i$ ) we consider periods in which volatility options should have been triggered if the intervention rule were in place, but was not, because the board of the Central Bank decided to suspend interventions. Finally, we conduct robustness checks by allowing for various event window sizes.

Results show that all types of interventions were successful according to the Smoothing criterion when considering the null hypothesis of $H_{0}: \leq 0.5$. Moreover, rule-based volatility options were successful according to all of the criteria considered. However, the case of Brazil casts some doubts when considering the Direction, Smoothing and Reversal criteria. On the one hand, when considering the null of $H_{0}: \leq 0.8$, results are significant for Colombia but not for Brazil. However, the Difference-in-Difference estimation show no significant results. The latter could simply be due to the small number of events when comparing exchange rate episodes with Brazil. Nonetheless, success for this mechanism should be further analyzed and results should be cautiously interpreted. 


\subsection{Figures}

Figure 3.1: Different Mechanisms of Foreign Exchange Intervention: 1999-2012

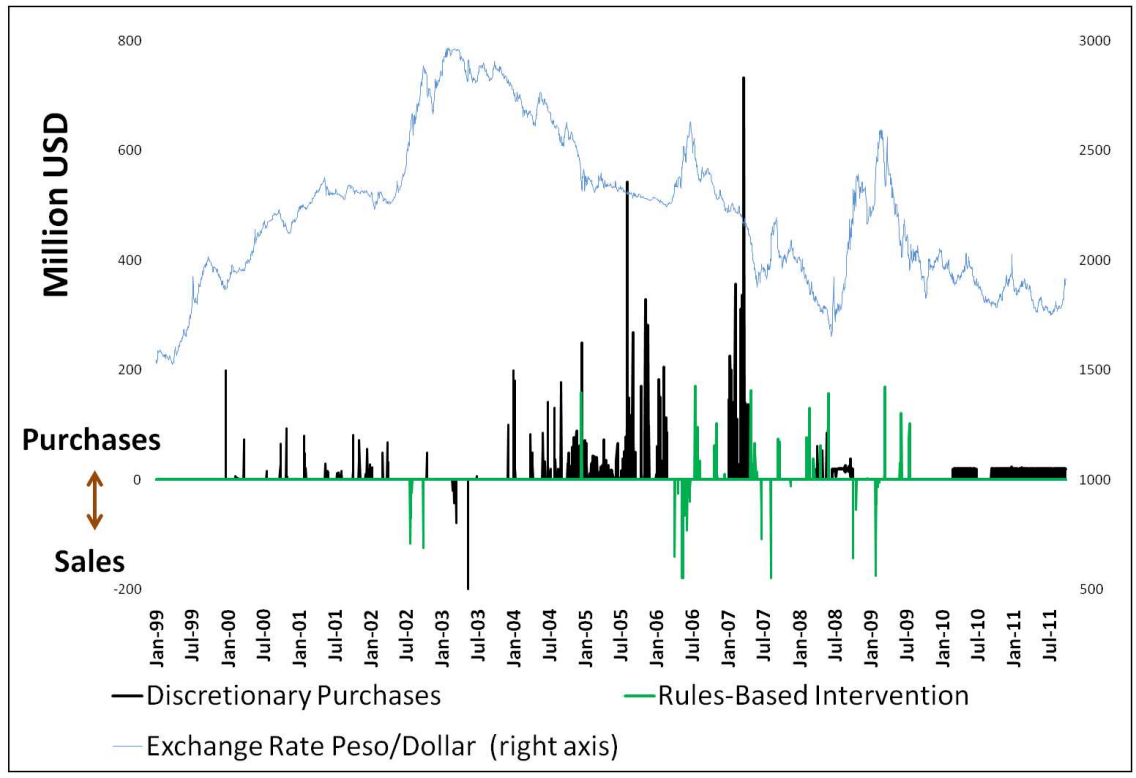


Figure 3.2: Robustness Exercise (Direction Criterion)

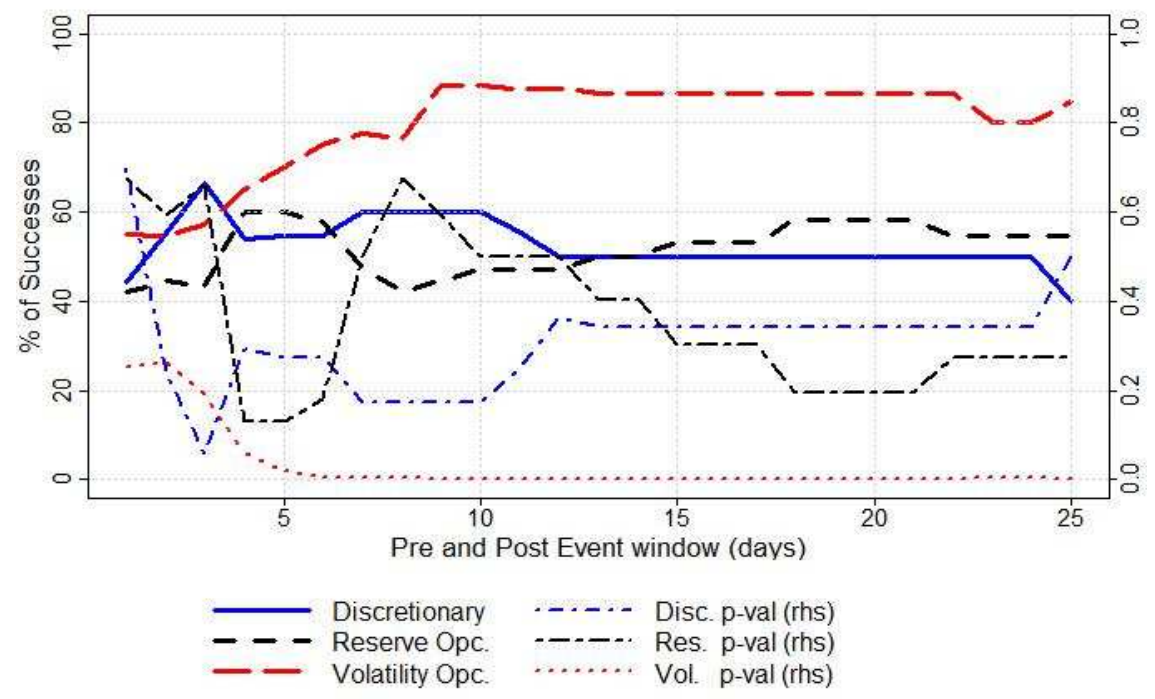

Figure 3.3: Robustness Exercise (Reversal Criterion)

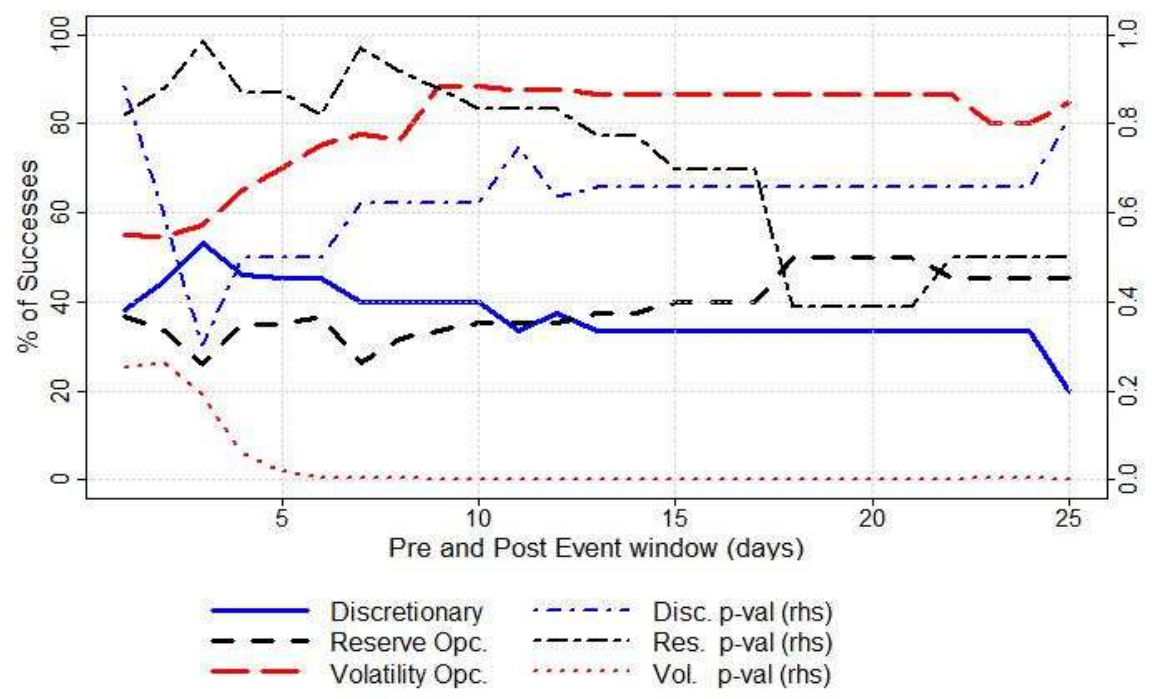


Figure 3.4: Robustness Exercise (Smoothing Criterion)

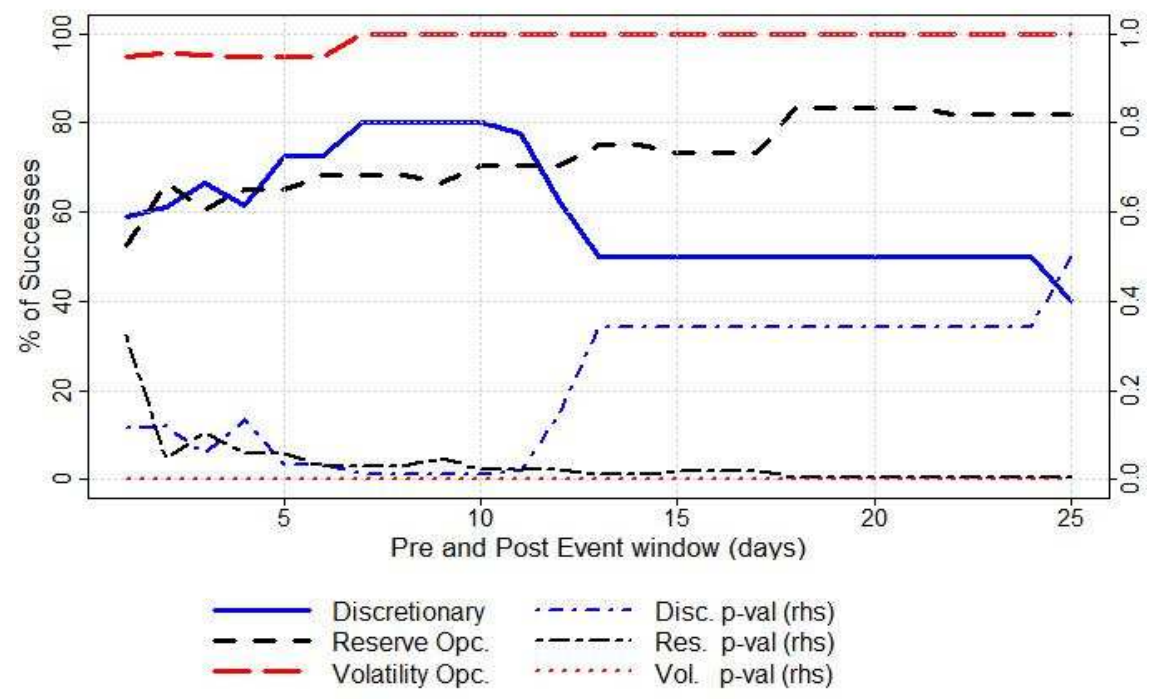

Figure 3.5: Robustness Exercise (Matching Criterion)

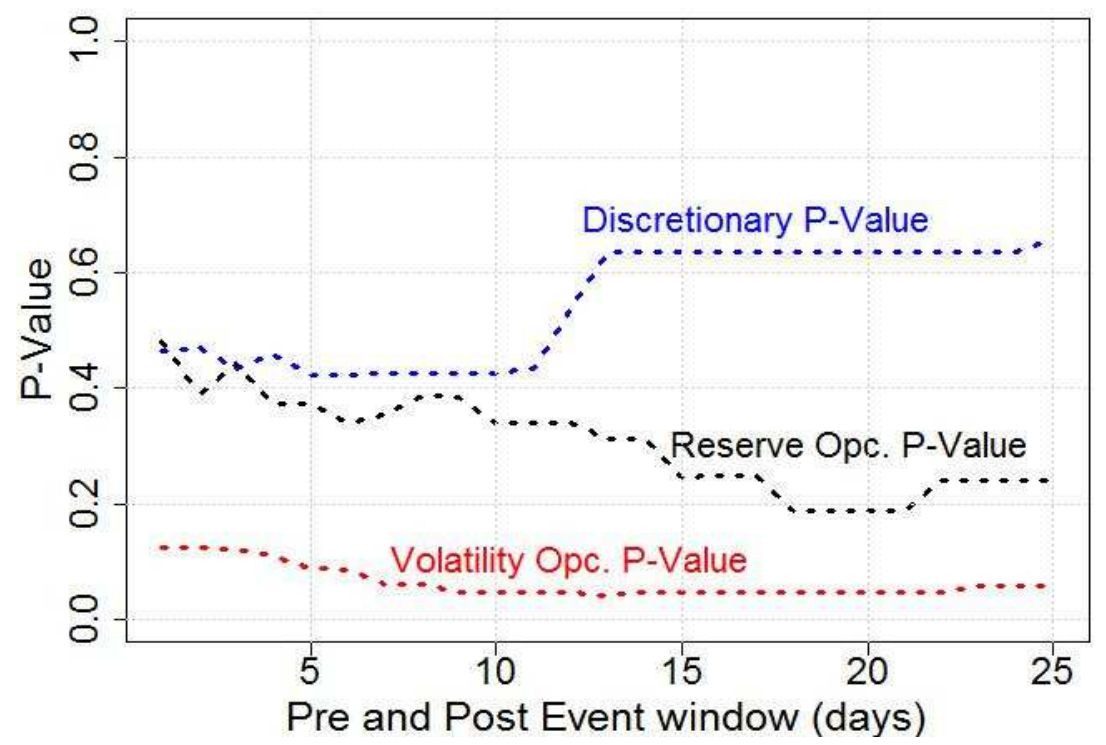




\subsection{TABLES}

Table 3.1: Definition of Criteria for Successful Interventions (Purchases of USD)

\begin{tabular}{|c|c|c|c|}
\hline Criteria & Pre-Event & Event & Post-Event \\
\hline Direction & & USD Purchases & $\Delta^{+} S_{t}>0$ \\
\hline Reversal & $\Delta S_{t}<0$ & USD Purchases & $\Delta^{+} S_{t}>0$ \\
\hline Smoothing & $\Delta S_{t}<0$ & USD Purchases & $\Delta S_{t}^{+}>\Delta S_{t}$ \\
\hline $\begin{array}{l}\text { Matching } \\
\text { (magnitude) }\end{array}$ & & USD Purchases & $\Delta^{+} S_{t}>\bar{\Delta}_{S_{t}}$ \\
\hline
\end{tabular}

This table intends to exemplify the definition of the 4 criteria as presented in Frankel (1994), Fatum and Hutchison (2003) and Humpage (1996). $\Delta S_{t}$ corresponds to exchange rate changes, and the superscripts " - " and "+" correspond to the pre and post intervention periods, respectively. Refer to Section 3.1 in the text.

Table 3.2: Definition of Criteria for Successful Interventions (Sales of USD)

\begin{tabular}{lccc}
\hline \hline Criteria & Pre-Event & Event & Post-Event \\
\hline & & & \\
Direction & & USD Sales & $\Delta^{+} S_{t}<0$ \\
Reversal & $\Delta_{t} S_{t}>0$ & USD Sales & $\Delta^{+} S_{t}<0$ \\
Smoothing & $\Delta^{-} S_{t}>0$ & USD Sales & $\Delta^{+} S_{t}<\Delta^{-} S_{t}$ \\
Matching & & USD Sales & $\Delta^{+} S_{t}<\Delta S_{t}$ \\
(magnitude) & & & \\
\hline \hline
\end{tabular}

This table intends to exemplify the definition of the 4 criteria as presented in Frankel (1994), Fatum and Hutchison (2003) and Humpage (1996). $\Delta S_{t}$ corresponds to exchange rate changes, and the superscripts "- " and "+ " correspond to the pre and post intervention periods, respectively. Refer to Section 3.1 in the text. 
Table 3.3: Event Study Estimation for Direction Criterion

\begin{tabular}{lcc}
\hline \hline FX Intervention & Favorable Cases & $H_{0}: p \leq 0.5$ \\
& Successful/Total & $(\mathrm{p}$-value $)$ \\
\hline
\end{tabular}

Discretionary (Spot market)

USD Purchases

Discretionary (Options)

USD Purchases

$11 / 19$

\section{Rules-Based (Options)}

USD Purchases

USD Sales

$7 / 9$

SOURCE: Authors' calculations. Pre, post, and event-windows correspond to 5 days. The statistical analysis consisted of counting the number of successful events and comparing it with the total number of events. we use a sign $t$-test, based on a binomial distribution, to check if the probability of a successful event $(p)$ is greater or equal than a given probability value. 
Table 3.4: Event Study Estimation for Reversal Criterion

\begin{tabular}{lcc}
\hline \hline FX Intervention & Favorable Cases & $H_{0}: p \leq 0.5$ \\
& Successful/Total & $(\mathrm{p}$-value $)$ \\
\hline
\end{tabular}

\section{Discretionary (Spot market)}

USD Purchases

$5 / 11$

Discretionary (Options)

USD Purchases

$6 / 19$

\section{Rules-Based (Options)}

USD Purchase

$7 / 11$

USD Sales

$7 / 9$

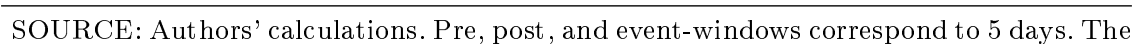
statistical analysis consisted of counting the number of successful events and comparing it with the total number of events. we use a sign $t$-test, based on a binomial distribution, to check if the probability of a successful event $(p)$ is greater or equal than a given probability value. 
Table 3.5: Event Study Estimation for Smoothing Criterion

\begin{tabular}{cccc}
\hline \hline FX Intervention & Favorable Cases & $H_{0}: p \leq 0.5$ & $H_{0}: p \leq 0.8$ \\
& Successful/Total & $(\mathrm{p}$-value $)$ & $(\mathrm{p}$-value $)$ \\
\hline
\end{tabular}

Discretionary (Spot market)

USD Purchases

$8 / 11 \quad(0.03)^{* *}$

$(0.62)$

Discretionary (Options)

USD Purchases

$12 / 19 \quad(0.08)^{*}$

\section{Rules-Based (Options)}

\begin{tabular}{lccc} 
USD Purchases & $10 / 11$ & $(0.00)^{* * *}$ & $(0.09)^{*}$ \\
USD Sales & $9 / 9$ & $(0.00)^{* * *}$ & $(0.00)^{* * *}$ \\
\hline \hline
\end{tabular}

SOURCE: Authors' calculations. Pre, post, and event-windows correspond to 5 days. The statistical analysis consisted of counting the number of successful events and comparing it with the total number of events. we use a sign $t$-test, based on a binomial distribution, to check if the probability of a successful event $(p)$ is greater or equal than a given probability value. 
Table 3.6: Event Study Estimation for Matching Criterion

\begin{tabular}{ccc}
\hline \hline FX Intervention & Average Difference & $H_{0}: \Delta^{+} S_{t}>\Delta \bar{S}_{t}$ \\
& \% Change $($ Peso/Dollar $)$ & $(\mathrm{p}$-value $)$ \\
\hline
\end{tabular}

Discretionary (Spot market)

USD Purchases

0.06

Discretionary (Options)

USD Purchases

0.05

Rules-Based (Options)

USD Purchases

1.08

$-0.72$

USD Sales

Authors' calculations. Pre, post, and event-windows correspond to 5 days. The statistical analysis consisted of computing the difference between the corresponding pre and post event exchange rate values. We assume that the variation of the exchange rate of both sub-samples is normally distributed, so we use a $t$-test with $n-1$ degrees of freedom (" $n$ " being the number of matched pairs) to draw inference. 
Table 3.7: Event Study Estimation for the case of Brazil (Counterfactual Exercise). Discretionary Interventions through the Spot Market

\begin{tabular}{lcccc}
\hline \hline Criteria & Favorable Cases & $\begin{array}{c}H_{0}: p \leq 0.5 \\
(\mathrm{p} \text {-value })\end{array}$ & $\begin{array}{c}H_{0}: p \leq 0.8 \\
(\mathrm{p} \text {-value })\end{array}$ & $\begin{array}{c}H_{0}: D \leq 0 \\
(\mathrm{p} \text {-value })\end{array}$ \\
\hline Smoothing & $7 / 11$ & 0.11 & 0.84 & \\
Direction & $3 / 11$ & 0.89 & 0.99 & \\
Reversal & $3 / 11$ & 0.89 & 0.99 & 0.99 \\
Matching & $0 / 11$ & & & \\
\hline \hline
\end{tabular}

Authors' calculations. The statistical analysis for the first three criteria (Direction, Reversal and Smoothing) consists of counting the number of successful events and comparing it with the total number of events. Specifically, we use a sign $t$-test, based on a binomial distribution, to check if the probability of a successful event $(p)$ is greater or equal than 0.5 (or a given probability value). As for the Matched criterion, the analysis consisted of computing the difference between the corresponding pre and post event exchange rate values. And, by assuming that the variation of the exchange rate of both sub-samples is normally distributed, we use a $t$-test with $n-1$ degrees of freedom (" $n$ " being the number of matched pairs). 
Table 3.8: Event Study Estimation for the case of Brazil (Counterfactual Exercise). Discretionary Interventions through FX Options

\begin{tabular}{lcccc}
\hline \hline Criteria & Favorable Cases & $\begin{array}{c}H_{0}: p \leq 0.5 \\
(\mathrm{p} \text {-value })\end{array}$ & $\begin{array}{c}H_{0}: p \leq 0.8 \\
(\mathrm{p} \text {-value })\end{array}$ & $\begin{array}{c}H_{0}: D \leq 0 \\
(\mathrm{p} \text {-value })\end{array}$ \\
\hline Smoothing & $14 / 20$ & $0.02^{* *}$ & 0.80 & \\
Direction & $14 / 20$ & $0.02^{* *}$ & 0.80 & \\
Reversal & $10 / 20$ & 0.41 & & 0.99 \\
Matching & $0 / 20$ & & & 0.96 \\
\hline \hline
\end{tabular}

Authors' calculations. The statistical analysis for the first three criteria (Direction, Reversal and Smoothing) consists of counting the number of successful events and comparing it with the total number of events. Specifically, we use a sign $t-t e s t$, based on a binomial distribution, to check if the probability of a successful event $(p)$ is greater or equal than 0.5 (or a given probability value). As for the Matched criterion, the analysis consisted of computing the difference between the corresponding pre and post event exchange rate values. And, by assuming that the variation of the exchange rate of both sub-samples is normally distributed, we use a $t$-test with $n-1$ degrees of freedom (" $n$ " being the number of matched pairs). 
Table 3.9: Event Study Estimation for the case of Brazil (Counterfactual Exercise). Rule-Based Interventions through FX Options

\begin{tabular}{lcccc}
\hline \hline Criteria & Favorable Cases & $\begin{array}{c}H_{0}: p \leq 0.5 \\
(\mathrm{p} \text {-value })\end{array}$ & $\begin{array}{c}H_{0}: p \leq 0.8 \\
(\mathrm{p} \text {-value })\end{array}$ & $\begin{array}{c}H_{0}: D \leq 0 \\
(\mathrm{p} \text {-value })\end{array}$ \\
\hline Smoothing & $17 / 20$ & $0.00^{* * *}$ & 0.21 & \\
Direction & $12 / 20$ & 0.13 & & \\
Reversal & $9 / 20$ & 0.58 & & 0.99 \\
Matching & $0 / 20$ & & & \\
\hline \hline
\end{tabular}

Authors' calculations. The statistical analysis for the first three criteria (Direction, Reversal and Smoothing) consists of counting the number of successful events and comparing it with the total number of events. Specifically, we use a sign $t$-test, based on a binomial distribution, to check if the probability of a successful event $(p)$ is greater or equal than 0.5 (or a given probability value). As for the Matched criterion, the analysis consisted of computing the difference between the corresponding pre and post event exchange rate values. And, by assuming that the variation of the exchange rate of both sub-samples is normally distributed, we use a $t$-test with $n-1$ degrees of freedom (" $n$ " being the number of matched pairs).

Table 3.10: Difference-in-Difference Estimation

\begin{tabular}{lcccc}
\hline \hline Criteria & $\begin{array}{c}\text { Favorable Cases } \\
\text { Colombia }\end{array}$ & $\begin{array}{c}\text { Favorable Cases } \\
\text { Brazil }\end{array}$ & Diff-in-Diff & $\begin{array}{c}H_{0}: p \leq 0.5 \\
(\mathrm{p} \text {-value })\end{array}$ \\
\hline Smoothing & $19 / 20$ & $17 / 20$ & $2 / 20$ & 0.99 \\
Direction & $14 / 20$ & $12 / 20$ & $2 / 20$ & 0.99 \\
Reversal & $14 / 20$ & $9 / 20$ & $5 / 20$ & 0.97 \\
\hline \hline
\end{tabular}

Authors' calculations. The statistical analysis for the first three criteria (Direction, Reversal and Smoothing) consists of counting the number of successful events and comparing it with the total number of events. Specifically, we use a sign $t$-test, based on a binomial distribution, to check if the probability of a successful event $(p)$ is greater or equal than 0.5 (or a given probability value). 
Table 3.11: Second Counterfactual Exercise

\begin{tabular}{lccc}
\hline \hline Criteria & Favorable Cases & $\begin{array}{c}H_{0}: p \leq 0.5 \\
(\mathrm{p} \text {-value })\end{array}$ & $\begin{array}{c}H_{0}: D \leq 0 \\
(\mathrm{p} \text {-value })\end{array}$ \\
\hline Smoothing & $7 / 10$ & $0.05^{* *}$ & \\
Direction & $7 / 10$ & 0.58 & \\
Reversal & $6 / 10$ & 0.17 & \\
Matching & $0 / 10$ & & 0.99 \\
\hline \hline
\end{tabular}

Authors' calculations. The statistical analysis for the first three criteria (Direction, Reversal and Smoothing) consists of counting the number of successful events and comparing it with the total number of events. Specifically, we use a sign $t$-test, based on a binomial distribution, to check if the probability of a successful event $(p)$ is greater or equal than 0.5 (or a given probability value). As for the Matched criterion, the analysis consisted of computing the difference between the corresponding pre and post event exchange rate values. And, by assuming that the variation of the exchange rate of both sub-samples is normally distributed, we use a $t$-test with $n-1$ degrees of freedom (" $n$ " being the number of matched pairs). 


\section{APPENDIX A}

- Policy instruments of the $\mathrm{CBoC}\left(D_{1 t}\right.$ and $\left.D_{2 t}\right)$

- FXI $I_{t}$ : Discretionary purchases of foreign currency (USD) conducted in the spot market and through foreign exchange rate options. (Daily frequency)

- IRI $I_{t}$ : Minimum overnight lending interest rate set by the CBoC. This variable is analogous to the US target Federal Funds rate. (Daily frequency)

- Variables in $X_{t}$

- Net position of the CBoC $\left(\right.$ Net $\left.P_{t}\right)$ : Total net credit/debit with respect to the financial system. $D_{\text {NetPt }}$ is a dummy variable that is switched on whenever the $\mathrm{CBoC}$ is a net debtor. The board usually considered this variable in order to avoid episodes of excess liquidity. (Daily frequency)

- Board Meetings (BoardMeet $)_{t}$ ): Board meeting dates are analogous to the meetings of the US Federal Open Market Committee (FOMC). Information on when monetary authorities met and whether they decided to loosen, tighten or leave monetary policy unchanged is critical to remove possible endogenous relationships between the intervention interest rate and economic conditions. (Daily frequency)

- EMBI $\left(E M B I_{t}\right)$ : 1-year yield spreads between the US and Colombia. (Daily frequency)

- Expected Inflation $\left(\pi_{t}^{e}\right)$ : Mean expected yearly inflation based on the Central Bank Expectations Survey. Interviewees include commercial banks, stockbrokers and pension funds. (Monthly frequency)

- Brazil's Exchange rate $\left(\operatorname{Brazil}\left(\Delta e_{t}\right)\right)$ : Nominal exchange rate changes between Brazil and the US (Real/USD). (Daily frequency)

- Capital Controls $\left(\operatorname{Tax}_{t}\right)$ : Capital controls were implemented between May 2007 and October 2008. They correspond to a tax (\%) imposed on capital inflows. Series corresponds to the one presented in Rincon and Toro (2011). (Daily frequency) 
- International Reserves $\left(\operatorname{Res}_{t}\right)$ : International Reserves of the CBoC. (Daily frequency)

- Exchange rate Misalignments forecasts $\left(e_{t}-\right.$ Forecast $\left.\left(e_{t}\right)\right)$ : Seven structural models are estimated by the Observatorio de Tasa de Cambio Real ( $\mathrm{CBoC}$ division). Specifically, two models are based on the purchasing power parity condition (PPP), two models are based on SVEC methodologies, two models are based on the current account equilibrium and one model simply uses Hodrick and Prescott filters. Exchange rate misalignments are measured as the log-difference of the exchange rate minus the average forecasted equilibrium value. (Daily frequency)

- Inflation forecasts minus yearly target rate $\left(\right.$ Forecast $\left.\left(\pi_{t}\right)-\operatorname{Target}\left(\pi_{t}\right)\right)$ : forecasts are estimated by the Departamento de Modelos Macroeconomicos (CBoC department). Since 2001, the CBoC adopted a model proposed by Gomez and Julio (2001) to forecast future inflation. This model includes 9 equations that govern prices, aggregate demand, wages, an interest rate rule, the uncovered interest rate parity condition, foreign real interest rates, risk premium, terms of trade and policy rates. (Daily frequency)

- GDP gap forecasts $\left(y_{t}-\right.$ Forecast $\left.\left(y_{t}\right)\right)$ : forecasts are estimated by the Departamento de Modelos Macroeconomicos (CBoC department). This DSGE model (PATACON) incorporates nominal and real rigidities and uses 5 main equations: cascade of Calvo pricing, staggered wages, endogenous depreciation, external habits in consumption, and investment costs. (Monthly frequency)

- US Fed Funds Rate $\left(i_{t}^{*}\right)$ : Self explanatory. (Daily frequency)

- Outcome variables in $Y_{t}$

- Exchange rate $\left(e_{t}\right)$ : Nominal Exchange rate between Colombia and the US (Pesos/USD). (Daily frequency)

- Exchange rate volatility $\left(\operatorname{Vol}_{t}\right)$ : Squared daily returns $\left(e_{t}-e_{t-1}\right)^{2}$. (Daily frequency)

- 1-year Treasury bond's yield $\left(i_{t}^{1 \text { year }}\right)$ : Self explanatory. (Daily frequency)

- Industrial production growth $\left(\Delta I n d_{t}\right)$ : Self explanatory. (Monthly frequency)

- Inflation $\left(\pi_{t}\right)$ : Yearly changes for the Colombian Consumer's Price Index (IPI). (Monthly frequency)

Source: Central Bank of Colombia (Banco de la Republica de Colombia) 


\section{APPENDix B}

\section{Table B.1: Fragments of Reports Presented to Congress}

Date Informe de la Junta Directiva del Banco de la Republica al Congreso

Mar-00 "Aun cuando se permita que la tasa de cambio flote, es necesario evitar volatilidades por los efectos perversos que esto podria tener sobre la estabilidad economica"

Mar-04 "En vista de la persistencia de las presiones revaluacionistas del tipo de cambio durante 2004, las cuales se considera pueden ser transitorias, la JDBR estimo prudente convocar a subastas de acumulacion de reservas

Mar-05 "En periodos en los que se requiere una estrategia monetaria expansiva, la compra de divisas puede actuar como complemento de reducciones en las tasas de interes Este tipo de politica monetaria... resulta superior a la que se concentra de manera exclusiva en el manejo de la tasas de interes"

Jul-06 "La estrategia de inflacion objetivo se ha combinado con intervenciones en el mercado cambiario por parte del Banco de la Republica, como mecanismo complementario para evitar volatilidad en el crecimiento economico y en la tasa de cambio real."

Jul-07 "En la medida en que se perciba alguna contradiccion en el logro simultaneo de ambos objetivos, la credibilidad de los mismos quedara en entredicho, y la efectividad de la intervencion en el mercado cambiario puede verse reducida."

Jul-08 "En junio 20 de 2008 el Emisor anuncio un nuevo mecanismo de intervencion en el mercado cambiario al determinar una acumulacion diaria de US $\$ 20 \mathrm{~m}$ a traves de subastas diarias de compra directa." 
ApPENDix C

Table C.1: Autocorrelations and Cross-Correlogram

\begin{tabular}{lccc}
\hline \hline LAG & AC of $\epsilon_{1 t}$ & AC of $\epsilon_{2 t}$ & Cross-Correlogram \\
\hline & & & \\
1 & 0.03 & 0.00 & 0.01 \\
2 & -0.01 & 0.00 & 0.00 \\
3 & -0.04 & 0.00 & 0.00 \\
4 & 0.06 & 0.00 & -0.01 \\
5 & 0.01 & 0.00 & 0.01 \\
6 & 0.02 & 0.00 & 0.00 \\
7 & 0.05 & -0.01 & 0.03 \\
8 & 0.07 & 0.00 & 0.02 \\
9 & 0.10 & 0.00 & -0.01 \\
10 & 0.03 & 0.00 & 0.00 \\
11 & 0.00 & 0.01 & 0.01 \\
12 & -0.04 & 0.00 & -0.01 \\
13 & 0.01 & 0.00 & -0.02 \\
14 & 0.02 & -0.07 & 0.01 \\
15 & 0.06 & 0.00 & 0.00 \\
16 & -0.03 & 0.00 & 0.01 \\
17 & 0.03 & 0.00 & 0.00 \\
18 & -0.03 & 0.00 & -0.01 \\
19 & 0.00 & 0.00 & 0.02 \\
20 & -0.04 & 0.00 & 0.01 \\
\hline \hline
\end{tabular}

Author's calculations. 


\section{BIBLIOGRAPHY}

[1] Abadie, A. (2005). "Semiparametric difference-in-differences estimators". Review of Economic Studies 72 (1): 1 Ü19.

[2] Abadie, A., and Gardeazabal, J. (2003) "The Economic Costs of Conflict: A Case Study of the Basque Country" The American Economic Review, Vol 93, No. 1:113-132.

[3] Adler, G., and Tovar, C. (2011) "Foreign Exchange Intervention: A Shield Against Appreciation winds?" IMF Working Papers 11/165.

[4] Allen, H., M. P. Taylor, (1990) "Charts, Noise and Fundamentals in the London Foreign Exchange Market", The Economic Journal, v.100-400, pp.49-59.

[5] Amemiya, T (1973). "Regression analysis when the dependent variable is truncated normal". Econometrica 41 (6): 997 Ú1016.

[6] Amemiya, T (1985) "Advanced Econometrics". Oxford: Basil Blackwell. ISBN 0-631-13345-3.

[7] Angrist, J. D., and Pischke, J.S. (2008) "Mostly harmless econometrics: An empiricist's companion" Princeton University Press.

[8] Angrist, J.D., and Kuersteiner, G.M. (2004) "Semiparametric Causality Tests Using the Policy Propensity Score" NBER Working Paper No. 10975.

[9] Angrist, J.D., and Kuersteiner, G.M. (2011) "Causal Effects of Monetary Shocks: Semiparametric conditional independence tests with a multinomial propensity score" The Review of Economic and Statistics, 93(3): 725-747.

[10] Angrist, J.D., and Pischke J.S. (2009) "Mostly Harmless Econometrics: An Empiricist's Companion" Princeton University Press (2009).

[11] Ashley, R., Granger, C.W.J., and Schmalensee R., (1980) "Advertising and aggregate consumption: an analysis of causality" Econometrica 48, 1149 Û́1168.

[12] Bagliano, F.C., and Favero C.A. (1998) "Measuring Monetary Policy with VAR Models: An Evaluation," European Economic Review, 42(6), 1069:1112.

[13] Baillie R.T (1996) "Long memory processes and fractional integration in econometrics" Journal of Econometrics, 73: 5-59. 
[14] Baillie R.T, Bollerslev, T. and Mikkelsen, H.O. (1996) "Fractionally integrated generalized autoregressive conditional heteroskedasticity" Journal of Econometrics 74:3-30

[15] Ball, L. (1995) "Time Consistent Policy and Persistent Changes in Inflation" NBER working paper No. 3525 .

[16] Barr, D.R. and Sherrill, E.T. (1999) "Mean and Variance of Truncated Normal Distributions" The American Statistician. Vol 53, 357-361.

[17] Bauer M.D., and Rudebsch G.D. (2013) "The Signaling Channel for Federal Reserve Bond Purchases" Federal Reserve Bank of San Francisco, Working Paper No. 2011-21

[18] Beine, M., A. Benassy-Quere, H. Colas, (2003) "Imitation Amongst ExchangeRate Forecasters: Evidence from Survey Data", CEPII Working Paper, v.200308.

[19] Beine, M., A. Benassy-Quere, R. Macdonald, (2007) "The Impact of Central Bank Intervention on Exchange-Rate Heterogeneity", Journal of the Japanese and International Economies, v.21-1, pp.38-63.

[20] Bekaert, Gaert (1996) "The Time Variation of Risk and Return in Foreign Exchange Markets: A General Equilibrium Perspective." Review of Financial Studies,1996, 9, pp. 427-470.

[21] Benassy-Quere, A., S. Larribeau, R. Macdonald, (2003) "Models of Exchange Rate Expectations: How Much Heterogeneity?", Journal of International Financial Markets, Institutions and Money, v.13-2, pp.113-136.

[22] Bernanke, B.S., and Blinder, A.S. (1992) "The Federal Funds Rate and the Channels of Monetary Transmission" The American Economic Review, Vol. 82, No. 4, pp. 901-921.

[23] Bernanke, B.S., and Mihov, I. (1998) "Measuring Monetary Policy" Quarterly Journal of Economics 113, 869-902.

[24] Bernanke, Ben S., and Blinder, Alan S. (1992) "The Federal Funds Rate and the Channels of Monetary Transmission" The American Economic Review, Vol. 82, No. 4, pp. 901-921.

[25] Bertrand, M., Duflo, E., and Mullainathan, S. (2004) "How Much Should We Trust Differences-in-Differences Estimates?". Quarterly Journal of Economics 119 (1): 249 Ü275.

[26] Bilson, J.F. (1981) "The Speculative Efficiency Hypothesis" Journal of Business 54. July 435-451. 
[27] Bilson, J.F., R. C. Marston, (1984) "Exchange Rate Theory and Practice", The University of Chicago Press, Chicago.

[28] Blinder, A.S. (2006) "Monetary Policy Today: Sixteen Questions and about Twelve Answers" Princeton University. CEPS Working Paper No. 129.

[29] Cameron, A.C., and Trivedi K.P. (2005) "Microeconometrics: Methods and Applications" Cambridge University Press, New York.

[30] Carlson, J.A. (1998) "Risk Aversion, Foreign Exchange Speculation and GamblerŠs Ruin" Economica, August 1998, 65, pp. 441-453.

[31] Cavaglia, S. M., Koedijk, K.G., W. F. Verschoor, C.C. Wolff (1998) "Interest expectations and exchange rates news" Empirical Economics, Springer, vol. $23(4)$, pages 525-534.

[32] Cavaglia, S. M., W. F. Verschoor, C. C. Wolff (1993) "Further Evidence on Exchange Rate Expectations", Journal of International Money and Finance, v.12, pp.78-98.

[33] Celasum, O., G. R. Gelos, A. Pratti, (2004) "Obstacles to Disinflation: What Is the Role of Fiscal Expectations?" Economic Policy: A European Forum, pp.441481.

[34] Chari, V.V., Christiano, L.J., and Eichenbaum, M. (1997) "Expectation Traps and Discretion" manuscript, Northwestern University.

[35] Cheung Y.W., Chinn M.D., and Pascual A.G. (2005) "Empirical Exchange Rate Models of the Nineties: Are any Fit to Survive?" Journal if International Money and Finance, 24:1150-1175.

[36] Chinn, M.D. (2007). "Interest Rate Parity 4", Entry Written for Princeton Encyclopedia of the World Economy.

[37] Chinn, M.D. , Frankel., J.A. (2002) "Survey data on exchange rate expectations: More currencies, more horizons, more tests" Monetary Policy, Capital Flows and Exchange Rates: Essays in honour of Maxwell Fry. D. G. D. a. W. A. Allen. London and New York, Routledge: 145-167.

[38] Chionis, D., R. Macdonald, (1997) "Some Tests of Market Microstructure Hypotheses in the Foreign Exchange Market", Journal of Multinational Financial Management, v.7-3, pp.203-229.

[39] Christ C. (1972) "Judging the Performance of Econometric Models of the US Economy" International Economic Review, 16:54-74. 
[40] Christiano, L. J., M. Trabandt, and K. Walentin (2011) "DSGE Models for Monetary Policy Analysis" Handbook of Monetary Economics, Volume 3A, ed. by B. M. Friedman, and M. Woodford, pp. 285-367.

[41] Christiano, L.J. (1989) "Not the inflation forecasterŠs holy grail" Federal Reserve Bank of Minneapolis, Quarterly Review 13, 3Ü18.

[42] Christiano, L.J., Eichenbaum, M., and Evans, C. (1996). "The effects of monetary policy shocks: evidence from the flow of funds" Review of Economics and Statistics 78 (1), 16 Ü34.

[43] Christiano, L.J., Eichenbaum, M., and Evans, C. (1999) "Monetary Policy Shocks: What Have We Learned and to What End?" in Handbook of Macroeconomics, Volume 1, ed. by J.B. Taylor, and M. Woodford, pp. 65-148.

[44] Christiano, L.J., Trabandt, M., and Walentin, K. (2010) "DSGE Models for Monetary Policy Analysis" NBER working paper No. 16074.

[45] Christiano, Lawrence J., Eichenbaum, Martin and Evans, Charles (1998) "Monetary Policy Shocks: What Have We Learned and to What End?" NBER Working Paper No. 6400.

[46] Christiano, Lawrence J.; Eichenbaum, Martin and Evans, Charles. (1996) "The effects of Monetary Policy Shocks: Evidence from the flow of funds" Review of Economics and Statistics, Vol. 78, No 1:16-34.

[47] Clarida H.R., and Gertler M. (1997) "How the Bundesbank Conducts Monetary Policy" NBER working paper No. w5581.

[48] Clark, T. E., K. D. West, (2006) "Using Out-of-Sample Mean Squared Prediction Errors to Test the Martingale Difference Hypothesis", Journal of Econometrics, v.135.

[49] Cohen, A. (1949) "On Estimating the Mean and Standard Deviation of Truncated Normal Distributions" Journal of the American Statistical Association. Vol 44, 518-525.

[50] Crowder W.J. (1994) "Foreign Exchange Market Efficiency and Common Stochastic Trends" Journal of International Money and Finance 13(5):551-564.

[51] Cumby, R. E., D. Modest, (1987) "Testing for Market Timing Ability: A Framework for Forecast Evaluation", Journal of Financial Economics, v.19-1, pp.169189.

[52] Dasgupta, S., B. Laplante, N. Mamingi, (1997) "Capital Market Responses to Environmental Performance in Developing Countries" The World Bank Development Research Group. 
[53] De Grauwe, P., Grimaldi, M. (2006) "The Exchange Rate in a Behavioral Finance Framework." Princeton University Press.

[54] De Grauwea, P. Markiewicz, A. (2013) "Learning to forecast the exchange rate: Two competing approaches" Journal of International Money and Finance 32: 42-76.

[55] De Long, J. B., A. Shleifer, L. H. Summers and R. J. Waldmann, (1989), "Noise Trader Risk in Financial Markets", (mimeo).

[56] Diebold, F.X., and Mariano, R.S. (1995) "Comparing predictive accuracy" Journal of Business and Economic Statistics 13, 253 Ü263.

[57] Disyatat, P., and Galati G. (2007) "The Effectiveness of Foreign Exchange Market: Intervention in Emerging Market Countries: Evidence from the Czech Koruna" Journal of International Money and Finance, Vol. 26(3), pp. 383-402.

[58] Dominguez, K. M., (1986) "Are Foreign Exchange Forecasts Rational? New Evidence from Survey Data", Economics Letters, v.21, pp.277-281.

[59] Dominguez, K. M., J. A. Frankel, (1993) "Does Foreign Exchange Intervention Matter? The Portfolio Effect", American Economic Review, v.83-5, pp.13561369.

[60] Dominguez, K., Fatum, R., and Vacek, P. (2012) "Do Sales of Foreign Exchange Reserves Lead to Currency Appreciation?". Forthcoming in Journal of Money, Credit and Banking.

[61] Dooley, M., J. Shafer, (1983) "Analysis of Short-Run Exchange Rate Behavior", D. Bigman, T. Taya, Exchange Rate and Trade Instability: Cases, Consequences and Remedies, Ballinger.

[62] Dornbusch, R., (1976) "Expectations and Exchange Rate Dynamics", Journal of Political Economy, v.84, pp.1161-1176.

[63] Eaton, M.L. (1983) "Multivariate Statistics: a Vector Space Approach" John Wiley and Sons. pp. 116 Ü117.

[64] Echavarria, J. J., D. Vasquez, M. Villamizar, (2008) "Expectativas, Tasa de Interes y Tasa de Cambio: Paridad Cubierta y No Cubierta en Colombia 20002007", Ensayos Sobre Politica Economica, v.26-56, pp.150-204.

[65] Echavarria, J.J. Melo L.F. and Villamizar M. (2013) "The impact of preannounced day-to-day interventions on the Colombian exchange rate" Bank for International Settlements Working Paper, v. 428. 
[66] Echavarria, J.J., and Villamizar, M. (2006) "El Proceso Colombiano de Desindustrialización" Borradores de Economia, Banco de la Republica No. 361.

[67] Echavarria, J.J., Lopez, E.E., and Misas, M.A. (2009a) "Intervenciones cambiarias y Politica Monetaria en Colombia. Un analisis de VAR estructural" Borradores de Economia, Banco de la Republica No. 580.

[68] Echavarria, J.J., Vasquez, D., and Villamizar, M. (2009b) "Impacto de las Intervenciones Cambiarias sobre el Nivel y la Volatilidad de la Tasa de Cambio en Colombia" Ensayos sobre Politica Economica, Vol. 28, No. 62.

[69] Egert B. (2007) "Central bank interventions, communication and interest rate policy in emerging European economies" Journal of Comparative Economics. Vol. 35, Issue 2: 387Ü413.

[70] Engel, C., (1996) "The Forward Discount Anomaly and the Risk Premium: A Survey of Recent Evidence", Journal of Empirical Finance, v.3-2, pp.123-192.

[71] Evans, M. and Richard L. (2005) "Meese-Rogoff Redux: Micro-based Exchange Rate forecasting" NBER Working Papers 11042.

[72] Fair, R. (1979) "An Analysis of the Accuracy of Four Macroeconomic Models" Journal of Political Economy 87:701-718.

[73] Fama, E. F., (1965) "The Behavior of Stock-Market Prices", The Journal of Business, v.38-1, pp.34-105.

[74] Fama, E. F., (1984) "Forward and Spot Exchange Rates", Journal of Monetary Economics, v.14-3, pp.319-338.

[75] Fama, E., and French, K. (1987) "Permanent and Temporary Components of Stock Prices" Center for Research on Security Prices, University of Chicago No. 178.

[76] Fatum, R., M. Hutchison (2008) "Evaluating Foreign Exchange Market Intervention: Self-selection, Counterfactuals and Average Treatment Effects" Hong Kong Institute for Monetary Research, Working Papers 022008.

[77] Fatum, R., M. Hutchison, (2003) "Is Sterilized Foreign Exchange Intervention Effective After All? An Event Study Approach" The Economic Journal, 113, 390Ü411, Royal Economic Society.

[78] Fischer, S. (2001a) "The International Financial System: Crises and Reform" The Robbins Lectures at the London School of Economics, October 29-31, 2001. Manuscript, 2001a. 
[79] Fischer, S. (2001b) "Exchange Rate Regimes: Is the Bipolar View Correct?" Journal of Economic Perspectives 15 (Spring 2001b): 3-24.

[80] Frankel, J. A., (1979) "On the Mark: A Theory of Floating Exchange Rates Based on Real Interest Differentials", American Economic Review, v.69-4, pp.610-622.

[81] Frankel, J. A., (1994) "Concerted Interventions and the Dollar: An Analysis of Daily Data" The International Monetary System, Cambridge University Press, pp.242-249.

[82] Frankel, J. A., A. K. Rose, (1994) "A Survey of Empirical Research on Nominal Exchange Rates", NBER Working Paper Series, v.4865.

[83] Frankel, J. A., K. A. Froot (1990b) "Exchange Rate Forecasting Techniques, Survey Data, and Implications for the Foreign Exchange Market", NBER Working Papers Series, v.3470.

[84] Frankel, J. A., K. A. Froot, (1986) "Understanding the US dollar in the Eighties: The Expectations of Chartists and Fundamentalists", Economic Record, v.62, pp.24-38.

[85] Frankel, J. A., K. A. Froot, (1987) "Using Survey Data to Test Standard Propositions Regarding Exchange Rate Expectations", The American Economic Review, v.77-1, pp.133-153.

[86] Frankel, J. A., K. A. Froot, (1990a) "Chartists, Fundamentalists, and Trading in the Foreign Exchange Market", American Economic Review, v.80-2, pp.181185.

[87] Fratzscher, M., (2012) "Official Intervention in the Foreign Exchange Market" Handbook of Exchange Rates, Wiley, pp.715-748.

[88] Frenkel, M. (1976) "A Monetary Approach to the Exchange Rate: Doctrinal Aspects and Empirical Evidence" Scandinavian Journal of Economics 78: 200224.

[89] Frenkel, M. (1997) "Exchange rate dynamics with chartists, fundamentalists, and rational speculators in the foreign exchange market" International Journal of Business 2: 1-24.

[90] Friedman, M., (1953) "The Case for Flexible Exchange Rates", M. Friedman, Essays in Positive Economics, University of Chicago Press., pp.413-437.

[91] Froot, K. A., J. A. Frankel, (1989) "Forward Discount Bias: Is it an Exchange Risk Premium?", Quarterly Journal of Economics, v.104-1, pp.139-161. 
[92] Froot, K. A., R. H. Thaler, (1990) "Anomalies: Foreign Exchange", Journal of Economic Perspectives, v.4-3, pp.179-192.

[93] Garbers H. (1987) "A misspecification analysis of the relationship between spot and forward exchange rates" European Economic Review, Volume 31, Issue 7: $1407-1417$.

[94] Gourinchas, P.-O., H. Rey, (2007) "International Financial Adjustment", Journal of Political Economy, v.115-4, pp.665-703.

[95] Granger, C.W.J., and Newbold, P. (1977) "Forecasting Economic Time Series" Academic Press, New York.

[96] Greene, W.H. (2003) "Econometric Analysis" (5th ed.). Prentice Hall.

[97] Guimaraes, R., and Karacadag, C. (2004) "The Empirics of Foreign Exchange Intervention in Emerging Market Countries: The Cases of Mexico and Turkey" IMF Working Paper 04/123.

[98] Hamilton, J. (1997) "Measuring the Liquidity Effect" American Economic Review, Vol 87, No 1:80-97.

[99] Hansen, L., and Hodrick R., (1980) "Forward Exchange Rates as Optimal Predictors of Future Spot Rates: An Econometric Analysis" Journal of Political Economy, 88, 829-853.

[100] Hansen, L., and Hodrick R., (1983) "Risk Averse Speculation in the Forward Foreign Exchange Market: An Econometric Analysis of Linear Models" in: J.A. Frenkel, ed., Exchange Rates and International Macroeconomics (University of Chicago Press, Chicago), 113-142.

[101] Hodrick, R. J. (1987) "The Empirical Evidence on the Efficiency of Forward and Futures Foreign Exchange Markets", Harword Academic Publishers, Switzerland.

[102] Hodrick, R.J., and S. Srivastava (1986) "The Covariation of Risk Premiums and Expected Future Spot Exchange Rates" Journal of International Money and Finance, 5, 5-21.

[103] Hodrick, R.J., S. Srivastava, (1984) "An Investigation of Risk and Return in Forward Foreign Exchange", Journal of International Money and Finance, pp.529.

[104] Hsieh D.A. (1982) "Tests of Rational Expectations and no Risk Premium in Forwards Exchange Market" NBER Working Paper No. 843 
[105] Humala, Alberto and Rodriguez, Gabriel. "Foreign Exchange Intervention and Exchange Rate Volatility in Peru," (2009) Working Papers 2009-008, Banco Central de Reserva del Peru.

[106] Humpage, O. F., (1996) "U.S. Intervention: Assessing the Probability of Success" Federal Reserve Bank of Cleveland Working Paper, No. 9608.

[107] Hutchison, M., (2002) "The Role of Sterilized Intervention in Exchange Rate Stabilization Policy" Conference Paper on ŞStabilizing the Economy: Why and How? Ť sponsored by the GeoEconomics Center of the Council on Foreign Relations, New York City.

[108] Imbens, G.W., and Wooldridge, J.M. (2009) "Recent Developments in the Econometrics of Program Evaluation" Journal of Economic Literature 47 (1):5Ü86.

[109] IMF, (2007) "Decoupling the Train? Spillovers and Cycles in the Global Economy" World Economic Outlook, Chapter 4.

[110] Ito, T., (1990) "Foreign Exchange Rate Expectations: Micro Survey Data", The American Economic Review, v.80-3, pp.434-449.

[111] Jensen, J (2000) "Statistics for Petroleum Engineers and Geoscientists" Amsterdam: Elsevier, Pg 207.

[112] Jongen, R., W. F. Verschoor, C. C. Wolff, (2008) "Foreign Exchange Rate Expectations: Survey and Synthesis", Journal of Economic Surveys, v.22-1, pp.140165.

[113] Jorda, O. (2005) "Estimation and Inference of Impulse Responses by Local Projections" The American Economic Review, Vol.95, pp. 161-182.

[114] Joyce, M., Lasaosa M., Stevens I., and Tong M. (2011) "The Financial Market Impact of Quantitative Easing in the United Kingdom" International Journal of Central Banking, 7 (3), 113Ü161.

[115] Kamil, H. (2008) "Is Central Bank Intervention Effective Under Inflation Targeting Regimes? The Case of Colombia" IMF Working Paper No. 88.

[116] Kaminsky G. and R. Peruga (1990) "Can a Time-Varying Risk Premium Explain Excess Returns in the Forward Market for Foreign Exchange?" Journal of International Economics, 28, 47-70.

[117] Keim D., and Stambaugh R. (1986) "Predicting Returns in Stock and Bond Markets" Journal of Financial Economics, 17:357-390. 
[118] Kim, S. (2003) "Monetary policy, foreign exchange intervention, and the exchange rate in a unifying framework" Journal of International Economics, 60: $355-386$.

[119] Kim, S., and Roubini, N. (2000) "Exchange rate anomalies in the industrial countries: A solution with a structural VAR approach" Journal of Monetary Economics, 45: 561 - 586.

[120] Krishnamurthy, A., and Vissing-Jorgensen A. (2011) "The Effects of Quantitative Easing on Interest Rates: Channels and Implications for Policy" Brookings Papers on Economic Activity, Fall 2011, pp. 215Ű265.

[121] Kuttner, K. N., A. S. Posen, (2007) "Do Markets Care who Chairs the Central Bank?", NBER Working Paper No. 13101.

[122] Levich R.M. (1979) "On the Efficiency of Markets for Foreign Exchange" International economic policy: Theory and Evidence Chapter 7. Johns Hopkins University Press.

[123] Lewis, K.K. (1995) "Puzzles in International Financial Markets" Handbook of International Economics, Vol. III, Elsevier Science, 1995, pp. 1913-1971.

[124] Litterman R. (1979) "Techniques of Forecasting using Vector Autoregressions" Federal Reserve Bank of Minneapolis, Working Paper No. 115.

[125] Lo A.W., and MacKinlay C. (1988) "Stock Market Prices do not Follow Random Walks: Evidence from a Simple Specification Test" The Review of Financial Studies, Vol 1 No.1: 41-66.

[126] Loaiza A.R., and Melo, L.F. (2012) "Latin American Exchange Rate Dependencies: A Regular Vine Copula Approach" Borradores de Economia, Banco de la Republica No. 729.

[127] Loaiza, R., L. F. Melo, (2012) "Latin American Exchange Rate Dependencies: A Regular Vine Copula Approach" Banco de la Republica, Borradores de Economía, v.729.

[128] Lucas, R. E., (1982) "Interest Rates and Currency Prices In a Two-Country World", Journal of Monetary Economics, v.10, pp.335-359.

[129] Macdonald, R., (2000) "Is the Foreign Exchange Market 'risky'? Some New Survey-Based Results", Journal of Multinational Financial Management, v.101, pp.1-14.

[130] Macdonald, R., and M. P. Taylor (1992). "Exchange Rate Economics: A Survey", IMF Staff Papers, 39 (1), 1-57. 
[131] Macdonald, R., T. S. Torrance, (1990) "Expectations Formation and Risk in Four Foreign Exchange Markets", Oxford Economic Papers, v.42-3, pp.544-561.

[132] MacKinlay, A.C., (1997) "Event Studies in Economics and Finance" Journal of Economic Literature, v.35-1, pp.13-39.

[133] Mark, N. and Wu, Y. (1998) "Rethinking Deviations From Uncovered Interest Parity: The Role of Covariance Risk and Noise" Economic Journal, November 1998, 108, pp, 1686-1706.

[134] Maynard A., and Phillips C.B. (2001) "Rethinking an Old Empirical Puzzle: Econometric Evidence on the Forward Discount Anomaly" Journal of Applied Econometrics 16:671-708.

[135] McCallum, B.T., (1994). "A Reconsideration of The Uncovered Interest Parity Relationship", Journal Of Monetary Economics, 33, 105-32.

[136] Meese, R., K. S. Rogoff (1988) "Was it real? The exchange rateŮinterest differential over the modern floating rate period" Journal of Finance 43, 933 Ü948.

[137] Meese, R., K. S. Rogoff, (1983) "Empirical Exchange Rate Models of the Seventies: Do they Fit Out of sample?", Journal of International Economics, v.14, pp.3-24.

[138] Menkhoff, L. (1998) "The noise trading approach-questionnaire evidence from foreign exchange" Journal of International Money and Finance 17: 304-314.

[139] Meredith, G. and Ma, Y. (2002) "The forward premium puzzle revisited" IMF Working Paper WP/02/28.

[140] Nelson C. (1972) "The Prediction Performance of the F.R.B.-M.I.T.-Penn. Model of the US Economy" American Economic Review 62, 902-917.

[141] Nieuwland, F. G., W. F. Verschoor, C. C. Wolff, (2000) "Exchange Risk Premia in the European Monetary System", Applied Financial Economics, v.10-4, pp.351-360.

[142] Nurkse, R., (1944) "International Currency Experience", League of Nations, Geneva

[143] Obstfeld, M., K. S. Rogoff, (2000) "The Six Major Puzzles in International Macroeconomics: Is There a Common Cause?", NBER Working Paper, v.7777.

[144] Ojeda, J., J. E. Gomez, (2012) "The Term-Structure of Sovereign Default Risk in Colombia and its Determinants", Borradores de Economía, v.709. 
[145] Payne R., and Vitale P. (2003) "A transaction level study of the effects of central bank intervention on exchange rates" Journal of International Economics. Volume 61, Issue 2: 331Ű352.

[146] Pesaran, M. H., (1987) "The Limits to Rational Expectations", Basil Blackwell, Oxford

[147] Ramirez, J.M., (2005) "Intervencion Cambiaria: Practicas y Evidencias Internacionales". Banco de la Republica (Mimeo).

[148] Rigobon, R., (2008) "Exchange Rate Volatility", S. N. Durlauf, L. E. Blume, The New Palgrave Dictionary of Economics.

[149] Rincon, H., and Toro, J. (2010) "Are Capital Controls and Central Bank Intervention Effective?" Borradores de Economia, Banco de la Republica No. 625.

[150] Rogoff, K. S., (2009) "Exchange Rates in the Modern Floating Era: What do we Really Know?", Review of World Economics, v.145-1, pp.1-12.

[151] Romer, C.D., and Romer, D.H. (1989) "Does Monetary Policy Matter? A New Test in the Spirit of Friedman and Schwartz" NBER Macroeconomics Annual, Cambridge, MIT Press 121-170.

[152] Romer, C.D., and Romer, D.H. (2004) "A new Measure of Monetary Shocks: Derivation and Implications" American Economic Review 94, 1055-1084.

[153] Rosenbaum, S. (1961) "Moments of a Truncated Bivariate Normal Distribution" Journal of the Royal Statistical Society, Series B, 23, 223-229.

[154] Rudebusch, D.G. (1998) "Do Measures of Monetary Policy in a VAR Make Sense?" International Economic Review, Vol.39 No.4:907-931.

[155] Sarno, L., M. P. Taylor, (2002) "The Economics of Exchange Rates", Cambridge University Press, Cambridge.

[156] Schnedler, W (2005) "Likelihood estimation for censored random vectors". Econometric Reviews 24 (2): 195 Ü217.

[157] Sims, C.A. (1992). "Interpreting the macroeconomic time series facts: the effects of monetary policy" European Economic Review 36 (5), 975Ü1000.

[158] Sims, C.A., and Zha, T. (2006) "Does monetary policy generate recessions? Ť Macroeconomic Dynamics, 10: 231 - 272.

[159] Swanson, E.T. (2011) "Lets Twist Again: A High-Frequency Event-Study Analysis of Operation Twist and Its Implications for QE2" Brookings Papers on Economic Activity, Spring 2011, pp. 151 Ü188. 
[160] Takagi, S., (1990) "Exchange Rate Expectations: A Survey of Survey Studies", IMF Working Paper, v.90/52

[161] Taylor, M. P., H. Allen, (1992) "The use of Technical Analysis in the Foreign Exchange Market", Journal of International Money and Finance, v.11, pp.304314.

[162] Tobin, J (1958) "Estimation of relationships for limited dependent variables". Econometrica 26 (1): 24Ü36.

[163] Toro, J., and Julio, J.M. (2005) "Efectividad de la Intervencion Discrecional del Banco de la Republica en el Mercado Cambiario" Borradores de Economia, Banco de la Republica No. 336.

[164] Vargas, H., Gonzales A., and Rodriguez D. (2013) "Foreign Exchange Intervention in Colombia" Borradores de Economia, Banco de la Republica No. 757.

[165] Villa, M. L., (2011), "Expectativas y Estabilidad Cambiaria. Son Desestabilizadores los Especuladores en Colombia?", (mimeo).

[166] Wakita, S., (1989) "Are Survey Forecasts Trusted?", Economics Letters, v.29-29, pp.339-344.

[167] Wasserfallen, W., and Kuersteiner, G.M. (1994) "Interest rates and exchange rates under money supply targets" Journal of Monetary Economics 33 201-230.

[168] West, K.D., Edison, H.J., and Cho, D. (1993) "A utility based comparison of some models of exchange rate volatility" Journal of International Economics $35,23 \tilde{U} 46$.

[169] Woodford, M., (2003) "Interest and Prices", Princeton University Press, Princeton.

[170] Wooldridge J.M. (2010) "Econometric Analysis of Cross Section and Panel Data" MIT Press Books, The MIT Press, edition 2, volume 1.

[171] Zha, T. (1997) "Identifying monetary policy: a primer" Federal Reserve Bank of Atlanta Economic Review 82 (2), 26-43. 